\title{
Middle School Students' Perceptions of and Responses to the Inclusion of Culturally Relevant Units in the Physical Education Curriculum
}

Luciana Carvalhal Braga

West Virginia University

Follow this and additional works at: https://researchrepository.wvu.edu/etd

\section{Recommended Citation}

Braga, Luciana Carvalhal, "Middle School Students' Perceptions of and Responses to the Inclusion of Culturally Relevant Units in the Physical Education Curriculum" (2014). Graduate Theses, Dissertations, and Problem Reports. 266.

https://researchrepository.wvu.edu/etd/266

This Dissertation is protected by copyright and/or related rights. It has been brought to you by the The Research Repository @ WVU with permission from the rights-holder(s). You are free to use this Dissertation in any way that is permitted by the copyright and related rights legislation that applies to your use. For other uses you must obtain permission from the rights-holder(s) directly, unless additional rights are indicated by a Creative Commons license in the record and/ or on the work itself. This Dissertation has been accepted for inclusion in WVU Graduate Theses, Dissertations, and Problem Reports collection by an authorized administrator of The Research Repository @ WVU.

For more information, please contact researchrepository@mail.wvu.edu. 
Middle School Students' Perceptions of and Responses to the Inclusion of Culturally Relevant Units in the Physical Education Curriculum

Luciana Carvalhal Braga, M.Ed.

Dissertation submitted to the College of Physical Activity and Sport Sciences at West Virginia University

in partial fulfillment of the requirements

for the degree of

Doctor of Philosophy

in

Kinesiology

Eloise Elliott, Ph.D., Chair

Sean Bulger, Ed.D.

Emily Jones, Ph.D

Christa Lilly, Ph.D.

Sam Zizzi, Ed.D.

Department of Coaching and Teaching Studies

\section{Morgantown, West Virginia \\ 2014}

Keywords: culturally relevant, physical education, curriculum, middle school, physical activity

Copyright 2014 Luciana Carvalhal Braga 


\section{ABSTRACT \\ Middle School Students' Perceptions of and Responses to the Inclusion of Culturally Relevant Units in the Physical Education Curriculum \\ Luciana Carvalhal Braga, M.Ed.}

Background/Purpose: This study was part of a three-year, multicomponent school-based health intervention implemented in two middle schools in an Appalachian county. The purpose of this study was to examine school students' perceptions of and responses to the inclusion of culturally relevant units in the physical education (PE) curriculum. Specifically, the study examined how less predisposed to be active (LPA) and more predisposed to be active (MPA) students perceived and responded to the inclusion of archery, mountain biking, and slacklining in PE. Methods: A mixed methods design was employed, in which the results of an initial quantitative phase served to identify LPA and MPA students to participate in a subsequent qualitative inquiry. Twelve focus groups were conducted (with a combined total of 47 students from one school) yielding qualitative data, which were analyzed through an inductive process. Results: Three overarching themes emerged from both LPA and MPA focus groups' data: (a) Expectations, (b) Engagement, and (c) Responses. Findings indicated that LPA and MPA participants had similar perceptions of and responses to the new units, with minor differences observed among LPA students. The three themes included a total of ten subthemes that depict students' thoughts, engagement, and responses to new units. These subthemes were aligned with the influencing factors of physical activity in children and adolescents outlined by the Youth Physical Activity Promotion Model (Welk, 1999). Conclusion: School-based physical activity programs at the middle school level should consider the influencing factors on physical activity and include content that is innovative, challenging, and relevant to the students, their community, and the culture in which they live. 


\section{Dedications}

This dissertation is dedicated in loving memory of my great-grandmother Adélia Vilela Marcondes and of my father Maurício Carvalho Braga. To Adélia, my dear and lovely great-grandmother who signed me up for English lessons when I was a child, paid for the lessons, and told me that they would take me to a great future. She was right! This document is a living proof of her positive predictions. To my dear and much missed father Maurício, who always told me that the United States of America is a great country.

He was also right! I am truly honored and thankful with the amazing opportunities I received at West Virginia University as an international student. Thank you! You both will be always in my heart. 


\section{Acknowledgements}

I will be forever thankful to all the individuals who have made this dream possible. I could never have achieved my goals without the great support of my family, friends, and professors. Each one of you played a critical role in this journey and my heart is full of gratitude. I truly had the "time of my life" at West Virginia University and enjoyed each opportunity and challenge presented to me as a doctoral student. To my family, who have fully supported my decision to leave my job in Brazil and pursue a degree in the U.S. To my mother, Maysa Carvalhal, who always encourages me to take risks and cheers my successes, thanks for always being there for me. To my godfather, Rogerio Braga, whose generosity and kindness overwhelms me. Thank you for your support and for allowing me to focus on my studies. To my uncle, Marcos Carvalhal, who has been an example of how hard work leads to success. Thank you for encouraging me to be my best. To my peers, whose company was much treasured while being so far from home. Specially, to a wonderful friend, Lindsay Hammond who assisted with data collection, walked every step of this journey with me, and held my hand when I struggled and needed encouragement. Also, to Philip Liversedge, a very helpful friend, who reminded me to relax and made me smile many times over the past three years.

To my dissertation chair and friend Dr. Eloise Elliott. Your guidance has been graceful and empowering. Thank you for spending so much time with me and for being positive $100 \%$ of the time. It has been a pleasure to share this work with you. To the members of my committee, thank you: Dr. Sean Bulger, for sharing your wisdom and powerful insights. Dr. Emily Jones, for encouraging me during challenging moments and always being available to discuss my work. Dr. Christa Lilly, for your kindness and willingness to help. Dr. Sam Zizzi, for mingling into the PETE world and giving me valuable advice. To all my professors at WVU, particularly to Dr. Andrew Hawkins and his wife Jean, who provided me with spiritual guidance and poured God's love and grace into my life. Finally, to the CHOICES project staff. It has been a pleasure to watch this project grow and reach its goals. Thank you for allowing me to be part of this amazing initiative, which has truly impacted the life of youth in West Virginia. I am very proud to be a member of this team. 


\section{Table of Contents}

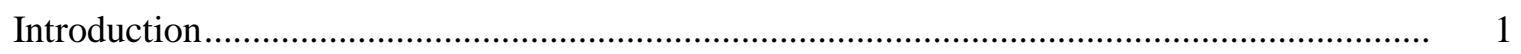

Research Questions ...................................................................................... 6

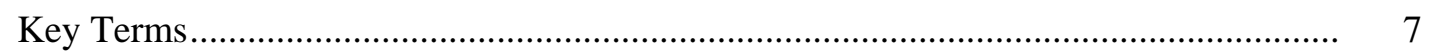

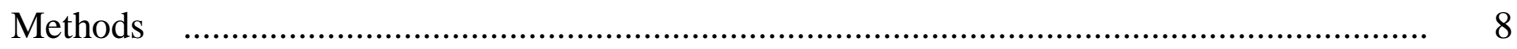

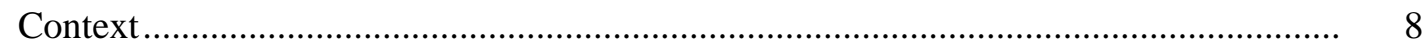

Culturally Relevant Units ............................................................................ 9

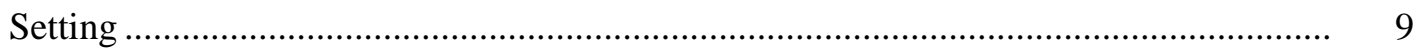

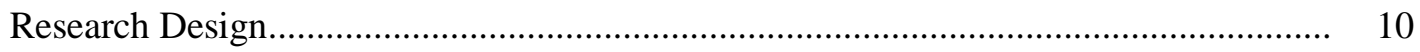

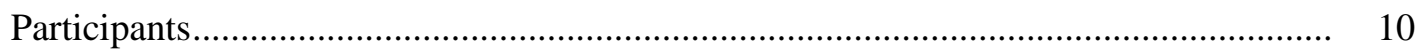

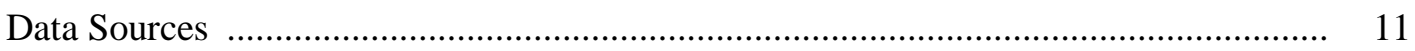

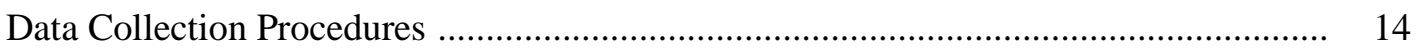

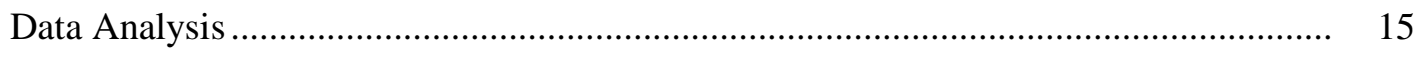

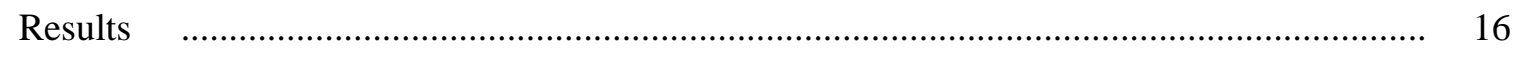

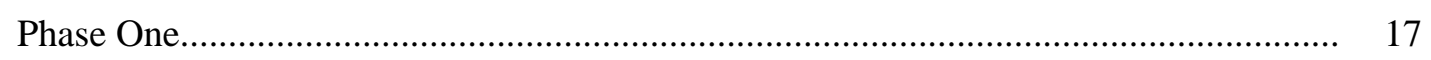

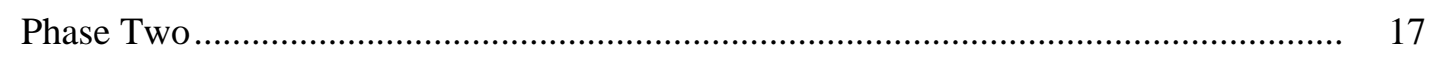

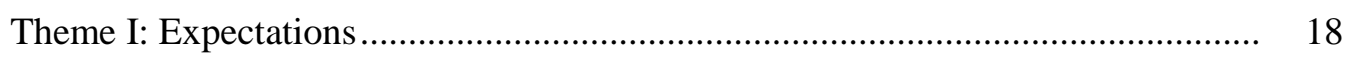

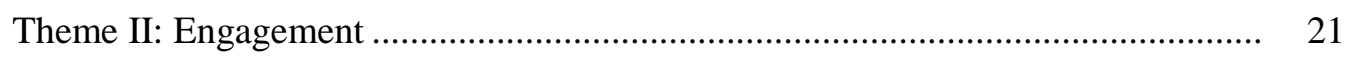

Theme III: Responses........................................................................ 28

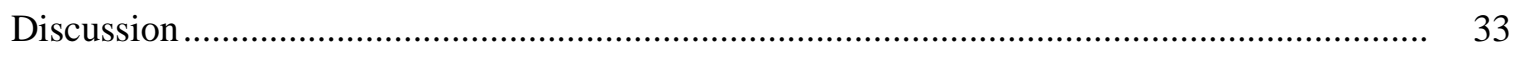

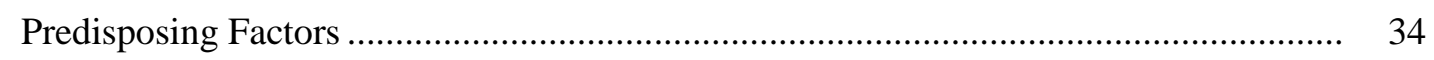

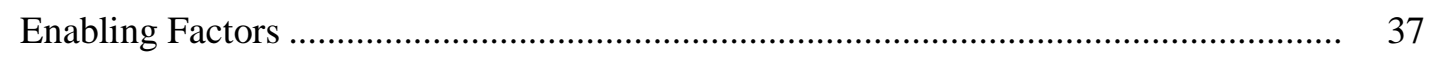

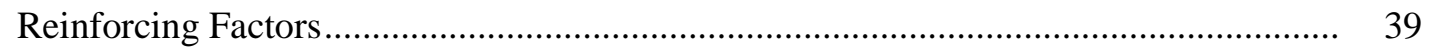

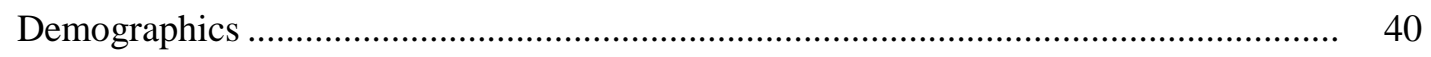

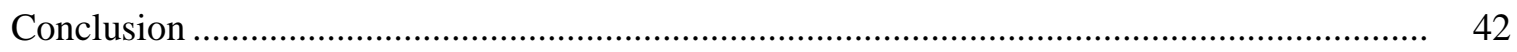




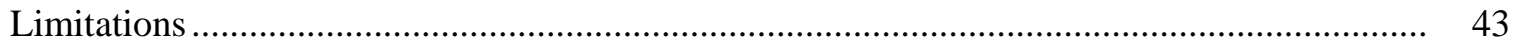

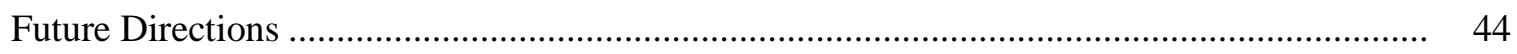

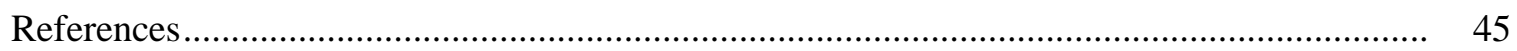

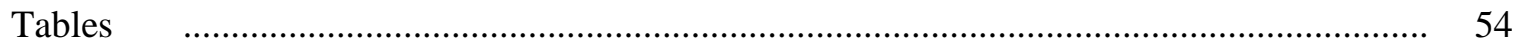

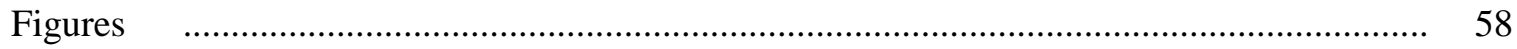

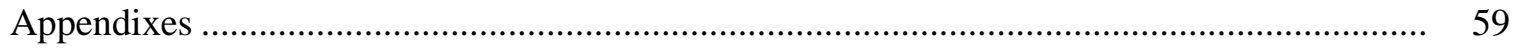

A. Extended Review of Literature ............................................................................ 59

B. Parental or Guardian Consent letter (Phase Two) ............................................... 122

C. Athletic Competence Subscale of the Self-Perception Profile for Children............. 124

D. Children's Attraction to Physical Activity Scale .................................................. 125

E. Combined Questionnaire ......................................................................... 127

F. Script for Questionnaire (Phase One) ............................................................ 130

G. Student Assent Letter (Phase Two) …........................................................... 131

H. Focus Groups Interview Script (Phase Two) ................................................... 132 


\section{Middle School Students' Perceptions of and Responses to the Inclusion of Culturally Relevant Units in the Physical Education Curriculum}

Ideally, all children and adolescents would engage frequently in various forms of physical activity. Regular participation in physical activity has several physical and psychological benefits for children and adolescents. An increasing body of research indicates that engagement in physical activity during childhood and adolescence can reduce the development of risks factors related to chronic diseases, improve mental health, support weight management, and promote the development of a physically active lifestyle that can be carried throughout adulthood (Hallal, Victora, Azevedo, \& Wells, 2006; Janssen \& LeBlanc, 2010; Rowland, 2007; Strong et al., 2005). According to the 2008 Physical Activity Guidelines for Americans, in order to obtain greater benefits of an active lifestyle, children and adolescents should participate in 60 minutes or more of daily moderate to vigorous physical activity (U.S. Department of Health and Human Services [USDHHS], 2008). However, despite the increasing support for physical activity among youth as a potential health promoter, studies have reported low percentages of young people meeting the guidelines outlined by the USDHHS and declining levels of physical activity as children move into adolescence (Belcher et al., 2010; Bélanger, Gray-Donald, O’Loughlin, Paradis, \& Hanley, 2009; Kahn et al., 2008). At the same time, obesity rates among children and adolescents in the U.S. have tripled in the past 30 years (Ogden, Carroll, Curtin, Lamb, \& Flegal, 2010). This increase in the prevalence of obesity among American children and adolescents has been associated with unhealthy dietary habits and sedentary behaviors, which has become a great concern in the field of public health (Cliff, Okely, Morgan, Jones, \& Steele, 2009).

In an attempt to reverse this situation, researchers have been striving to determine the factors that influence children and adolescents' participation in physical activity in order to inform interventions targeting active lifestyles among youth. Numerous cross-sectional studies have been conducted with the intent of examining the associations between a myriad of variables and physical activity levels in children and adolescents. Findings from these studies have indicated that youth physical activity is a complex behavior influenced by multiple individual, social, and environmental factors (Biddle, Atkin, Cavill, \& 
Foster, 2011; Biddle, Whitehead, O’Donovan, \& Nevill, 2005; Sallis, Prochaska, \& Taylor, 2000; Van der Horst, Paw, Twisk, \& Van Mechelen, 2007). Hence, it has been argued that interventions directed at enhancing the opportunities for youth to be active should address all of these factors and be designed based on ecological models of health behavior (Perry, Garside, Morones, \& Hayman, 2012; Spence \& Lee, 2003). Ecological models recognize that health behaviors are influenced at the individual, social, and environmental levels by numerous variables and that initiatives targeting behavior change are most likely to succeed when they account for more than one level of influence (McLeroy, Bibeau, Steckler, \& Glanz, 1988; Sallis \& Owen, 2002). Welk (1999) proposed the Youth Physical Activity Promotion (YPAP) model, which is a conceptual framework based on ecological approaches to explain the individual, social, and environmental factors associated with children and adolescents' physical activity engagement. The YPAP model organizes these factors into three categories: (a) enabling, (b) predisposing, and (c) reinforcing (see Figure 1). The YPAP model has been identified as a comprehensive framework for the design of physical activity interventions targeting youth because it addresses the multiple variables research has shown to be associated with children's and adolescents' physical activity behavior (Rowe, Raedeke, Wiersma, \& Mahar, 2007; Seabra et al., 2013; Welk, 1999; Welk \& Schaben, 2004).

The school setting has been identified as an optimal environment for the implementation of interventions targeting youth physical activity because children and adolescents spend a large proportion of time in school and schools already have many of the resources needed for the implementation of a variety of physical activity programs (Naylor \& McKay, 2009; Trost \& Loprinzi, 2008). As a result, the past two decades have been marked by a significant growth in school-based physical activity interventions across the U.S. along with an increase in local, state, and federal support for these types of initiatives (Demetriou \& Höner, 2012; Sallis et al., 2012; Song, Carroll, \& Fulton, 2013). In 2011, the Centers for Disease Control and Prevention (CDC) published an extensive set of recommendations for K12 schools to plan, implement, and evaluate practices and policies related to physical activity and nutrition (Centers for Disease Control and Prevention [CDC], 2011). Among these guidelines and 
strategies was the development of comprehensive school physical activity initiatives, which are founded in physical education (PE). This concept is based on the position statement released by the National Association for Sports and Physical Activity (NASPE) in 2008 recommending that all K-12 schools implement a Comprehensive School Physical Activity Program (CSPAP) (National Association for Sports and Physical Activity [NASPE], 2008). This position statement was recently revised and published by the American Association for Health, Physical Education, Recreation, and Dance (AAHPERD), and now emphasizes the call for schools to be the key agents in the promotion of opportunities for youth to be active (American Association for Health PE, Recreation, and Dance [AAHPERD], 2013). The main goal of CSPAP is to help children and adolescents to meet the recommended daily 60 minutes of physical activity and to develop the competencies and dispositions necessary to engage in various forms of physical activity (AAHPERD, 2013). Comprehensive School Physical Activity Programs are based on ecological models of health behavior (Sallis \& Owen, 2002) and recognize that the school setting can best influence youth physical activity habits through multiple component approaches. According to AAHPERD (2013), CSPAP include five components: (a) highquality PE, (b) physical activity during school, (c) physical activity before and after school, (d) staff involvement, and (e) family and community engagement (AAHPERD, 2013). Each of these five components represents the different possibilities to promote physical activity in the school setting through programs that have the potential to affect individual, social, and environmental influences on youth physical activity engagement.

High-quality PE has been designated as the foundation of CSPAP because it is in PE that children and adolescents' receive appropriate instruction that will result in the development of the "skills, knowledge, and confidence needed to lead physically active lifestyles" (AAHPERD, 2013, p. 3). Since PE is a curricular subject, mandated in more than $80 \%$ of the states (NASPE \& American Heart Association [AHA], 2012) it has the potential to reach more children and adolescents than any other type of structured physical activity programming (Sallis et al., 2012; Trost, 2004). According to AAHPERD (2013), high-quality PE includes: (a) standards based curriculum; (b) developmentally appropriate 
activities that focus on skill development; (c) appropriate instructional practices, and (d) moderate to vigorous physical activity during at least $50 \%$ of the class time (AAHPERD, 2013). Unfortunately, PE programs across the country often fail to include these critical elements of high-quality PE and consequently have not been successful in motivating youth toward physically active lifestyles (Bulger \& Housner, 2009; Singerland \& Borghouts, 2011). Inadequate PE programs are even more frequent at the middle and high school levels, which is a stage marked by declining levels of physical activity (Bélanger et al., 2009; McKenzie, 2001). Physical education programs at the middle school level usually follow a multi-activity curriculum model, which is characterized by units of instruction focused on team sports (Ennis, 1999; Garn, Cothran, \& Jenkins, 2011). This approach is problematic because it does not account for the discrepancies in motor competence existent among middle school students and offers minimal opportunities for skill development. Consequently, multi-activity curriculum models often favor students who are highly skilled and already involved in active pursuits (Garn et al., 2011). Moreover, since multi-activity curriculum models are centered on team sports, they do not provide students with the skills and confidence needed to participate in alternative forms of physical activities (McCracken, 2001, Mohr, Towsend, \& Pritchard, 2006). The multi-activity approach has also been criticized for being disconnected from the students' interests, values, and cultural backgrounds as well as for being an exclusivist practice which might cause middle school students to develop negative attitudes towards physical activity (Ennis, 1999; Garn et al., 2011).

Because the ultimate purpose of PE is to foster the development of physically educated individuals, who have the necessary proficiencies and dispositions to participate in various forms of physical activity, it has been suggested that middle school PE programs adopt alternative curriculum models, which include meaningful activities that are connected to the students' interests and their cultural background, and can be pursued for a lifetime (Ennis, 1999; McCraken, 2001; McCaughtry, 2009; Pagnano, 2006). Ennis (1999) proposed a culturally relevant approach to PE characterized by the establishment of opportunities for skill development regardless of individuals' proficiency levels and by the development of communities of learners in which every students is valued and supported. Similarly, 
McCaughtry (2009) referred to an alternative perspective for PE as "cool" suggesting that innovative curriculum models include activities that resonate with the popular culture, which can be learned in authentic settings, and foster student involvement through problem solving and socialization with their peers. These approaches aim at promoting successful movement experiences in PE through studentcentered curriculum models that are related to the students' values and culture, which has been suggested as a critical force to attract youth into active lifestyles (Kretchmar, 2000; McCaughtry, 2009; McCraken, 2001; Pagnano, 2006).

Since alternative PE curriculum models aim to integrate activities that resonate with the students' interests, values, and culture, it is important that students' responses to the content are understood and considered in the process of curriculum development and implementation (McCaughtry, 2009; Prusak, Davis, Pennington, \& Wilkinson, 2014). One of the ways this understanding can be obtained is through studies directed at examining students' perceptions and responses related to specific PE programs. Although much has been investigated in regards to the effects of PE programs on youth's physical activity levels, few studies have examined how children and adolescents' experienced those programs (Brown, Hume, Pearson, \& Salmon, 2013; Darbyshire, MacDougall, \& Schiller, 2005). According to Darbyshire, MacDougall, and Schiller (2005) the most common research approach used to study youth's physical activity experiences is to conduct research "on children" as opposed to research "with or for children", neglecting their perspectives as vital informants about issues related to their health and wellbeing. Concerning school-based physical activity interventions, there is a lack of research investigating children and adolescents' perceptions about specific components of those initiatives, particularly in regard to innovative approaches to PE (Buckley \& Waring, 2005, Prusak et al., 2014). Examining how children and adolescents perceive and experience specific components of CSPAP will yield invaluable insights about the meaning of these programs for youth, which is relevant for the design of future interventions. According to MacPhail (2011):

The complexities in identifying how best to instill in young people an appreciation of physical activities, and promote a positive attitude towards establishing and sustaining an active lifestyle, 
is compounded by the individual experiences one has towards physical education and sport. (MacPhail, 2011, p.121)

Therefore, obtaining a deeper understanding of youth's experiences related to PE is crucial for the design and implementation of school-based physical activity initiatives that are meaningful for youth at different age levels, who have different characteristics and interests, and live in different cultural contexts. The purpose of this study was to examine middle school students' perceptions of and responses to the inclusion of culturally relevant units in the PE curriculum. Specifically, this study aimed to gain understanding of how students who are more- and students who are less- predisposed to be physically active perceived and responded to the inclusion of culturally relevant units in the PE curriculum as part of a CSPAP implemented in two middle schools in an Appalachian state.

\section{Research Questions}

This study aimed to examine the following questions:

1. How do middle school students who are less predisposed to be physically active perceive and respond to the inclusion of culturally relevant units in the PE curriculum?

2. How do middle school students who are more predisposed to be physically active perceive and respond to the inclusion of culturally relevant units in the PE curriculum?

3. Are there similarities and differences between how middle school students who are less- and middle school students who are more- predisposed to be physically active perceive and respond to the inclusion of culturally relevant units in the PE curriculum? 


\section{Key Terms}

For the purpose of this study the following terms were defined as:

Culturally relevant units: Physical education units of instruction, where content is selected based on specific cultural referents with the purpose developing the knowledge, skills, and attitudes necessary for physical activity engagement.

Physical Activity: "Bodily movement produced by the skeletal muscles that expends energy beyond resting levels" (Ward, Saunders, \& Pate, 2007, p.4).

Less predisposed to be active (LPA): Students who have lower perceptions of athletic competency and are less attracted to physical activity.

More predisposed to be physically active (MPA): Students who have higher perceptions of athletic competency and are more attracted to physical activity.

Students' perceptions: Students' thoughts about the inclusion of culturally relevant activities in the PE curriculum.

Students' responses: Students' reactions to the inclusion of culturally relevant activities in the PE curriculum.

Youth: School-aged children and adolescents (6-17 years old).

Archery: A target sport that requires shooting arrows at a target using a bow (Haywood \& Lewis, 2006).

Mountain biking: Cycling on trails and rough terrains (Trombley, 2005).

Slacklining: The activity of maintaining balance while standing on or traveling across a tightened band (Gabel \& Burkett, 2013). 


\section{Methods}

\section{Context}

This study was part of a larger, three-year multicomponent school-based intervention funded by the U.S. Department of Education Carol M. White Physical Education Program (PEP) grant. The project, titled CHOICES (Children's Health Opportunities Involving Coordinated Efforts in Schools) was designed based on ecological models of health behavior (Sallis \& Owen, 2002) and is an integrated approach aimed at adolescent health improvement using three complementary components: schools, communities, and health care settings. The school component of CHOICES focuses on the development of a CSPAP in the two middle schools located in a school district in an Appalachian state. The program aims to increase physical activity opportunities through the following initiatives: (a) PE curriculum enhancements through the inclusion of culturally relevant units, (b) continuous professional development workshops for physical educators focusing on curriculum development, (c) establishment of after school physical activity clubs, and (d) family and community involvement in physical activity events.

The school component of CHOICES has placed great emphasis on the development of a standards-based middle school PE curriculum. Physical education teachers have been guided through curriculum development workshops in the process of designing a Middle School Standards-based Physical Education Curriculum Guide. This curriculum guide includes culturally relevant physical activity units (e.g., mountain biking, archery, slacklining). The curriculum development and unit implementation process happened as a collaboration between PE teachers, content experts, and a curriculum specialist who worked together in order to establish a curriculum that reflects the national and state PE standards and include activities that are relevant to the students' culture an environment. Prior to the implementation of the new units, appropriate equipment was purchased (i.e., mountain bikes and helmets, arrows and targets, slacklines) and teachers received training in content and delivery of each unit. 


\section{Culturally Relevant Units}

The signature feature of the Middle School Standards-based Physical Education Curriculum Guide is the inclusion of culturally relevant units. These units were selected based on: (a) the results of a Student Physical Activity Interest Survey, (b) PE teachers' input, (c) availability of resources in the community, and (d) overall meaning of the activities for the Appalachian county in which this study was conducted. Prior the start of the project, 645 students from both schools answered to an online survey indicating their interest in a wide variety of physical activities and sports. Students were asked to rate the activities and sports on a four-point scale ranging from no way to so cool. Equipped with the results of the survey, the PE teachers, the curriculum specialist, and the CHOICES project director deliberated about the feasibility of implementing those units in the curriculum. Factors that played an important role in this discussion included the available resources in the community (e.g., built environment, content experts, local business for equipment purchase and maintenance) and the meaning of those activities to the local culture and community. Although twelve different activities and sports have been included in the PE curriculum, this study focused on archery, mountain biking, and slacklining.

\section{Setting}

Although the CHOICES project has been implemented in the two middle schools within the school district, this study was conducted in only one of the schools. The middle school that was the setting for this study is located in the western portion of this predominantly rural Appalachian county. Approximately one third of all middle school-aged children in this county attend this school; which will be referred as Western School. In the year this study was conducted enrollment in Western School was 312 students (169 female and 143 male). The predominant ethnicity in the Western school is white accounting for $96.2 \%$ of the students, while black and other ethnicities account for $3.8 \%$ of the student body. Exposure to the new PE content was the criteria for selecting the Western school to be the setting of this study. At the time of data collection, all students enrolled in PE at Western School had been exposed to at least three new culturally relevant units included in the PE curriculum: mountain biking, archery, and slacklining. 


\section{Research Design}

This study employed a sequential mixed methods design to examine middle school students' perceptions of and responses to the new, culturally relevant units included in the PE curriculum. The study followed a quan $\rightarrow Q U A L$ design (Creswell, 2009), with the qualitative approach being the predominant method used to answer the research questions. In Phase One, two questionnaires were used to collect quantitative data related to middle school students' perceived athletic competence and attraction to physical activity. This information was used to select two distinct groups of participants for Phase Two, who were then interviewed through focus groups.

\section{Participants}

Phase One. A convenience sampling strategy was used to select participants for Phase One (Gay, Mills, \& Airasian, 2009). All sixth, seventh, and eighth grade students enrolled in PE, who had not opted out of the CHOICES study, and who attended school on data collection day were selected to participate in Phase One. A total of 120 students completed Phase One combined questionnaire (see appendix E), but four participants were not included in the final sampling because their questionnaires were not filled-out appropriately (missing data or completed incorrectly). The total number of participants in Phase One was 116 middle school students (53 male; 63 female) ranging in age from 11 to 15 years old $(M=12.3 ; S D=1.54)$ (Table 1: Phase One Participants).

Phase Two. A theory-based sampling strategy, stratified by grade (Marshall \& Rossman, 2006; Patton, 2002) was used to select participants for Phase Two. According to Patton (2002) theory-based sampling is characterized by the selection of "incidents, slices of life, time periods or people on the basis of their potential to represent important theoretical constructs" (p.238). In Phase Two participants were sampled according to their potential to represent the predisposing factors included in the YPAP model (Welk, 1999). The YPAP model suggests that children and adolescents who are attracted to and feel competent about engaging in physical activities are more predisposed to be active. Potential participants for Phase Two were selected based on Phase One data analysis and results. In each grade level (sixth, seventh, and eight) the sample mean scores for both questionnaires was split into thirds (33\%). Students 
who had the 33\% lowest mean scores in Phase One were invited to participate in Phase Two and were called less predisposed to be active (LPA). Students who had the 33\% highest mean scores in Phase One were also invited to participate in Phase Two and were called more predisposed to be active (MPA). A total of 76 students across sixth, seventh, and eighth grades were invited to participate in Phase Two (38 LPA; 38 MPA). A consent letter was sent home with the sampled students containing the following information: (a) purpose of the study, (b) data collection procedures, and (c) statements explaining voluntary participation, confidentiality, and reward for participation (see Appendix B). Parents/guardians were asked to sign the consent letter and return it to the PE teacher within a week. Initially, Phase Two aimed for a total of 24 to 36 participants and a higher number of students were recruited in expectancy that some would decline participation. The response rate from potential participants was higher than anticipated and a total of 57 middle school students returned the consent letters signed by their parents/guardians. Out of these 57 potential participants, ten students were not available to take part in the focus groups either because they were absent on data collection day or had conflicting schedules with other classes. Therefore, Phase Two participants were 47 students (17 male, 30 female; 21 LPA, 26 MPA) in grades sixth, seventh, and eight, ranging in age from 11 to 15 years old. (Table 2: Phase Two Participants).

\section{Data Sources}

Phase One. Two questionnaires were used in Phase One to measure middle school students' perceived athletic competence and attraction to physical activity. These variables are included in the YPAP model (Welk, 1999) within the predisposing factors associated with youth physical activity behavior. Perceived athletic competence is associated with the question Am I able? while attraction to physical activity is associated with the question Is it worth it?. Welk (1999) proposes that these two questions incorporate elements of distinct behavioral theories and provide a comprehensive and didactic description of predisposing factors of children and adolescents' physical activity behavior. According to Welk (1999) “youth who can answer yes to both questions will likely possess an 'active identity' and be 
predisposed to an active lifestyle" (p.13). The following instruments were used to measure the aforementioned variables:

Athletic competence subscale of the Self-Perception Profile for Children. The athletic competence subscale of the Self-Perception Profile for Children (SPPC) scale (Harter, 1982) assessed middle school students' perceptions of athletic competence. The SPPC scale was developed with the purpose of measuring the multiple domains that influence children's self-perception and includes six specific subscales (Harter, 2012) (see Appendix C). The athletic competence subscale of the SPPC scale measures children perceptions of their ability to successfully participate in sports and physical activities. The question format used in the SPPC scale follows a structured alternative format, in which each item presents children with two statements for them to determine which one best represents them and then choose if the statement is sort of true or really true for them. Items of the SPPC scale are scored from 1 to 4 , being the highest score corresponded to the answer that represents the most adequate self-evaluation (Harter, 2012). The subscale has six items and individual scores are obtained averaging all items' score. Previous research have found satisfactory internal reliability $(\alpha>.70)$ within the athletic competence subscale of the SPPC scale across different samples (Baker \& Davison, 2011; Harter, 2012; Muris, Meesters, \& Fijen, 2003).

Children's Attraction to Physical Activity scale. Participants' attraction to physical activity was measured by the Children's Attraction to Physical Activity (CAPA) scale (see Appendix D). Brustad (1993) developed the CAPA scale targeting children ages 7 to 13 and its items focus on children's emotional responses about their involvement in physical activity. The CAPA short version with 15 questions was used in this study to facilitate participants' response. Similar to the SPPC scale, each item of the CAPA scale presents children with two statements from which to choose the one that best represents then and then decide if the statement is sort of true or really true for them. Items of the CAPA scale are scored from 1 to 4 , being the highest score corresponded to the answer that shows the most compelling attraction to physical activity. Individual scores are obtained by averaging all the items' scores. The CAPA scale has also been indicated to have satisfactory internal reliability across different 
samples (Brustad, 1993, 1996; Paxton et al., 2004). For the purpose of this study, the two questionnaires were combined into a single document in order to facilitate administration. In this combined questionnaire the first six questions corresponded to the athletic subscale of the SPPC scale and the remaining 15 questions corresponded to the CAPA scale questions (see Appendix E).

Phase Two. Focus groups interviews were used in Phase Two to gather qualitative data related to middle school students' perceptions of and responses to the inclusion of culturally relevant units in the PE curriculum. Focus groups were chosen as the interview strategy in Phase Two because of their potential to encourage participants to express a variety of viewpoints in a safe atmosphere through group interactions (Krueger \& Cassey, 2009). Also, focus groups have been recognized as an appropriate method to interview adolescents because they may be more comfortable communicating with their peers than with adults through one-on-one interviews (Peterson-Sweeney, 2005).

This study aimed to conduct six focus groups (two groups per grade level, one composed of LPA students and the other of MPA students). However, given the high participation rate, 12 focus groups were conducted. Seven groups were composed of LPA students and five groups were composed of MPA students. The number of participants in each focus group ranged from two to seven, with an average of four participants per group. Each focus group followed a semi-structured questioning format in which questions were designed to obtain an understanding of: (a) students' thoughts about each culturally relevant activity prior and after unit delivery, (b) students' engagement in PE during the units, and (c) students' responses to the new units, particularly in regard to their participation in those activities outside of school. The duration of the focus groups ranged from 16 to 29 minutes, with an average of 21 minutes.

Pilot test. Both Phase One and Phase Two data sources were piloted prior data collection. The combined questionnaire used in Phase One was piloted with 70 students during PE classes in a local public middle school. Results from this pilot test were used to inform the questionnaire administration (e.g., duration, instructions) and data analysis procedures. The focus group script used in Phase two was piloted with two groups of six students at another public middle school. Results from this pilot test were 
used to inform the design of the focus group questioning route (e.g., number of questions, depth or responses, duration).

\section{Data Collection Procedures}

Phase One. Phase One of this study was added to the Institutional Review Board (IRB) protocol for the larger CHOICES study because of prior permission to use implied consent for collecting similar data considered normal educational practices (e.g., 3 day PA recall, nutritional surveys). Once the addendum to the CHOICES study's IRB protocol was approved, a date for data collection at Western School was arranged with the approval of the school principal, the CHOICES project director and the PE teachers. On data collection day, the combined questionnaire was administered during PE classes by the primary researcher with the assistance of the PE teachers. Participants were informed of the purpose of the study, voluntary participation, and were then given the choice to opt out of questionnaire completion. All students who had not opted out from the CHOICES study agreed to participate. The primary researcher followed a script to provide children with instructions for answering the questionnaire and guided them through the sample question completion (see Appendix F).

Phase Two. An additional IRB protocol (independent from the CHOICES study) was created for Phase Two of this study. Once the IRB approval was granted, the CHOICES project director, with the approval of the school principal and the PE teachers, arranged a date for data collection. All focus groups were conducted at the Western school during regular school hours over two consecutive days. The primary researcher and a research assistant were the focus groups facilitators. The research assistant, who had previous experience in conducting focus groups, received appropriate training in regards to this study's focus group protocol and procedures by the primary researcher. On data collection day, students whose parents/guardians consented to participate in this study were asked to report to a room during one PE or health class period at a pre-scheduled time.

Upon arrival to the focus groups session, the assent forms were distributed and read aloud to the students. The assent forms contained the following information: (a) purpose of the study, (b) focus groups procedures, and (c) statements explaining voluntary participation, confidentiality, and reward for 
participation (see Appendix G). Once all students signed the assent forms the facilitators started the discussion according to the focus group script (see Appendix H). Pictures of the culturally relevant activities (mountain biking, archery, and slacklining) were used to prompt and facilitate discussion. All focus groups were audio recorded and students were asked to not use names when referring to their peers in order to maintain confidentiality.

\section{Data Analysis}

Phase One. Data collected through the CAPA scale and the athletic subscale of the SPPC scale were entered into a database using the Statistical Package for Social Sciences 21 (SPSS). The following analyses were conducted for the entire sample and for each grade level sample independently (sixth, seventh, and eight): (a) internal consistency reliability analysis using Cronbach's Alpha for the CAPA scale, the SPPC's athletic competence subscale, and for the combined questionnaire, (b) descriptive statistics for the CAPA scale, the SPPC's athletic competence subscale, and the combined questionnaire, (c) distribution tertiles for the combined questionnaire, and (d) descriptive statistics for the lower and upper tertiles.

Phase Two. The focus groups' recordings were saved digitally and transcribed verbatim by a professional transcriber. Each focus group was transcribed independently and saved as an individual file. All data were kept confidential and saved in a password-protected format. Phase Two data were analyzed through an inductive process and data obtained by the two distinct groups of participants (LPA \& MPA) were analyzed independently so that results could be compared and contrasted. Phase two of this study employed an inductive content analysis in order to identify patterns or themes emergent from the data. Particularly, a three-phase approach suggested by Miles and Huberman (1994) was used and the process involved the following actions: (a) data reduction, (b) data display, and (c) conclusion drawing and verification (Miles \& Huberman, 1994). The constant comparative method (Glaser \& Strauss, 1967) was also employed throughout the analysis in order to assess if the coded segments of text were consistent and belonged to the assigned themes and subthemes. 
In the data reduction phase the primary researcher attributed codes to segments of data according to their meaning. An independent coder who is a knowledgeable and experienced researcher also attributed codes to segments of data across one focus group transcription. The consistency of codes between both researchers was verified during a debriefing meeting, in which the codes were discussed until an agreement about the coding scheme was established. After this meeting, the primary researcher proceeded with the coding of the remaining focus groups transcripts. Subsequently, a codebook was created in which the various segments of coded data were clustered into categories representing the similar patterns found in the data (Patton, 2002). The primary researcher revisited the codebook several times and closely examined the categories' meanings while comparing and contrasting the segments of data within each category in order to verify their consistency (Glaser \& Strauss, 1967). Once the data were condensed into themes, the independent coder also revisited the emergent themes and subthemes looking for congruency within the findings. An agreement among the researchers was established indicating that the emergent themes were a valid representation of the data and the analysis proceeded to the next phase.

In the data display phase the emergent themes and subthemes were displayed in a table format along with quotations representing the findings. The purpose of data display was to describe the data in a systematic way allowing for data interpretation and conclusions drawing (Miles and Huberman, 1994). In the conclusion drawing and verification phase the primary researcher thoroughly examined the displayed themes, subthemes, and sample data with the purpose of interpreting what had been described in the initial phases of data analysis. During this phase significance and meaning was attached to the data and findings obtained from the two distinct groups of participants were compared and contrasted.

\section{Results}

The purpose of this study was to examine middle school students' perceptions of and responses to the inclusion of culturally relevant units in the PE curriculum. In addition, the study aimed to examine if middle school students' perceptions and responses were similar or different according to their levels of predisposition to be physically active. This study used a mixed methods approach, in which quantitative 
and qualitative data were mixed sequentially (Teddie \& Tashakkori, 2009). Phase One results were used to inform Phase Two sampling and data analysis.

\section{Phase One}

One hundred sixteen students (53 male; 63 female) responded to the combined questionnaire. The internal consistency reliability analysis showed that Cronbach's Alphas for the combined questionnaire were equal to or greater than the Cronbach's Alpha for each individual scale across the entire sample and in each grade level sample (see Table 3). Therefore, participants' mean scores were computed by averaging the total 21 items from both the athletic competence of the SPPC scale and the CAPA scale, and subsequent data analyses were based on participants' mean scores for the combined questionnaire (means and standard deviations for each scale are presented in Table 4). The combined questionnaire average scores in the entire sample was $M=2.98, S D=.60$ (range 1-4). Although scores were relatively high in grade levels, they were higher in seventh grade $(M=3.15, S D=.61)$, than either in eighth grade $(M=3.06, S D=.54)$, or sixth grade $(M=2.81, S D=.61)$. Mean scores distributions were slightly negatively skewed in all grade levels, indicating that participants generally reported (on a 4 point scale) high degrees of perceived athletic competence and attraction to physical activity. Hence, in order to obtain the two distinct groups of participants for Phase Two (LPA \& MPA), the mean scores' distribution in each grade was divided into tertiles: the lower $33 \%$ scores, the middle $33 \%$ scores, and the upper 33\% scores. Students whose scores were in the lower tertile were characterized as LPA while students who were in the upper tertile were characterized as MPA. Table 5 presents the score ranges, means, and standard deviation for the lower and upper tertiles in the entire sample and in each grade level.

\section{Phase Two}

Forty-seven middle school students (21 LPA, 26 MPA; 17 male, 30 female) participated across twelve focus groups, yielding Phase Two qualitative data. As a result of the inductive analysis, three themes emerged from both the LPA and MPA focus groups data: (a) Expectations, (b) Engagement, and

(c) Responses. Although findings indicated that LPA and MPA had similar perceptions of and responses to the culturally relevant units, a few differences in the LPA groups were observed. The following 
sections present the themes and subthemes while discussing the similarities and differences found between the LPA and MPA groups. Please see Table 6 for frequencies of comments within each theme and subtheme, and review Table 7 and 8 for summaries of themes, subthemes, and supporting data from the LPA and MPA groups, respectively.

Theme I: Expectations. Participant students were asked to reflect back to the moment when they first heard that new, culturally relevant units would be included in the PE program and talk about their thoughts related to each one of them. Students across all grade levels, from both the LPA and MPA groups described having some type of expectation in regard to the units, which were either related to apprehension or excitement, and sometimes a combination of both. Therefore, two subthemes are included in the Expectations theme: Apprehension and Excitement.

Apprehension. Many students in both groups indicated having apprehensive thoughts preceding the following three units included in PE: archery, mountain biking, and slacklining. Participants identified the safety risks associated with each one of the activities and demonstrated concerns with the possibility of getting injured or injuring someone else. In regard to archery, students mentioned being surprised that they were allowed to have "weapons" in the school. Students from both groups who had not shot a bow before expressed greater concern with safety and were apprehensive with the chance of making a mistake and accidently shooting an arrow at another classmate. Data revealed that students' apprehension was also associated with lack of trust in their peers, specifically in regard to how classmates who usually display inappropriate behavior would handle the archery equipment. Concerns about how classmates' behavior in archery could impact students' safety were evident among both LPA and MPA students.

When asked about their expectations related to mountain biking, several LPA students expressed fear of "wrecking" their bikes. Apprehensive thoughts about mountain biking were more frequent in the LPA groups and mostly associated with lack of past experiences or involvement in previous bicycle accidents. Students who haven't ridden a mountain biking before were concerned with their ability to control a bike in a different and more challenging terrain (e.g., trail, grass), while students who have had 
negative experiences with a bike predicted getting into an accident again. A LPA participant who mentioned crashing a bike in the past commented on how anxious he was about being on a bicycle once more given that past traumatic experience. Interestingly, a few MPA students also mentioned being apprehensive about mountain biking, but expressed concerns about others "wrecking their bikes" or getting hurt, not themselves.

Concerning slacklining, LPA and MPA participants said that they were scared of trying to walk across the slackline, which is a band tensioned between two points, hanging at two to three feet above the ground. Although it was evident that participants' apprehensive thoughts related to slacklining were associated with the safety risks inherent to this activity, perceptions of difficulty, lack of previous experience, and low perceptions of athletic competence also contributed to increased fear of engagement. When asked to recall their thoughts prior to being exposed to slacklining, LPA and MPA students consistently described the activity to be challenging and "too hard". These perceptions might have been associated with the fact that slacklining was a new activity to most of the children. In addition, perceived athletic competence appeared to influence some students' concerns. For example, one LPA student described being afraid to walk across the slackline because he perceived himself as not having enough balance. Likewise, a MPA student believed that balancing on the slackline was so difficult that he didn't even want to try it. Data suggests that perceived athletic competence influenced participants' levels of apprehension about slacklining independently of their levels of predisposition to be active, which can be explained by their lack of experience in this particular activity. The following data best support the tenants of the Apprehension sub-theme:

Oh no! Somebody is going to wreck. $8^{\text {th }} L P A^{l}$

I kept saying, I am going to die because I'm not very balanced. $7^{\text {th }}$ LPA

I have never shot a bow before and I know some other students have never done it either so I was kind of going like well I don't know if this is a pretty good idea, cause I just felt like it might've been unsafe if some students kind of got cocky with it or decided it could be used on another student really. $7^{\text {th }}$ L $L P A$

\footnotetext{
${ }^{1}$ Reference at the end of each quote indicate: grade $\left(6^{\text {th }}, 7^{\text {th }}\right.$, or $\left.8^{\text {th }}\right)$ and group (LPA or MPA)
} 
When I just heard mountain biking I was, I had really mixed feelings on it because I had not rode a bike in a long time and I was really kind of concerned what if something had happened like somebody wrecked into another or somebody had gotten hurt and I was figuring well I'm going to of course wreck this bike. I just knew it. $7^{\text {th }}$ LPA

I thought it was going to be scary because I was afraid somebody was going to get shot with a bow. $6^{\text {th }}$ MPA

First of all, some of those people in there they kind of scare me. So I was like he's going to trust us with bows and arrows? I was like what's wrong? I was like we can do this? $8^{\text {th }}$ MPA

At first I was scared. I was like oh my Lord I'll fall off and break my face. $8^{\text {th }}$ $M P A$

Excitement. When asked about their anticipating thoughts regarding archery, mountain biking, and slacklining, several LPA and MPA students in all grade levels indicated having positive expectations about the units. Most of the students foresaw that this new PE content would be fun and commented that they were excited with the opportunity to learn and participate. Students' positive expectations were either related to the content novelty, the opportunity to practice in school what they already enjoyed doing at home, and their perceptions of athletic competence.

Numerous LPA and MPA students were enthusiastic about the new units because they had never had a chance to take part in mountain biking, archery, or slacklining. For example, a few students were keen to learn archery in PE because they had often seen other people shoot bows and have always wanted to be given an opportunity to try it. Likewise, despite their apprehension, students demonstrated curiosity and eagerness to learn slacklining because it was a brand new experience to most of them. However, it became evident from the data that a great portion of LPA and MPA students were excited and pleased with the opportunity to engage in archery and mountain biking in the school because of their previous experiences in those activities. These students often communicated being happy about the chance to ride bikes and shoot bows in the school because these are things that they usually do at home and are different than the regular PE content. Similarly, students perceived that the inclusion of archery and mountain biking in PE represented an opportunity for them to have extra shooting and riding practice. One student mentioned that he was thrilled about riding at the school because his bike had a flat tire and he hadn't being able to ride much at home. 
In addition to novelty and opportunity for practice, LPA and MPA students' perceived athletic competence seemed to influence their positive expectations. Participants in both groups described being enthusiastic about archery, mountain biking, and slacklining because they perceived themselves competent enough to be successful in one or more activities. These students said that they were glad with the chance to take part in PE content that they felt confident about and could be successful at. This suggests that independently of their levels of predisposition to be active, participants' valued and appreciated the possibility of experiencing and demonstrating success in PE. Data below reflect the Excitement sub-theme:

I thought okay I've never done it before so I'm happy to try it. $6^{\text {th }}$ LPA

I was excited for it. Cause we never get to do this stuff in gym. ${ }^{\text {th }}{ }_{-} L P A$

Because I was excited that I'd be able to do something and be confident about it. $7^{\text {th }}$ LPA

I thought I was going to do good because a few years ago I did archery in Girl Scouts so I knew a lot about archery. $8^{\text {th }}$ LPA

... whenever I heard it I thought it was going to be awesome because you know we get to ride a bike at school. It's not that often that we get to like, that'd be like driving in high school. $\sigma^{\text {th }}$ L $L P A$

I was like well I already knew how to ride a bike so it should be a piece of cake. $8^{\text {th }}$ LPA

I thought it was going to be fun because I never really shot a bow, especially at school too, so yeah, fun. $6^{\text {th }}$ MPA

I was excited cause like I love shooting my bow and stuff. $8^{\text {th }}$ _MPA

I was excited too. I thought it was going to be a great opportunity for us to learn how to do it. $8^{\text {th }}{ }_{-} M P A$

I thought myself it was going to be pretty fun because I'm good at balancing myself where I took gymnastics and stuff like that. $8^{\text {th }}$ MPA

Theme II: Engagement. The second theme emergent from the data was Engagement. During the focus groups, students were prompted to reflect upon their participation in the mountain biking, archery, and slacklining lessons and identify the things they liked the most and the things that they liked the least about them. Students were also prompted to recall their most memorable moment in each unit and describe their thoughts about taking part in these activities during PE. The Engagement theme 
reflects students' perceptions of their participation in each unit and the outcomes associated with their experiences. Two subthemes comprise the Engagement theme: (a) Learning environment and (b) Learning outcomes.

Learning environment. Participants often described the learning environment features that facilitated their engagement in the new units. These features included competition, equipment, support, and the outdoor facilities.

Competition. Students across both groups and in all grades perceived competition as an element that fostered participation because it increased motivation, promoted social interactions, and challenged them to succeed. Students in LPA groups reported enjoying the competitive aspect of all three activities, while students in MPA groups only mentioned competition in archery. In slacklining, LPA students commented on how they viewed walking across the slackline as a constant competition against self, which motivated them to reach their goal of getting to the opposite end. According to these students competing with their friends when attempting to walk across the slackline also enhanced their willingness to practice and improve performance. In regards to archery, LPA and MPA students indicated competition as one of their favorite aspects about the unit. Participants' comments about competition in archery revolved around their desire to shoot arrows at the "bulls' eye" and their increased motivation to practice resulted from watching their peers' performance and constantly attempting to "beat them". Interestingly, LPA and MPA girls mentioned enjoying competing against boys in archery because they had an opportunity to succeed as well as to show the boys that they were capable of winning. For these girls, being able to win a sports competition against boys was something important that made them value and enjoy participating in archery during PE. Concerning mountain biking, a few LPA students commented that they liked to race their friends through the biking course, indicating enjoyment of the competition aspect present in the sport.

Cause you're like trying to compete against each other and then you're showing them like how you can, I mean what you've got. Like just do it your best I guess. $7^{\text {th }}$ LPA

You get really competitive trying to get to the end because it's actually, you think you won't do good at the end but as you see how thrilling it is $6^{\text {th }}$ LPA 
I basically agree with the others. It's fun watching them and like competing with them and seeing who can do the best or see if you can actually learn from their mistakes or learn from them. $7^{\text {th }}$ _LPA

Getting to see other people hit the bull's eye so you can challenge yourself to hit it closer to the middle than they are. $6^{\text {th }}$ MPA

Yeah, cause all the boys were talking about how they were so good at it and that just made you want to do it so much more and be like yeah I won and you're a guy. I thought you were supposed to be good. $8^{\text {th }}$ MPA

Equipment. Another feature of the learning environment frequently addressed by the students was equipment. Participants referred to the equipment used in archery, mountain biking, and slacklining several times during the focus groups indicating its benefits but also pointing out some of their flaws. Although the students recognized that the bikes provided were of good quality, they described the saddles as being uncomfortable and a hindrance to riding. Also, participants demonstrated frustration about riding bikes that were either too small or too big for their statures as well as about sharing the bicycles and helmets with their classmates. Comments about bikes' saddles and sizes occurred in both LPA and MPA groups across all grade levels. In regard to archery, participants frequently alluded to the fact that having bows with different degrees of tension was helpful because it allowed them to select and use equipment that best matched their ability and strength levels. Some students also said that they were pleased with the bows, arrows, and targets offered in PE because their equipment at home was broken or of an inferior quality. Concerning the slacklining equipment, students explained that having different sizes of slacklines placed at varied heights allowed them to progress from simple to more advanced tasks. Similarly, students mentioned using training tubes prior to experiencing the slacklines, which were designed to foster the practice of balance skills, such as arms positioning, body posture, and eyes direction. Some children also said that they would like to use wider slacklines because they thought it would facilitate learning and enable them to have better balance while walking across.

Like I have a bow of my own at my house and I was shooting in a rug with a target sprayed on it. I don't have an actual target but having a legit bow and a legit target was just awesome. $6^{\text {th }}$ LPA

... whenever you got your bike you had to be on your tippy toes for the size and stuff and I'm not used to that cause I usually have to fully touch the ground. $8^{\text {th }}$ LPA 
Those pipes, they had like pipes that you like stood on to like get the feel of it and then you could like go over to the other things. $8^{\text {th }}$ MPA

I dreaded those seats. It was nice though. The bikes was whooo. $8^{\text {th }}{ }_{\text {MPA }}$

She just had them like, well the black bows, the black bows with the red strings is for left hand, and then like the blue bows and the yellow bows and the orange one's for right hands and you could pick whichever one you wanted to. $6^{\text {th }}{ }_{-} \mathrm{MPA}$

Support. A third aspect related to the learning environment described by the participants was the support they received from their teachers, peers and the slacklining professionals who visited the school to do a demonstration and deliver an introductory lesson. More specifically, LPA and MPA students referred to the support received from their teachers in archery, from the visiting professionals in slacklining, and from their friends in both archery and slacklining. In archery, students indicated that the teachers established a safe environment by carefully setting the rules, explaining the shooting technique, and using auditory signs to designate when students could shoot and retrieve arrows. Students also alluded to the teachers' instruction in archery as being helpful and effective. When talking about their peers in archery and slacklining, participants repeatedly indicated that there was an exchange of emotional support among classmates. According to the students, cheering their peers or being encouraged by their friends was an important component of the learning environment, which enhanced their confidence and motivation to participate. Data also showed that students' remarks about support emphasized their appreciation for slacklining professionals introducing the unit. Participants indicated that watching the professionals demonstrate a high level of proficiency in slacklining was exciting and inspired them to engage and learn new skills. When asked to recall their most memorable moment across the three activities, many participants mentioned the professionals visit to the school and described being amazed at their abilities to perform tricks and being sparked to engage as a result.

Because they [professionals] could just help you in like how to do it right. Well the teachers do but like they could tell you like their experiences with it and stuff. $6^{\text {th }}$ LPA

Yeah, and it kind of like makes us determined to try and learn how to do that. $8^{\text {th }}$ LPA

I mean they'll [friends], let me see how to put it, they'll help you, like they'll cheer you on if you don't know how to do it. Like if you can't pull it back if you're weak they'll cheer you on and then you can do it then. $7^{\text {th }}$ LPA 
Ifelt safer cause the teachers described what to do and how to do it. $8^{\text {th }}$ MPA

Yeah, and if somebody didn't get it like he [teacher] would show you and correct you and he'd like lift your arm if it was like down or slanted. $8^{\text {th }}{ }_{M}$ MPA

The professionals coming in and helping us and actually trying to motivate your body, trying to balance out, get your muscles stronger and your knees. $8^{\text {th }}{ }_{-}$MPA

Like that dude that was here he was like talking about how he does like competitions and goes up against people and I was like yeah that would be cool. $8^{\text {th }}$ MPA

Outdoor facilities. The fourth element described by the students to be associated with the learning environment was the biking trail built outside of the school building. Once students learned the basic mountain biking skills inside the gymnasium (e.g., break and chain checks, safety protocols, making turns, and changing gears) they were allowed to ride the bikes on the trail, which was recently built around the school. Data provided evidence that numerous LPA and MPA participants across all grades enjoyed being outdoors and valued the opportunity to be active outside of the gymnasium simply because of the change in the environment and the pleasant feelings of being outdoors. However, LPA and MPA students presented divergent thoughts about riding on the trail and mentioned having either positive or negative experiences related to it. Many students said that they enjoyed riding on the trail given the challenge it presented to them. These students referred to the hills, obstacles, and holes as something amusing, challenging, and fun. Alternatively, several students perceived the trail as not as enjoyable and referred to the hills, obstacles and holes as troublesome and unpleasant. These students said that the uneven characteristics of the trail terrain caused riding to be more difficult and less enjoyable. These two different perspectives about the biking trail might have been associated with students previous experiences with mountain biking and their ability to handle a bicycle on a rough and challenging terrain. Although LPA and MPA participants reported divergent perceptions about the bike trail most of the negative comments about it came from the LPA groups.

I liked it cause we got to go outside and ride through the fields and down through the woods and it was kind of like going on an adventure. $8^{\text {th }}$ LPA

We get stuck in other periods for a long time and then you just get to go outside and feel the breeze and air and the sun on your skin and you just get to have fun out there, be a little kid again. $7^{\text {th }}$ LPA 
I didn't like two of the hills. They were like real steep. $6^{\text {th }}$ LPA

Well, mountain biking isn't mountain biking without some hills. $7^{\text {th }}$ L LPA

Yeah, get out of the gym and actually like ride around the school. $8^{\text {th }}{ }_{\text {M }}$ MPA

I think we should've rode it somewhere else because that grass was way too bumpy and like too many of us like fell off our bikes. $8^{\text {th }}$ MPA

It was fun because we got to go outside and we went around in the grass and then we went into holes and stuff. $6^{\text {th }}{ }_{-} M P A$

Learning Outcomes. The second subtheme within the Engagement theme refers to the outcomes of participating in the newly implemented units. Students who were in LPA and MPA groups frequently recounted the new skills and concepts learned in archery, mountain biking, and slacklining as a result of the lessons delivered in PE. Students from both groups in all grades were able to describe in detail the archery techniques developed during the lessons (e.g., bow set up, draw, release, aim, etc.). In respect to mountain biking, numerous participants mentioned learning to shift gears. Students' comments showed that they also gained understanding that employing proper shifting techniques helped them to master the trail and successfully ride uphill and downhill. A few students also recalled learning personal and social responsible behaviors associated with mountain biking such as the importance of always wearing helmets, conducting safety checks prior riding, controlling speed, and riding carefully while being on the trail with others. Concerning slacklining, data indicated a consensus among LPA and MPA students regarding the development of balancing skills as an outcome of participating in the lessons. Several students mentioned perceiving improvement on their balance skills and reported achieving greater levels of performance in the activity as a result. Data suggests that LPA and MPA students demonstrated increased satisfaction with all three activities as a consequence of skills acquisition. Some students referred to skill improvement as "getting the hang of it" and expressed being more comfortable to engage in mountain biking, archery, or slacklining as they regarded themselves as being more proficient.

Of course I learned how to hold the bow and shoot it, how to [lock] it, and I learned different things about it. $7^{\text {th }}$ LPA

I learned how to aim down the arrow and judge wind and your elevation with your target to hit the bull's eye. $8^{\text {th }}$ LPA 
I learned that on mountain bikes that they have gears and you have to keep your gears like with your terrain that you're in and like if you're going uphill or downhill that you have to be constantly switching your gears for the different terrains. $8^{\text {th }}$ LPA

Once you get the hang of balancing on slacklining you can do it cause I did. $8^{\text {th }}$ LPA

Probably just learning how to ride the mountain bike cause I mean I have a regular bike at home but changing the gears I didn't think I would like that, but I do. $6^{\text {th }}$ MPA

In mountain biking I learned how to like stay safe and wear a helmet and stuff. $6^{\text {th }}{ }_{-}$MPA

For slackline it would be how it was brand new and how you got to learn so much about it and maybe even try it yourself. $7^{\text {th }}$ MPA

I liked it because when we got used to it you could walk farther and then you could turn around and then you can do different stuff. $6^{\text {th }}{ }_{-} M P A$

In addition to skill acquisition, LPA and MPA students frequently described specific instances in which they were successful in accomplishing a certain task. Comments about successful experiences pertained mostly to archery and slacklining, which might be explained by the fact that both activities' structure provides participants with immediate feedback of performance. In those activities, students did not need other people to assess them; rather the activities' inherent components (i.e., hitting the "bulls 'eye", getting across the entire line) were sufficient to provide information about their accomplishments. In archery, students measured their achievements by the frequency in which they were able to shoot arrows and successfully hit the target. In slacklining, students measured their success by the amount of times they could travel across the line without falling or by their ability to perform more complex skills such as lunges and turns. Data from the LPA groups revealed that some students' remarks about their successful experiences in archery were linked to enhanced perceptions of athletic competence. One student mentioned that he had finally found a physical activity in which he could succeed at. Similarly, another one said he was surprised by not being a failure in PE anymore and thrilled to show the teacher his ability in archery. This increased perception of athletic competence was accompanied by pleasant feelings and positive thoughts about learning archery in PE.

Despite the positive learning experiences shared by participants, a few LPA and MPA students identified unsuccessful experiences as what they liked the least about the new units. Although data 
showed that the amount of statements about unsuccessful experiences was significantly less than those about successful experiences, it is important to recognize that students pointed out their frustration with not being able to accomplish an activity task. Most of the unsuccessful experiences mentioned by the students pertained to slacklining such as "falling off" the lines and not being able to reach the opposite end of it. Data showed that most of the remarks related to successful and unsuccessful experiences came from LPA students, suggesting that for these students being able or not to accomplish tasks had a greater influence on their level of enjoyment in the new, culturally relevant units.

I'll never forget in archery when I got my very first bull's eye. $8^{\text {th }}{ }_{-} L P A$

I like the noise. Like it whistled and then you heard a thud. That was my favorite part because like whenever you hear the thud you know that you hit it. $8^{\text {th }}$ LPA

I thought the satisfaction of knowing how well my balance was. $6^{\text {th }}$ LPA

Some people doubt their selves about what they can do on it and then it kind of makes them feel a little bit better when they realize in practice doing it, which makes them feel proud of their selves. $6^{\text {th }}$ L $L P A$

Yeah, I got all the way across the little one twice, frontwards and backwards. $8^{\text {th }}$ LPA

Just the fact that I fell about maybe once or twice just because I lost too much speed going up a hill and I slipped, and that's just the only part I didn't like. $7^{\text {th }}$ LPA

Just to try to, just trying new things but then also to keep your balance and if you can get that it's like a really big success and achievement for that. It's just fun for me. $8^{\text {th }}{ }_{M} \mathrm{MPA}$

I liked it cause I could walk across and not fall. I was balanced enough to do it. $7^{\text {th }}$-MPA

That I kept falling off. That made me mad. $6^{\text {th }}{ }_{M}$ MPA

Theme III: Responses. The third theme emergent from the data represents students' responses to their exposure to the three new units. During the focus groups, participants were prompted to reflect upon the influence of the new units on their thoughts about PE and their physical activity habits outside of school. Data indicated that students found meaning in the new units and were able to make connections between the content learned in PE and their physical activity experiences outside of the school setting. Furthermore, data revealed the participants' thoughts about PE were influenced by their engagement in archery, slacklining, and mountain biking, which was emphasized by their call for more opportunities to 
participate. Hence, three subthemes comprise the Reponses theme: (a) Relevance (b) New perspectives, and (c) More opportunities.

Relevance. When questioned about their thoughts regarding the introduction of mountain biking, archery, and slacklining in PE, numerous LPA and MPA students connected these activities to their physical activity habits outside of the school setting. These connections were related to the individual, social, and cultural meanings students attributed to each activity. Concerning individual meaning, many students commented that archery and mountain biking lessons provided them with the necessary skills and confidence to participate in those sports outside of the school environment. Also, many LPA and MPA students reported liking to have archery and mountain biking in the school because these activities represented an extension of the leisure pursuits they would normally engage in at home. In regard to slacklining, some students perceived that the balancing skills developed during the unit were relevant because they could be transferred to other sports and help them to become better athletes.

It makes me more confident to do it outside of school. $6^{\text {th }}{ }_{-} L P A$

It's just exciting to try something new every now and then cause I just started shooting a bow like a couple of weeks before we did it in class so it gave me a little bit more practice when we did it in class. $8^{\text {th }} L P A$

I like it because you have to learn how to keep your balance and in sports you have to have balance so it makes you a better athlete. $6^{\text {th }}{ }_{-}$MPA

I think it was fun cause like I like riding bikes cause like at my house I like to ride bikes up in the mountains and stuff and it's just like extra, like more time that I get to ride. $8^{\text {th }} \_$MPA

Concerning social meaning, various MPA and LPA participants indicated that they appreciated having mountain biking and archery lessons in PE because those are activities that they frequently engage in with their family or friends. For instance, one student commented that the biking lessons were preparing him to ride in the summer, when his grandmother would buy him a bike and take him to ride at the local biking trail with her cousin. Similarly, some students were glad to do archery in school because they have bows and arrows at home and usually spend time playing with them with relatives or friends. One participant said that he would often shoot bows with his dad and he was proud to show him that after the archery lessons she was indeed able to successfully shoot arrows at targets. 
Because I really like shooting with bow and arrows because I know someone who does archery. I guess he's like an archery champion or something like that, and he teaches me and my brother and my two sisters a lot about archery and stuff like that. $8^{\text {th }}$ LPA

I always did it [shoot bows] with my dad outside of school and I really enjoyed it. $7^{\text {th }}$-MPA

Usually we have like this [version of] like behind our house and me and my sister usually go out there and ride our bikes. $6^{\text {th }}$ MPA

In addition to individual and social meaning, it was evident from the data that LPA and MPA

students in all grade levels valued the inclusion of archery in PE due to its relevance for their culture and community. Students associated archery with hunting, which is a longstanding tradition in the rural Appalachian county where this study was conducted. Students' remarks about archery showed that they perceived shooting arrows with a bow as an "important life skill" and "useful for the future". Students also said that engaging in archery made them feel connected to their environment and it was fun because it represented aspects of their culture. One student even mentioned he liked to have his arm scratched by the bow's string while engaging in archery during PE because it was a sign that he had actually shot bows.

Well it's just exciting how you've got to get everything ready. It's kind of like you were hunting. $\sigma^{\text {th }}$ L $L P A$

I thought like the people that don't know how, they just learned how that you could. This might be handy when they grow up. Maybe they want to be a hunter. $7^{\text {th }}$ LPA

Well I like to do a lot of hunting and fishing at my house and so being able to get and you know be able to shoot archery it was just another experience with hunting. $8^{\text {th }}$ MPA

I'm a country person so I don't know I just like doing stuff like that. I think it's just fun to me. $8^{\text {th }}{ }_{-} M P A$

New Perspectives. The second subtheme within the Responses theme refers to a newly developed perspective about PE among LPA and MPA students. During the focus groups participants were also asked if the culturally relevant units had any influences on their thoughts about PE. Data revealed that the majority of LPA and MPA students across all grades, indicated that participating in archery, mountain biking, and slacklining changed their perspectives about PE. Students compared these new activities with the traditional forms of PE they have experienced in elementary school or in previous 
years at the middle school level. Participants portrayed their previous experiences in PE as being unpleasant, boring, and not engaging. According to the students, PE classes rooted in exercise routines (e.g., running laps, jumping jacks, and push-ups), tag games, or team sports were not interesting or motivating. Students often referred to these approaches as being repetitive and dull, which caused many students to develop aversive feelings towards PE. For example, one LPA student mentioned that she used to "drag" going to PE classes, while another recounted faking injures in order to avoid playing kickball in elementary PE.

In contrast, both MPA and LPA students reported developing a different perspective about PE as they were exposed to the culturally relevant content. Participants' comments indicated that their thoughts about PE have changed because they perceived the new units to be innovative, challenging, meaningful, and fun. Students mentioned viewing the units as a chance to engage in interesting content and learn different skills that could be transferred to outside of school opportunities. Furthermore, several students recognized that those units allowed them to be physically active while having fun and identified the potential health-related fitness benefits they could gain as a result of riding bikes, shooting bows, and balancing on slacklines. This suggests that these middle school students are aware of the benefits of regular engagement in physical activity and value movement experiences that allow them to do so in pleasant ways. Students indicated that the culturally relevant units influenced their perspectives about PE because they learned skills that would be useful in the future. In fact, it was evident from the data that students were surprised they could actually learn meaningful content PE. This implies that their negative previous experiences might have shaped their beliefs about the discipline's relevance.

Another interesting finding was the fact that some LPA students identified the cognitive aspects pertinent to the new units as a motivating factor to engage. These students mentioned liking to participate in archery, mountain biking, and slacklining because these activities required them to focus and concentrate in order to reach their goals. One participant said that he enjoyed slacklining because he had to think of each aspect of that activity in order to be successful, while another child mentioned that archery helped her to develop "brain skills". This indicates that LPA students perceived cognitive 
engagement as an important aspect of the culturally relevant units, which influenced their new perspectives about PE.

Although most participants acknowledged changes in their thoughts regarding PE, a few LPA and MPA students stated that engaging in the new activities did not change their perspectives. These students said that they always enjoyed PE because they like to be physically active regardless of the type of activity. Specifically, four students in one of the MPA groups and two students in one of the LPA groups indicated having no differences in their perspectives about PE as a result of the new units added to the curriculum. Data below represents the sub theme New Perspectives:

It made it more interesting than just doing stretches and running and doing the same routine every single day. $6^{\text {th }} L P A$

I liked the idea of getting new activities in gym because a lot of basic gym classes we do just like volleyball, basketball and stuff like that and getting new stuff and keeping people interested in gym class and getting their physical activity is important. $8^{\text {th }}$ LPA

And here you get to learn new things and stuff that can help you a long ways. $6^{\text {th }}{ }_{-}$MPA

I don't know. It's just like pushing your brain to test your balance skills to test so like you've got to just focus and not mess up and try to get to the other side of the line. $8^{\text {th }}$ LPA

Like you would think of PE as something where you would do like, something that you've got to do like constantly, like workout or something. But you like get to exercise but you get to do it in a fun way. $6^{\text {th }}$ MPA

Well, normally in PE we don't really do... We just play kickball or have a free day or something like that. On this we actually focus on it and actually like try to achieve something instead of just going out and doing whatever. $8^{\text {th }}$ MPA

They all have a physical activity, like mountain biking helps your legs; archery helps your strength for your arms, and balance. $6^{\text {th }}{ }_{-} M P A$

It really didn't change the way I thought about PE cause like I've always loved PE. I've always loved like playing the different games and stuff like that, and I like to run and like to just play sports. I just love to be active in this stuff. $8^{\text {th }}$ MPA

More Opportunities. The third subtheme within the Responses theme depicts students call for more opportunities to engage. Data from the focus groups revealed that the vast majority of LPA and MPA students fully enjoyed the introduction of the new culturally relevant activities in PE. Hence, when asked about the things they liked the least about the new units, participants recurrently mentioned the 
desire to have more opportunities to engage in archery, slacklining, and mountain biking. The call for more learning opportunities were expressed in two ways: (a) students wanted to have more practice time during the lessons and (b) students believed that each unit should be extended over a longer period of time. According to the students, practice time during the lessons was limited because PE classes are already short and they had to take turns using the equipment, which increased waiting time. Furthermore, the safety protocols pertaining to archery (i.e., waiting until all students had shot to retrieve arrows), slackling (i.e., only one students is allowed to travel across the line at a time), and mountain biking (i.e., bike checks and helmets) contributed to decreased time in learning experiences, which was frustrating to the students. Along with the desire for more practice time during the lessons, participants communicated that they would like to engage in these types of activities more often and would prefer to have the units extended to more days. The students also identified the potential benefits of having more opportunities to engage in biking, archery, and mountain biking. According to the students, more learning time would result in enhanced skill learning, more enjoyable experiences in PE and further involvement with each of the new culturally relevant units. Data below illustrates the More Opportunities subtheme:

We only got to do it for only three days but if they like did it like the end of every month that'd be so much better because we could then like get more practice $6^{\text {th }}$ LPA

It was pretty cool, like they should have it again. Like I said with archery they could have archery at the end of every month they could have mountain biking at the beginning of every month. $6^{\text {th }}$ LPA

Archery we did it for a few days. Like we should do it at least for a week at a time so we can like actually get into it and do it longer and stuff like that. $8^{\text {th }}$ LPA

\section{Discussion}

It has been argued that the quality of PE experiences might be one of the most important influences on youth's participation in physical activity outside of this school setting (Cox, Smith, \& Williams, 2008; MacPhil, 2010). Accordingly, researchers have recommended that studies consider the voices of students in order to gain understand about their attitudes towards their PE programs (MacPhil, 2010; Prusak et al., 2014). This study aimed to examine how middle school students perceived and 
responded to the inclusion of culturally relevant units in the PE curriculum. An additional purpose of the study was to examine if LPA and MPA perceived and responded to the changes in the curriculum differently. More specifically, this study investigated students' reactions to the introduction of archery, mountain biking, and slacklining in the PE program of a middle school located in a rural Appalachian county as part of a multicomponent school-based health intervention. Findings revealed that three overarching themes representing the voices of LPA and MPA students emerged from the qualitative data: (a) Expectations, (b) Engagement, and (c) Responses. Each theme was composed of subthemes, which portrayed students' thoughts about each activity, their learning experiences, and their responses to the enhancements made in the curriculum. Furthermore, it could be observed that the subthemes shed light on the elements that influenced participants' perceptions of and responses to their engagement in the new units. Interestingly, these elements are in line with the predisposing, enabling, and reinforcing factors of youth physical activity behavior outlined by the YPAP model (Welk, 1999) (see Figure 1) and provide insight about programmatic features that have the potential to encourage both LPA and MPA middle school students to engage in physically active lifestyles.

\section{Predisposing Factors}

Predisposing factors are at the center of the YPAP model and encompass variables that have been found by researchers to enhance the likelihood of physical activity engagement. These variables have been identified by multiple behavioral theories and are summarized in the YPAP model by two questions: (a) Am I able? and (b) Is it worth it? (Welk, 1999). The first question relates to the individual's perceptions of his competence to perform an activity while the second question relates to the individual's perceptions of the outcomes related to physical activity participation (Welk \& Schaben, 2004).

According to Welk and Schaben (2004) "Predisposing factors are presumed to represent the most direct influence because they reflect the child's personal 'predisposition' or interest in being physically active" (p.66).

Predisposing factors were key in this study because they were used to generate the two distinct groups of participant middle school students: LPA and MPA. Although findings showed that students 
from both groups had similar perceptions of and responses to the culturally relevant activities, a few differences in their perspectives were observed. Findings revealed that in contrast to MPA participants, LPA students: (a) were more apprehensive about riding bikes in PE and more uncomfortable about riding on the trail, (b) emphasized their successful experiences, (c) indicated developing enhanced perceptions of motor competence as a result of participating in the new units, and (d) identified cognition as a valuable aspect of PE. Nevertheless, in spite of these minor different perspectives, findings showed that predisposing factors influenced both LPA and MPA students' reactions to the new PE program.

Am I able? Perceptions of competence, which in the YPAP model is a construct associated with the question Am I able? influenced MPA and LPA students' thoughts about the activities and moderated both apprehension and excitement feelings prior to each unit delivery. Students' statements about their perceptions of athletic competence were positively associated with excitement feelings and negatively associated with apprehension. Students' perceptions of competence also influenced their engagement in the mountain biking, archery, and slacklining lessons. Because the lessons fostered skill development in all three activities, participants from both groups often addressed their accomplishments and constantly referred to the positive feelings and pride associated with successful experiences. Moreover, achievement during the lessons contributed to an increase in perceptions of motor competence among the LPA students, which was also related to the changes in their perspectives about PE. When asked about what made them like the new activities, one LPA student mentioned: "The fact that I was okay at it, I found something I was okay at." ( $8^{\text {th }}-$ LPA).

The voices of LPA and MPA students revealed that their positive perceptions of competence in all three activities increased satisfaction and willingness to participate emphasizing the relationship between perceived competence and enjoyment outlined in the YPAP model. Children and adolescents perceptions of athletic competence have been indicated as one of the most influential factors on physical activity engagement (Ridgers, Fazey, \& Fairclough, 2007; Welk \& Schaben, 2004). However, evidence shows that PE programs, especially at the secondary level, often fall short of fostering student achievement and, consequently developing competent movers who view themselves as such (Bernstein et 
al., 2011; Garn et al., 2011; Mohr et al., 2006). Accordingly, school-based physical activity programs that aim to engage youth who have lower perceptions of athletic competence must carefully consider alternative strategies to enhance the opportunities for skill development and consequent successful performance.

Another interesting finding revealed participant's compelling feelings towards competition in all three activities, indicating that being successful in trial tasks promoted enhanced perceptions of competence, which resulted in increased motivation to practice. Also, data indicated that the new units leveled the playing field among students, which increased their chances to be successful while competing against others (e.g., girls wining over boys). These findings supports the importance of developmentally appropriate competition in PE as a means for skill development, application, and assessment (Bernstein et al., 2011). It is worthwhile to consider that the immediate feedback of performance inherent to archery, mountain biking, and slack-lining (e.g., hitting the target, getting across the slack line, not falling off the bikes) allowed students to assess their own performance and make inferences about their competence in each unit.

Is it worth it? In the YPAP model enjoyment is a construct embedded in the question Is it worth it? There is evidence in the literature showing that enjoyment is a critical element in the development of active habits that can be carried on for a lifetime (Carrol \& Loumidis, 2001; Schneider \& Cooper, 2012). Participant students enjoyed learning new skills and engaging in activities that are relevant for their culture. They appreciated being outdoors and having the opportunity to socialize with their friends. They liked to compete, to be challenged, and to reach new goals. Students also appreciated being active while having fun and frequently compared this new approach to PE with traditional models that are based on exercise routines and team sports. According to the students, the main difference between these two approaches to PE was their levels of enjoyment, which clearly influenced their eagerness to engage. Also, numerous students indicated that they would like to spend more time in each unit and have more opportunities to engage with the content. This finding contradicts proponents of multi-activity approaches who often argue that children and adolescents might lose interest in an activity if exposed to it 
for longer periods. Participant students identified the benefits of deeper engagement with the content and showed to value longer units of instruction, which has been indicated by Kretchmar (2000) as a prerequisite for the development of meaningful movement experiences in PE.

Beliefs about physical activity outcomes is another construct embedded in the question Is it worth it? Students from both groups found value in the new units and mentioned that learning mountain biking, archery, and slacklining was beneficial for leisure pursuits, fitness enhancement, and social interactions. In addition, students identified meaning in the new activities and perceived that PE could indeed introduce them to movement experiences that are personally, socially, and culturally relevant. Kretchmar (2001) suggested that alternative models of PE curriculum should strive to promote personal and shared meaning through the inclusion of meaningful content. Likewise, McCaughtry (2009) used the concept of “cool" PE to describe programs in which students "learn new, exciting things, in creative, problemsolving ways, while having fun and socializing with their peers and while feeling safe physically and emotionally, as well as cared for by the teacher" (p.191). Participants in this study generally referred to archery, mountain biking, and slack-lining as "cool" and their voices suggest that those activities made them think it is worth it to be physically active and engage in PE. In the words of a student:

Like mountain biking, like that can help you in like your leg muscles and that can help you if you want to do tournaments on mountain biking. And slack-lining helps you with your balance and archery can help you if you ever want to go hunting. $6^{\text {th }}{ }_{-} M P A$

It was clear from the data that both LPA and MPA students valued this alternative approach to PE and perceived the culturally relevant content as more attractive than team sports and exercise routines. Hence, it is possible that the positive experiences associated with archery, mountain biking, and slacklining may increase the likelihood of students' engagement in the other units included in the PE curriculum.

\section{Enabling Factors}

In the YPAP model, enabling factors are variables that potentially allow children and adolescents to be active and comprise both biological and environmental correlates of physical activity (Welk, 1999). It has been suggested that favorable biological variables such as motor skill competence and enhanced 
levels of physical fitness can foster active lifestyles among children and adolescents (Hands, Larkin, Parker, Straker, \&Perry, 2009; Kristensen et al., 2006; Raudsepp \& Päll, 2006; Reed, Metzker, \& Phillips, 2004). Likewise, access to various forms of physical activity and adequate environmental conditions have been associated with higher levels of physical activity engagement (Haerens et al., 2009; Millstein et al., 2011). Findings from this study indicated that skill acquisition, access, and the environment were factors that allowed students to engage and benefit from the mountain biking, archery, and slacklining lessons. Participants in both the LPA and MPA groups clearly valued skill development throughout each unit and emphasized that learning new skills led them to successful participation in the newly implemented activities. Moreover, skill acquisition contributed to students' renewed perspectives on PE, which was revealed by their surprising comments about learning movement techniques during the lessons. A common criticism of traditional PE curriculum models is the lack of opportunities for skill development and emphasis in full-sided game play, which have been shown to hinder students' participation, particularly for those who are less skillful (Bernstein, Phillips, \& Silverman, 2011; Garn et al., 2011). According to AAHPERD (2013), physically literate individuals have developed the necessary skills to engage in various forms of physical activity. Hence, quality PE programs should aim to foster motor competence pertinent to a variety of sports and physical activities, thus expanding youth's range of movement possibilities and increasing likelihood of physical activity engagement.

Access was another enabling factor often mentioned by the students. Children who haven't had previous access to archery, mountain biking, or slacklining were excited with the opportunity to engage. Students also recognized that if the school had not provided them with a chance to take part in these experiences, many of them would not have had such opportunities outside of the school setting. Granting students access to mountain biking, archery, and slacklining enabled them to participate in activities that they were unfamiliar with and even elicited apprehension. It can be inferred then, that access preceded skill development, which in turn was a condition for successful engagement, confirming that these two enabling factors played a key role in both LPA and MPA students' positive perceptions of the new PE units. Therefore, establishing school-based programs that create access to a variety of physical activities 
and allow for skill development has the potential to attract youth into physically active lifestyles, especially in rural or low socio-economic areas, where limited access has been commonly identified as a barrier to physical activity (Giles-Corti \& Donovan, 2002).

In addition to motor skills and access, the outdoor environment increased motivation and enjoyment, despite the challenges students faced when riding their bikes on the trail. Recent studies have indicated that access to outdoor recreational facilities is associated with increased physical activity in youth (Chomitz, Aske, McDonald, Howard, Hacker, 2011). Likewise, proponents of alternative PE models have emphasized the idea of allowing students to learn motor skills in authentic settings (McCaughtry, 2009). Outdoor activities in PE have the potential to make programs more attractive and promote benefits to students' mental and physical health (Tomik \& Mynarski, 2009). Appropriate equipment and safety also facilitated engagement in the new units. There is agreement in the literature that one of the critical impediments for quality PE is the inadequacy of environmental conditions such as equipment shortage, large class sizes, and poor facilities (Bulger \& Housner, 2009). Findings from this study showed that despite minor complaints about bike sizes and uncomfortable saddles, students demonstrated appreciation for the equipment introduced in PE and referred to them as enablers of participation and learning. In addition, students were concerned with safety and more prone to engage when a safe environment was established by the teachers. These findings reinforce the argument that building environments conductive to learning (e.g., appropriate and innovative equipment, adequate facilities, and outdoor and authentic experiences) can remove some of the barriers faced by physical educators to implement quality programs (Prusak et al., 2014).

\section{Reinforcing Factors}

Reinforcing factors refer to the influences of social relationships on youth physical activity behavior (Welk, 1999). It became evident from the data that the teachers, peers, family, and the slacklining professionals influenced students' perceptions of and responses to the new units. It has been suggested that teachers might be the primary influence on levels of motivation during PE classes (Patterson \& Collins, 2012). Students reported that their teachers made them feel safe and taught 
effective lessons that helped them to learn new skills. It is important to note that the establishment of the new units in the curriculum happened as a result of on-going professional development for teachers designed to assist them with activity-specific content learning, units design, lessons delivery, and student assessment. Another reinforcing factor on physical activity consistently mentioned by the students was the opportunity to socialize with their peers. Children mentioned enjoying the activities because they could talk to, "hang-out" with, cheer on, compete against, and show off to their friends. Previous research has provided evidence that peers and friends can be a powerful influence on youth physical activity behavior (Fitzgerald, Fitzgerald, \& Aherne, 2012; Maturo \& Cunningham, 2013). Hence, findings from this study support the view that physical activity programming ought to consider the role that friends and peers play in active behaviors. In the same way, the influence of family on physical activity behavior has also been widely documented (Cheung \& Chow, 2010; Davison, 2004). Although family didn’t play a direct role on students' engagement in the culturally relevant units, it appeared that they were eager to take part in archery and mountain biking lessons because these activities connected them with their family outside of the school environment. Students frequently commented that they enjoyed learning archery and mountain biking because they would be able to ride their bikes and shoot bows with siblings, cousins, or parents. This indicated that the social meaning pertaining to these activities fostered a positive attitude towards the new PE curriculum. Finally, the slack-lining professionals who visited the school to introduce the unit influenced students' reactions to this activity. According to the students, the professionals helped them to learn and inspired them to engage as they shared their experiences and expertise. This suggests that bringing expert guests to introduce sports and other forms of physical activities in the school setting might enhance youth motivation to be active.

\section{Demographics}

Demographics are placed at the base of the YPAP model suggesting that gender, age, socioeconomic status, ethnicity, and culture influence how children and adolescents respond to the enabling, predisposing, and reinforcing factors of physical activity (Welk, 1999). Participants in this study were 30 girls $(63.8 \%)$ and 17 boys (36.2\%), but focus groups were not gender specific. However, given the higher 
number of girls in each group, it can be suggested that findings largely represent the voices of female students. Evidence shows that girls tend to be less active than boys (Belcher et al., 2010; Biddle et al., 2011) and findings from this study present valuable insight about strategies to promote physical activity among middle school girls. It could be heard from participant girls' remarks that they truly valued opportunities to be successful in PE and show to the boys that they are competent movers. Traditional approaches to PE often favor highly skilled, male students, who have expertise in team sports (Bernstein et al., 2011; Garn et al., 2011; Ennis, 1999). Hence, the inclusion of individual sports and lifetime activities in the PE curriculum might be a possible avenue to attract girls into active lifestyles by fostering skill development and successful performance in a wide variety of sports and physical activities.

Participants in this study ranged in age from 11-15 years old, a developmental stage in which levels of physical activity tend to decline (Belcher et al., 2010). Unfortunately, middle school PE has been reported as being of mediocre quality (e.g., not enough allocated time, lack of adequate equipment and facilities, large class sizes, content focused on team sports) and not helpful to captivate early adolescents into active lifestyles (McKenzie, 2001; Bulger \& Housner, 2009). Early adolescence is characterized by significant physical, cognitive, and affective changes. Middle school students come to the gymnasium with emerging new social interests, new intellectual abilities and an unfamiliar body that are all in constant transformation (Pagnano, 2006). Therefore, it is imperative that PE programs account for the variables associated with middle-school aged children and adopt developmentally appropriate pedagogies. Findings from this study suggest that some programmatic features were able to meet the specific tenants of middle school-aged students: (a) individual activities, in which performance is assessed against self, (b) ample opportunities for skill development (c) differentiated tasks designed to meet a wide range of skill ability, (d) opportunities for socialization (e) innovative, "cool", and challenging content, and (f) outdoor activities.

In addition to gender and age, students' socio-economic status appeared to have influenced their perceptions and responses to the new units. This study was conducted in a rural, predominately low socio-economic area. Participant students frequently used the word opportunity to depict the new units 
implemented in the curriculum. It was evident from their voices that they were thrilled to have access to new forms of activities, in which quality equipment and adequate instruction was provided. Several students mentioned having broken or inadequate equipment at home, which made them appreciate the investments made by the school in the PE program.

In regard to cultural relevance, archery was the activity that resonated the most with both LPA and MPA students' cultural background. Participants' reactions to archery were positive regardless of their expertise in the sport because of its relevance to a valued practice in their community and culture: hunting. This association between archery and hunting made the activity appealing to the students and fostered their willingness to learn and engage. This is an important finding and indicates that the design of PE programs must take in consideration the cultural values and beliefs of students and their communities in order to maximize involvement. Kretchmar (2000) proposed that "the cultural connotations of movement remind individuals who they are (a family, a tribe, a nation), who they belong to (their parents, the values and truths of their time), and where they came from (their particular traditions and history)" (p.5). Accordingly, Ennis (1999) argued that culturally relevant educational practices open opportunities for identity development as individual and social meanings are considered and embedded in the curriculum. Overall students had a favorable response to mountain biking and slack-lining, which are also activities relevant to their culture and environment. However, their reactions to archery showed that this activity largely contributed to their renewed perspectives about the purpose and meaning of schoolbased PE, given its relevance to the rural Appalachian community in which this study was conducted.

\section{Conclusion}

Findings from the study underlined the importance of including innovative, culturally relevant content in middle school PE. Participant LPA and MPA students demonstrated similar perceptions and responses to the inclusion of archery, mountain biking, and slacklining in the curriculum. Students indicated valuing: (a) opportunities for skill development, (b) successful experiences (c) peer interactions, (d) outdoor environment, (e) competition, (f) adequate equipment, (g) positive role models (h) new, challenging, and fun movement and experiences, and (i) activities that connect them with their family, 
culture, and environment. These findings support that alternative PE curriculum models have the potential to attract middle school-aged children into active lifestyles, particularly females and those who are LPA. In regards to LPA students, findings emphasized that skill development and successful experiences in PE can lead to increased perceptions of athletic competence and, consequently enjoyment of physical activity. This study also indicated that the culturally relevant units positively influenced students' thoughts about PE. Students' remarks showed that a sense of meaning related to PE was developed as a result of their engagement in archery, mountain biking, and slacklining. Finally, findings revealed the enabling, predisposing, reinforcing, and demographic factors outlined by the YPAP model influenced students' renewed perspective about PE. It could be noticed that predisposing factors were influenced by both enabling and reinforcing factors of physical activity as well as by the specific demographics of the population under study. Skill development, access, and a favorable learning environment which are enabling factors, positively influenced students' perceptions of competence and consequent enjoyment of the units. Similarly, teachers, peers, and family, which are reinforcing factors appeared to influence students' perceived value of engagement in the culturally relevant content. Thus, it is recommended that school-based physical activity initiatives consider the elements that influence active behaviors in youth and design programs accordingly.

\section{Limitations}

A limitation of this study is the extent to which the instruments employed in Phase One provided an accurate classification of LPA and MPA students. The results of Phase One indicated that students reported high levels of attraction to physical activity and perceptions of athletic competence. Because the questionnaires were administered during PE, it is possible that students provided socially desirable answers indicating to be more predisposed to active lifestyles. Another limitation of the study is the extent to which students provided socially desirable answers during the focus groups, indicating high levels of enjoyment of the new units. This study was also limited to students' perceptions of and responses to archery, mountain biking, and slacklining in the curriculum. Other culturally relevant units have been included in the PE curriculum (e.g., disc golf, rock climbing) but when data was collected, the 
students had not been exposed to them yet. In addition, the study was limited to the perceptions and responses of students in only one of the schools in which the CHOICES project was implemented.

\section{Future Directions}

Future studies on children and adolescents' perceptions of and responses to school-based physical activity initiatives are encouraged. Research may investigate students' engagement in alternative PE curriculum models longitudinally and identify changes in their perceptions and responses over time. Also, research examining students' reactions to culturally relevant units in the PE programs of urban schools should be considered. Finally, studies are encouraged to control for gender when examining students' engagement in innovative approaches to PE in order to identify potential strategies to motivate females to adopt physically active lifestyles. 


\section{References}

American Alliance for Health, PE, Recreation and Dance. (2013). Comprehensive school physical activity programs: Helping students achieve 60 minutes of physical activity each day [Position statement]. Reston, VA: Author. Retrieved from http://www.aahperd.org/naspe/standards/upload/CSPAP-Final7-22-13-2.pdf

Baker, B. L., \& Davison, K. K. (2011). I know I can: A longitudinal examination of precursors and outcomes of perceived athletic competence among adolescent girls. Journal of Physical Activity \& Health, 8(2), 192-199.

Bélanger, M., Gray-Donald, K., O’Loughlin, J., Paradis, G., \& Hanley, J. (2009). When adolescents drop the ball: Sustainability of physical activity in youth. American Journal of Preventive Medicine, 37(1), 41-49. doi:10.1016/j.amepre.2009.04.002

Belcher, B., Berrigan, D., Dodd, K., Emken, B., Chih-Ping Chou, \& Spruijt-Metz, D. (2010). Physical activity in us youth: Effect of race/ethnicity, age, gender, and weight status. Medicine \& Science in Sports \& Exercise, 42(12), 2211-2221. doi:10.1249/MSS.0b013e3181e1fba9

Bernstein, E., Phillips, S. R., \& Silverman, S. (2011). Attitudes and perceptions of middle school students toward competitive activities in physical education. Journal of Teaching in Physical Education, 30(1), 69-83.

Biddle, S. J. H., Atkin, A. J., Cavill, N., \& Foster, C. (2011). Correlates of physical activity in youth: A review of quantitative systematic reviews. International Review of Sport \& Exercise Psychology, $4(1), 25-49$.

Biddle, S. J. H., Whitehead, S. H., O’Donovan, T. M., \& Nevill, M. E. (2005). Correlates of participation in physical activity for adolescent girls: A systematic review of recent literature. Journal of Physical Activity \& Health, 2(4), 423-436.

Brown, H., Hume, C., Pearson, N., \& Salmon, J. (2013). A systematic review of intervention effects on potential mediators of children's physical activity. BMC Public Health, 13(165), 1-10. doi:10.1186/1471-2458-13-165 
Brustad, R. (1993). Who will go out and play? Parental and psychological influences on children's attraction to physical activity. Pediatric Exercise Science, 5(3), 210-223.

Brustad, R. J. (1996). Attraction to physical activity in urban schoolchildren: Parental socialization and gender influences. Research Quarterly for Exercise and Sport, 67(3), 316-323. doi:10.1080/02701367.1996.10607959

Buckley, C., \& Waring, M. (2009). The evolving nature of grounded theory: Experiential reflections on the potential of the method for analyzing children's attitudes towards physical activity. International Journal of Social Research Methodology: Theory \& Practice, 12(4), 317-334. doi:10.1080/13645570802221198

Bulger, S. M., \& Housner, L. D. (2009). Relocating from easy street: Strategies for moving physical education forward. Quest (00336297), 61(4), 442-469.

Carroll, B., \& Loumidis, J. (2001). Children's perceived competence and enjoyment in physical education and physical activity outside school. European Physical Education Review, 7(1), 24-43. doi:10.1177/1356336X010071005

Centers for Disease Control and Prevention. (2011). School Health Guidelines to Promote Healthy Eating and Physical Activity - United States 2010. MMWR 2011; 60 (5).

Cheung, P. Y. P., \& Chow, B. C. (2010). Parental mediatory role in children's physical activity participation. Health Education, 110(5), 351-366.

Chomitz, V. R., Aske, D. B., McDonald, J., Cabral, H., \& Hacker, K. A. (2011). The Role of Recreational Spaces in Meeting Physical Activity Recommendations Among Middle School Students. Journal of Physical Activity \& Health, 8, S8-S16.

Cliff, D. P., Okely, A. D., Morgan, P. J., Jones, R. A., \& Steele, J. R. (2010). The impact of child and adolescent obesity treatment interventions on physical activity: A systematic review. Obesity Reviews, 11(7), 516-530.

Cox, A., Smith, A., \& Williams, L. (2008). Change in physical education motivation and physical activity behavior during middle school. Journal of Adolescent Health, 43(5), 506-513. 
Creswell, J. W. (2009). Research design: Qualitative, quantitative, and mixed methods approaches. Thousand Oaks, CA: Sage Publications.

Darbyshire, P., MacDougall, C., \& Schiller, W. (2005). Multiple methods in qualitative research with children: More insight or just more? Qualitative Research, 5(4), 417-436. doi:10.1177/1468794105056921

Davison, K. K. (2004). Activity-related support from parents, peers and siblings and adolescents' physical activity: Are there gender differences? Journal of Physical Activity \& Health, 1(4), 363.

Demetriou, Y., \& Höner, O. (2012). Physical activity interventions in the school setting: A systematic review. Psychology of Sport and Exercise, 13(2), 186-196. doi:10.1016/j.psychsport.2011.11.006

Ennis, C. D. (1999). Creating a culturally relevant curriculum for disengaged girls. Sport, Education \& Society, 4(1), 31-48.

Fitzgerald, A., Fitzgerald, N., \& Aherne, C. (2012). Do peers matter? A review of peer and/or friends' influence on physical activity among american adolescents. Journal of Adolescence, 35(4), 941-958.

Gabel, C. P., Osborne, J., \& Burkett, B. (n.d.). The influence of “Slacklining” on quadriceps rehabilitation, activation and intensity. Journal of Science and Medicine in Sport. doi:10.1016/j.jsams.2013.11.007

Garn, A. C., Cothran, D. J., \& Jenkins, J. M. (2011). A qualitative analysis of individual interest in middle school PE: Perspectives of early-adolescents. PE \& Sport Pedagogy, 16(3), 223-236.

Gay, L. R., Mills, G. E., \& Airasian, P. (2009). Educational research: Competencies for analysis and applications. Upper Saddle River, NJ: Pearson Education.

Giles-Corti, B., \& Donovan, R. J. (2002). Socioeconomic status differences in recreational physical activity levels and real and perceived access to a supportive physical environment. Preventive Medicine, 35(6), 601-611. doi:10.1006/pmed.2002.1115

Glaser, B.G., \& Strauss, A.L. (1967). The Discovery of Grounded Theory: Strategies for Qualitative Research. New York: Aldine. 
Haerens, L., Craeynest, M., Deforche, B., Maes, L., Cardon, G., \& De Bourdeaudhuij, I. (2009). The contribution of home, neighborhood and school environmental factors in explaining physical activity among adolescents. Journal of Environmental and Public Health, 2009. doi:

$10.1155 / 2009 / 320372$

Hallal, P. C., Victora, C. G., Azevedo, M. R., \& Wells, J. C. K. (2006). Adolescent physical activity and health: A systematic review. Sports Medicine, 36(12), 1019-1030. doi:10.2165/00007256200636120-00003

Hands, B., Larkin, D., Parker, H., Straker, L., \& Perry, M. (2009). The relationship among physical activity, motor competence and health-related fitness in 14-year-old adolescents. Scandinavian Journal of Medicine \& Science in Sports, 19(5), 655-663.

Harter, S. (1982). The perceived competence scale for children. Child Development, 53(1), 87-97. doi:10.2307/1129640

Harter, S. (2012) Self-Perception Profile for Children: Manual and questionnaires (grades 3-8) [Revision of the Self- profile for Children, 1985]. University of Denver, Retrieved from http://portfolio.du.edu/SusanHarter/page/44210

Haywood, K., \& Lewis, C. (2006). Archery: Steps to success. Champaign, IL: Human Kinetics

Janssen, I., \& LeBlanc, A. G. (2010). Systematic review of the health benefits of physical activity and fitness in school-aged children and youth. International Journal of Behavioral Nutrition \& Physical Activity, 7, 40-55.

Kahn, J., Huang, B., Gillman, M., Field, A., Austin, S., Colditz, G., \& Frazier, A. (2008). Patterns and determinants of physical activity in U.S. adolescents. Journal of Adolescent Health, 42(4), 369-377.

Kretchmar, R. s. (2000). Movement subcultures: Sites for meaning. JOPERD: The Journal of PE, Recreation \& Dance, 71(5), 19-25.

Kristensen, P. L., Moeller, N. C., Korsholm, L., Kolle, E., Wedderkopp, N., Froberg, K., \& Andersen, L. B. (2010). The association between aerobic fitness and physical activity in children and adolescents: The European youth heart study. European Journal of Applied Physiology, 110(2), 267-275. 
Krueger, R. A., \& Casey, A. M., (2009). Focus groups: A practical guide for applied research. Thousand Oaks, CA: Sage Publications.

MacPhail, A. (2011) Youth voices in PE and sport: What are they telling us?. In Armour, K. (Ed.) Sport pedagogy: An introduction for teaching and coaching (pp.105-116). New York, NY: Routledge.

Marshall, C., \& Rossman, G. B. (2006). Designing qualitative research. Thousand Oaks, CA: Sage Publications.

Maturo, C. C., \& Cunningham, S. A. (2013). Influence of friends on children's physical activity: a review. American Journal of Public Health, 103(7), e23-e38.

McCaughtry, N. (2009). The child and the curriculum: Implications of Deweyan Philosophy in the pursuit of “cool” PE for children. In L. Housner, M. Metzler, P. Schempp, \& T. Templin (Eds.), Historic traditions and future directions of research on teaching and teacher education. Morgantown, WV: Fitness Information Technology.

McCracken, B. (2001) It's not just gym anymore: Teaching secondary school students to be active for life. Champaign: IL: Human Kinetics.

McKenzie, T. L. (2001). Promoting physical activity in youth: Focus on middle school environments. Quest, 53(3), 326-334.

McLeroy, K., Bibeau, D., Steckler, A., \& Glanz, K. (1988). An ecological perspective on health promotion programs. Health Education Quarterly, 15(4), 351-377.

Miles, M., B., \& Huberman, A., M. (1994). Qualitative data analysis. Thousand Oaks, CA: Sage Publications.

Millstein, R. A., Strobel, J., Kerr, J., Sallis, J. F., Norman, G. J., Durant, N., ... Saelens, B. E. (2011). Home, school, and neighborhood environment factors and youth physical activity. Pediatric Exercise Science, 23(4), 487-503.

Mohr, D. J., Townsend, J. S., \& Pritchard, T. (2006). Rethinking middle school PE: Combining lifetime leisure activities and sport education to encourage physical activity. Physical Educator, 63(1), 1829. 
Muris, P., Meesters, C., \& Fijen, P. (2003). The Self-Perception Profile for Children: Further evidence for its factor structure, reliability, and validity. Personality and Individual Differences, 35(8), 17911802. doi:10.1016/S0191-8869(03)00004-7

National Association for Sport and PE. (2008). Comprehensive school physical activity programs [Position statement]. Reston, VA: National Association for Sport and PE. Retrieved from http://www.aahperd.org/naspe/

National Association for Sport and PE \& American Heart Association. (2012). 2012 Shape of the Nation Report: Status of PE in the USA. Reston, VA: American Alliance for Health, PE, Recreation and Dance. Retrieved from http://www.aahperd.org/naspe/publications/shapeofthenation.cfm

Naylor, P. J., \& McKay, H. A. (2008). Prevention in the first place: Schools a setting for action on physical inactivity. British Journal of Sports Medicine, 43(1), 10-13. doi:10.1136/bjsm.2008.053447

Ogden, C. L., Carroll, M. D., Curtin, L. R., Lamb, M. M., \& Flegal, K. M. (2010). Prevalence of high body mass index in US children and adolescents, 2007-2008. JAMA: The journal of the American Medical Association, 303(3), 242-249.

Pagnano, K. B. (2006). Finding meaning in middle school PE. Teaching Elementary PE, July 2006, $12-$ 14.

Patterson, D. L., \& Collins, J. (2012). Middle school girls' perceptions of their physical education classes and teachers. Medicina Sportiva, 16(1), 12-16.

Patton, M. (2002). Qualitative evaluation and research methods. Thousand Oaks, CA: Sage Publications.

Paxton, R. J., Estabrooks, P. A., \& Dzewaltowski, D. (2004). Attraction to physical activity mediates the relationship between perceived competence and physical activity in youth. Research Quarterly for Exercise and Sport, 75(1), 107-111. doi:10.1080/02701367.2004.10609139

Perry, C. K., Garside, H., Morones, S., \& Hayman, L. L. (2012). Physical activity interventions for adolescents: An ecological perspective. Journal of Primary Prevention, 33(2-3), 111-135. 
Peterson-Sweeney, K. (2005). The use of focus groups in pediatric and adolescent research. Journal of Pediatric Health Care, 19(2), 104-110. doi:10.1016/j.pedhc.2004.08.006

Prusak, K. A., Davis, T., Pennington, T. R., \& Wilkinson, C. (2014). Children's perceptions of a districtwide physical education program. Journal of Teaching in Physical Education, 33(1), 4-27. doi:10.1123/jtpe.2013-0004

Raudsepp, L., \& Päll, P. (2006). The relationship between fundamental motor skills and outside-school physical activity of elementary school children. Pediatric Exercise Science, 18(4), 426-435.

Reed, J. A., Metzker, A., \& Phillips, D. A. (2004). Relationships between physical activity and motor skills in middle school children. Perceptual \& Motor Skills, 99(2), 483-494.

Ridgers, N. D., Fazey, D. M. A., \& Fairclough, S. J. (2007). Perceptions of athletic competence and fear of negative evaluation during physical education. British Journal of Educational Psychology, 77(2), 339-349. doi:10.1348/0265006X28909

Rowe, D. A., Raedeke, T. D., Wiersma, L. D., \& Mahar, M. T. (2007). Investigating the Youth Physical Activity Promotion Model: Internal structure and external validity evidence for a potential measurement model. Pediatric Exercise Science, 19(4), 420-435.

Rowland, T. W. (2007). Promoting physical activity for children's health. Sports Medicine, 37(11), 929936.

Sallis, J. F., McKenzie, T. L., Beets, M. W., Beighle, A., Erwin, H., \& Lee, S. (2012). PE's role in public health: Steps forward and backward over 20 years and HOPE for the future. Research Quarterly for Exercise and Sport, 83(2), 125-135.

Sallis, J. F., \& Owen, N. (2002). Ecological models of health behavior. In K. Glanz, B. K. Rimer, \& F.M. Lewis (Eds.), Health behavior and health education: Theory, research, and practice (pp. 462-484). San Francisco, CA: Jossey-Bass.

Sallis, J., Prochaska, J., \& Taylor, W. (2000). A review of correlates of physical activity of children and adolescents. Medicine \& Science in Sports \& Exercise, 32(5), 963-975. 
Seabra, A. C., Maia, J., Seabra, A. F., Welk, G., Brustad, R., \& Fonseca, A. M. (2013). Evaluating the youth physical activity promotion model among Portuguese elementary schoolchildren. Journal of Physical Activity \& Health, 10(8), 1159-1165.

Slingerland, M., \& Borghouts, L. (2011). Direct and indirect influence of physical education-based interventions on physical activity: A review. Journal of Physical Activity \& Health, 8(6), 866-878.

Song, M., Carroll, D. D., \& Fulton, J. E. (2013). Meeting the 2008 physical activity guidelines for Americans among U.S. youth. American Journal of Preventive Medicine, 44(3), 216-222. doi:10.1016/j.amepre.2012.11.016

Spence, J. C., \& Lee, R. E. (2003). Toward a comprehensive model of physical activity. Psychology of Sport and Exercise, 4(1), 7-24. doi:10.1016/S1469-0292(02)00014-6

Strong, W. B., Malina, R. M., Blimkie, C. J. R., Daniels, S. R., Dishman, R. K., Gutin, B., ... Trudeau, F. (2005). Evidence based physical activity for school-age youth. The Journal of Pediatrics, 146(6), 732-737. doi:10.1016/j.jpeds.2005.01.055

Teddie, C., \& Tashakkori, A. (2009). Foundations of mixed methods research: Integrating quantitative and qualitative approaches in the social and behavioral sciences. Thousand Oaks, CA: Sage Publications.

Tomik, R., \& Mynarski, W. (2009). School tourism and physical education in natural settings based on the principles and practices of outdoor education. Studies in Physical Culture \& Tourism, 16(4), $421-430$.

Trombley, A. (2005). Serious mountain biking. Champaign, IL: Human Kinetics

Trost, S. G. (2004). School PE in the post-report era: an analysis from public health. Journal of Teaching in PE, 23(4), 318-337.

Trost, S. G., \& Loprinzi, P. D. (2008). Exercise: Promoting healthy lifestyles in children and adolescents. Journal of Clinical Lipidology, 2(3), 162-168. doi:10.1016/j.jacl.2008.03.001

U.S. Department of Health and Human Services. (2008). 2008 Physical activity guidelines for Americans. Retrieved from http://www.health.gov/paguidelines/pdf/paguide.pdf 
Ward, D.S., Saunders, R.P., \& Pate, R.R. (2007). Physical activity interventions in children and adolescents. Champaing, IL: Human Kinetics.

Welk, G.J. (1999). The youth physical activity promotion model: A conceptual bridge between theory and practice. Quest, 51(1), 5-23.

Welk, G. J., \& Schaben, J. A. (2004). Psychosocial correlates of physical activity in children: A study of relationships when children have similar opportunities to be active. Measurement in PE and Exercise Science, 8(2), 63-81. 


\section{Tables}

Table 1. Phase One Participants

\begin{tabular}{cccccc}
\hline Grade & Boys & Girls & Total & Percentage & Age \\
\hline $6^{\text {th }}$ & 22 & 26 & 48 & 41.4 & $11-12$ \\
$7^{\text {th }}$ & 12 & 15 & 27 & 23.3 & $12-13$ \\
$8^{\text {th }}$ & 19 & 22 & 41 & 35.3 & $13-15$ \\
All & 53 & 63 & 116 & 100 & $11-15$ \\
\hline
\end{tabular}

Table 2. Phase Two Participants

\begin{tabular}{ccccccc}
\hline Grade & \multicolumn{2}{c}{ LPA } & \multicolumn{2}{c}{ MPA } & \multicolumn{2}{c}{ Total } \\
\hline & Boys & Girls & Boys & Girls & Boys & Girls \\
\cline { 2 - 7 } $6^{\text {th }}$ & 3 & 4 & 4 & 8 & 7 & 12 \\
$7^{\text {th }}$ & 3 & 3 & 2 & 5 & 5 & 8 \\
$8^{\text {th }}$ & 4 & 4 & 1 & 6 & 5 & 10 \\
All & 10 & 11 & 7 & 19 & 17 & 30 \\
\hline
\end{tabular}

Table 3. Phase One Instruments Reliability Statistics: Cronbach's Alpha

\begin{tabular}{cccc}
\hline Grade & $\begin{array}{c}\text { Athletic competence of } \\
\text { the SPPC scale }\end{array}$ & CAPA scale & $\begin{array}{c}\text { Combined } \\
\text { questionnaire }\end{array}$ \\
\hline $6^{\text {th }}$ & .68 & .89 & .91 \\
$7^{\text {th }}$ & .72 & .91 & .92 \\
$8^{\text {th }}$ & .52 & .90 & .90 \\
All & .65 & .90 & .91 \\
\hline
\end{tabular}

Table 4. Phase One mean scores (M) and standard deviations (SD)

\begin{tabular}{ccccccc}
\hline Grade & \multicolumn{2}{c}{$\begin{array}{c}\text { Athletic competence of } \\
\text { the SPPC scale }\end{array}$} & \multicolumn{2}{c}{ CAPA scale } & \multicolumn{2}{c}{ Both scales combined } \\
\hline & $M$ & $S D$ & $M$ & $S D$ & $M$ & $S D$ \\
\cline { 2 - 6 } $6^{\text {th }}$ & 2.74 & .65 & 2.84 & .65 & 2.81 & .61 \\
$7^{\text {th }}$ & 3.06 & .67 & 3.18 & .65 & 3.15 & .61 \\
$8^{\text {th }}$ & 2.95 & .54 & 3.10 & .63 & 3.06 & .57 \\
All & 2.89 & .63 & 3.02 & .65 & 2.98 & .60 \\
\hline
\end{tabular}


Table 5. Phase One Tertiles for both scales combined

\begin{tabular}{ccccccc}
\hline Grade & \multicolumn{3}{c}{ Lower 33\% } & \multicolumn{3}{c}{ Upper 33\% } \\
\hline & Range & $M$ & $S D$ & Range & $M$ & $S D$ \\
\cline { 2 - 7 } $6^{\text {th }}$ & $1.38-2.39$ & 2.12 & .28 & $3.24-3.86$ & 3.53 & .16 \\
$7^{\text {th }}$ & $2.00-2.81$ & 2.40 & .28 & $3.57-4.00$ & 3.78 & .16 \\
$8^{\text {th }}$ & $1.62-2.81$ & 2.43 & .39 & $3.38-3.81$ & 3.62 & .13 \\
All & $1.38-2.67$ & 2.27 & .32 & $3.38-4.00$ & 3.62 & .17 \\
\hline
\end{tabular}

Table 6. Frequencies of LPA and MPA students' comments related to each theme and subtheme

\begin{tabular}{|c|c|c|c|c|c|c|}
\hline \multirow[t]{2}{*}{ Themes \& Subthemes } & \multicolumn{2}{|c|}{ LPA } & \multicolumn{2}{|c|}{ MPA } & \multicolumn{2}{|c|}{ Both groups } \\
\hline & Number & Percentage & Number & Percentage & Number & Percentage \\
\hline I. Expectations & 77 & 15.1 & 66 & 18.6 & 143 & 16.6 \\
\hline - Apprehension & 28 & 5.5 & 28 & 7.9 & 56 & 6.5 \\
\hline - Excitement & 49 & 9.6 & 38 & 10.7 & 87 & 10.1 \\
\hline II. Engagement & 262 & 51.4 & 154 & 43.5 & 416 & 48.1 \\
\hline environment & 129 & 25.3 & 85 & 24 & 214 & 24.7 \\
\hline Outcomes & 133 & 26.1 & 69 & 19.5 & 202 & 23.4 \\
\hline III. Responses & 171 & 33.5 & 134 & 37.9 & 305 & 35.3 \\
\hline - Relevance & 47 & 9.2 & 39 & 11 & 86 & 10 \\
\hline - New perspective & 99 & 19.4 & 82 & 23.2 & 181 & 21 \\
\hline $\begin{array}{l}\text { More } \\
\text { opportunities }\end{array}$ & 25 & 4.9 & 13 & 3.7 & 38 & 4.4 \\
\hline Total & 510 & 100 & 354 & 100 & 864 & 100 \\
\hline
\end{tabular}


Table 7. Summary of Themes and Subthemes from LPA Groups

\begin{tabular}{|c|c|c|}
\hline Themes & Subthemes & Sample data \\
\hline \multirow[t]{4}{*}{ I. Expectations } & \multirow[t]{2}{*}{ Apprehension } & $\begin{array}{l}\text { When I just heard mountain biking I was, I had really mixed feelings on it because I had not rode a bike in a long time and I was really kind of } \\
\text { concerned what if something had happened like somebody wrecked into another or somebody had gotten hurt and I was figuring well I'm going to of } \\
\text { course wreck this bike. I just knew it. } 7^{\text {th }} \text { LPA }\end{array}$ \\
\hline & & $\begin{array}{l}\text { I have never shot a bow before and I know some other students have never done it either so I was kind of going like well I don't know if this is a pretty } \\
\text { good idea, cause I just felt like it might've been unsafe if some students kind of got cocky with it or decided it could be used on another student really. } \\
7^{\text {th }} \text { _LPA }\end{array}$ \\
\hline & \multirow[t]{2}{*}{ Excitement } & Because I was excited that I'd be able to do something and be confident about it. $7^{\text {th }}-L P A$ \\
\hline & & $\begin{array}{l}\text {... whenever I heard it I thought it was going to be awesome because you know we get to ride a bike at school. It's not that often that we get to like, } \\
\text { that'd be like driving in high school. } 6^{\text {th }} \text { LPA }\end{array}$ \\
\hline \multirow[t]{6}{*}{ II. Engagement } & \multirow[t]{4}{*}{$\begin{array}{l}\text { Learning } \\
\text { Environment }\end{array}$} & $\begin{array}{l}\text { I basically agree with the others. It's fun watching them and like competing with them and seeing who can do the best or see if you can actually learn } \\
\text { from their mistakes or learn from them. } 7^{\text {th }} L P A\end{array}$ \\
\hline & & $\begin{array}{l}\text { Like I have a bow of my own at my house and I was shooting in a rug with a target sprayed on it. I don't have an actual target but having a legit bow } \\
\text { and a legit target was just awesome. } 6^{\text {th }} L P A\end{array}$ \\
\hline & & $\begin{array}{l}\text { I mean they'll [friends], let me see how to put it, they'll help you, like they'll cheer you on if you don't know how to do it. Like if you can't pull it back } \\
\text { if you're weak they'll cheer you on and then you can do it then. } 7^{\text {th }} L P A\end{array}$ \\
\hline & & $\begin{array}{l}\text { We get stuck in other periods for a long time and then you just get to go outside and feel the breeze and air and the sun on your skin and you just get to } \\
\text { have fun out there, be a little kid again. } 7^{\text {th }} \text { LPA }\end{array}$ \\
\hline & \multirow{2}{*}{$\begin{array}{l}\text { Learning } \\
\text { Outcomes }\end{array}$} & I learned how to aim down the arrow and judge wind and your elevation with your target to hit the bull's eye. $8^{\text {th }}{ }_{-} L P A$ \\
\hline & & $\begin{array}{l}\text { Some people doubt their selves about what they can do on it and then it kind of makes them feel a little bit better when they realize in practice doing it, } \\
\text { which makes them feel proud of their selves. } 6^{\text {th }} \text { LPA }\end{array}$ \\
\hline \multirow[t]{6}{*}{ III. Responses } & \multirow[t]{3}{*}{ Relevance } & It makes me more confident to do it outside of school. $6^{\text {th }} \_L P A$ \\
\hline & & I shoot with my dad. $8^{\text {th }}$ L LPA \\
\hline & & $\begin{array}{l}\text { I thought like the people that don't know how, they just learned how that you could. This might be handy when they grow up. Maybe they want to be a } \\
\text { hunter. } 7^{\text {th }} \text { L LPA }\end{array}$ \\
\hline & \multirow{2}{*}{$\begin{array}{l}\text { New } \\
\text { perspective } \\
\text { about PE }\end{array}$} & $\begin{array}{l}\text { I liked the idea of getting new activities in gym because a lot of basic gym classes we do just like volleyball, basketball and stuff like that and getting } \\
\text { new stuff and keeping people interested in gym class and getting their physical activity is important. } 8^{\text {th }} \text { LPA }\end{array}$ \\
\hline & & $\begin{array}{l}\text { I don't know. It's just like pushing your brain to test your balance skills to test so like you've got to just focus and not mess up and try to get to the } \\
\text { other side of the line. } 8^{\text {th }} \text { _LPA }\end{array}$ \\
\hline & $\begin{array}{l}\text { More } \\
\text { opportunities }\end{array}$ & $\begin{array}{l}\text { It was pretty cool, like they should have it again. Like I said with archery they could have archery at the end of every month they could have mountain } \\
\text { biking at the beginning of every month. } 6^{\text {th }} L P A\end{array}$ \\
\hline
\end{tabular}


Table 8. Summary of Themes and Subthemes from MPA Groups

\begin{tabular}{|c|c|c|}
\hline Themes & Subthemes & Sample data \\
\hline \multirow[t]{4}{*}{ I. Expectations } & Apprehension & $\begin{array}{l}\text { First of all, some of those people in there they kind of scare me. So I was like he's going to trust us with bows and arrows? I was like what's wrong? } \\
\text { I was like we can do this? } 8^{\text {th }} \text { _MPA }\end{array}$ \\
\hline & & At first I was scared. I was like oh my Lord I'll fall off and break my face. $8^{\text {th }} \_M P A$ \\
\hline & Excitement & I thought it was going to be fun because I never really shot a bow, especially at school too, so yeah, fun. $6^{\text {th }}$ _MPA \\
\hline & & I was excited too. I thought it was going to be a great opportunity for us to learn how to do it. $8^{\text {th }}{ }^{M P A}$ \\
\hline \multirow[t]{6}{*}{ II. Engagement } & Learning & Getting to see other people hit the bull's eye so you can challenge yourself to hit it closer to the middle than they are. $6^{\text {th }}$ _MPA \\
\hline & Environment & I dreaded those seats. It was nice though. The bikes was whooo. $8^{\text {th }} \_M P A$ \\
\hline & & Yeah, and if somebody didn't get it like he [teacher] would show you and correct you and he'd like lift your arm if it was like down or slanted. 8 _MPA \\
\hline & & It was fun because we got to go outside and we went around in the grass and then we went into holes and stuff. $6^{\text {th }}$ _MPA \\
\hline & $\begin{array}{l}\text { Learning } \\
\text { Outcomes }\end{array}$ & $\begin{array}{l}\text { Probably just learning how to ride the mountain bike cause I mean I have a regular bike at home but changing the gears I didn't think I would like } \\
\text { that, but I do. } 6^{\text {th }} \text { MPA }\end{array}$ \\
\hline & & $\begin{array}{l}\text { Just to try to, just trying new things but then also to keep your balance and if you can get that it's like a really big success and achievement for that. } \\
\text { It's just fun for me. 8th_MPA }\end{array}$ \\
\hline \multirow[t]{6}{*}{ III. Responses } & Relevance & I like it because you have to learn how to keep your balance and in sports you have to have balance so it makes you a better athlete. $6^{\text {th }}$ MPA \\
\hline & & Usually we have like this [version of] like behind our house and me and my sister usually go out there and ride our bikes. $6^{\text {th }}{ }_{\text {MPA }}$ \\
\hline & & I'm a country person so I don't know I just like doing stuff like that. I think it's just fun to me. $8^{\text {th }}$ _MPA \\
\hline & $\begin{array}{l}\text { New } \\
\text { perspective }\end{array}$ & $\begin{array}{l}\text { Like you would think of PE as something where you would do like, something that you've got to do like constantly, like workout or something. But you } \\
\text { like get to exercise but you get to do it in a fun way. } 6^{\text {th }} \text { _MPA }\end{array}$ \\
\hline & about PE & $\begin{array}{l}\text { Well, normally in PE we don't really do... We just play kickball or have a free day or something like that. On this we actually focus on it and actually } \\
\text { like try to achieve something instead of just going out and doing whatever. } 8^{\text {th }} \text { MPA }\end{array}$ \\
\hline & $\begin{array}{l}\text { More } \\
\text { opportunities }\end{array}$ & $\begin{array}{l}\text { Archery we did it for a few days. Like we should do it at least for a week at a time so we can like actually get into it and do it longer and stuff like that. } \\
8^{\text {th }} \text { _LPA }\end{array}$ \\
\hline
\end{tabular}




\section{Figures}

Figure 1. The Youth Physical Activity Promotion Model (Welk, 1999)

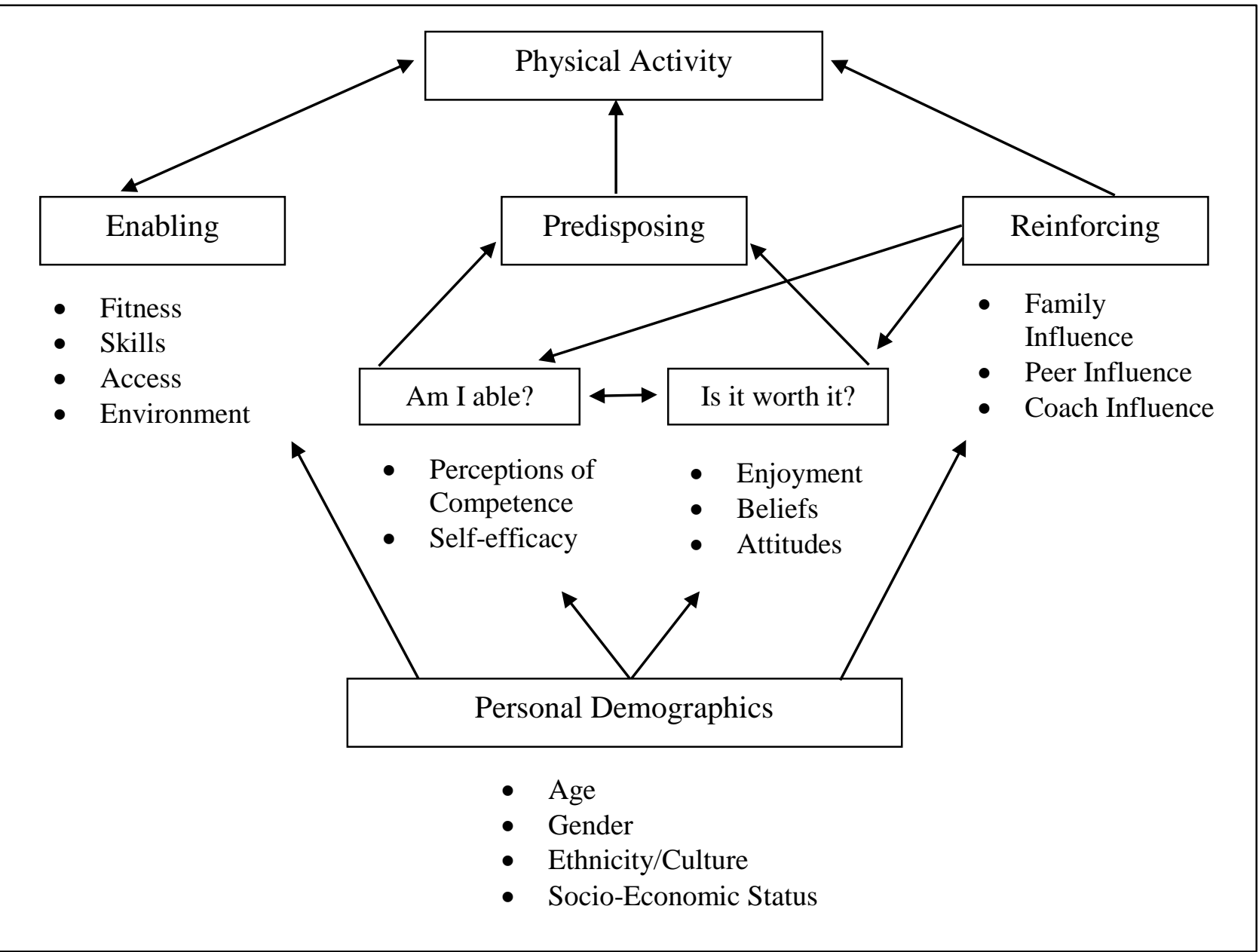

Note. From "The youth physical activity promotion model: A conceptual bridge between theory and practice”, by G. Welk, 1999, Quest, 51(1), p. 12. Copyright 1999 by Taylor \& Francis LLC. Reprinted with permission. 


\section{Appendix A \\ Extended Review of Literature \\ Physical Activity and Adolescent's Health}

\section{Benefits of Physical Activity}

Regular participation in physical activity during childhood and adolescence has been associated with numerous health benefits for youth. A growing body of research indicates that youth engagement in physical activity can result in health benefits in four main areas: (a) preventing the development of risk factors related to heart disease and other chronic diseases, (b) facilitating weight management, (c) improving mental health, and (4) developing a physically active lifestyle that can be carried out through adulthood (Janssen \& Le Blanc, 2010; Rowland, 2007; Strong et al., 2005).

Prevention of risk factors development. The literature exploring the influence of physical activity on the development of risk factors associated with chronic diseases (e.g., high blood pressure, unfavorable lipid levels, adiposity) indicates that active lifestyles during childhood and adolescence might help prevent the development of risk factors over time (Rowland, 2007). Although the debilitating effects of heart disease, osteoporosis, and other chronic health conditions usually appear in adulthood, increasing evidence suggests that their development may begin in childhood and adolescence (Twisk, 2001). As a result, researchers have been investigating the effects of adolescents' physical activity behavior on preventing the development of risk factors associated with heart diseases, osteoporosis, type 2 diabetes, and some types of cancers. Strong et al. (2005) published a systematic review of studies that investigated the effects of physical activity on children's health. The review, promoted by the U.S. Centers for Disease Control and Prevention (CDC) and conducted by a panel of health experts, searched for evidencebased associations between youth physical activity and health outcomes. The expert panel analyzed over 850 studies and concluded that data was strong enough to indicate that physical activity might positively affect adiposity levels, musculoskeletal health, blood pressure, and plasma lipid levels in adolescents (Strong et al., 2005). 
Similarly, Hallal, Victora, Azevedo, \& Wells (2006) conducted a comprehensive review of studies that investigated the benefits of physical activity during adolescence and found consistent results indicating that youth physical activity may reduce the risk of bone fracture and osteoporosis later in life due to exercises that induce gains in bone mass (Hallal et al., 2006). Rowland (2007) also conducted a literature review with the purpose of examining the scientific explanations for the promotion of physical activity among youth. Rowland concluded that regular participation in physical activity might positively affect blood pressure, body fat, and blood lipids in youth. However, according to Rowland the most evident finding regarding the effects of physical activity on risk factors was related to bone health and the prevention of osteoporosis (Rowland, 2007). Similarly, Jansen and LeBlanc (2010) systematically reviewed studies that had searched for the relationship between physical activity and health outcomes in youth. Specifically, the authors examined studies which investigated the association between physical activity and physiological indicators of health such as blood cholesterol, blood pressure, body fat, and bone density. Regarding the effects of physical activity on the development of chronic diseases risk factors, Jansen and LeBlanc reported that even moderate levels of physical activity might generate positive health outcomes in young people (Jansen \& Le Blanc, 2010). In summary, the aforementioned reviews presented evidence that regular participation in physical activity can inhibit or decrease the development of risk factors related to chronic diseases in children and adolescents (Hallal et al., 2006; Janssen \& Le Blanc, 2010; Rowland, 2007; Strong et al., 2005).

Weight management. The rate of overweight and obese youth in the U.S. has increased considerably in the last years. In 1998, the prevalence of obesity in adolescents 12-19 years of age was $11.3 \%$ among boys and $9.7 \%$ among girls. Twenty years later, in 2008, the prevalence of obesity in adolescents was $19.3 \%$ among boys and $16.8 \%$ among girls, showing an alarming growth in obesity rates in both male and female adolescents (Ogden \& Carroll, 2010). Because of this rapid increase in the prevalence of obesity among youth and the potential medical complications caused by excessive adiposity, children and adolescents' obesity is now considered a major public health concern (Sallis et al., 2012). 
Obesity is caused by habitual energy imbalance causing the accumulation of excessive energy in the body in the form of adipose tissue (Astrup, Hill, \& Rössner, 2004). The causes of such imbalance are attributed to complex interactions between genetics, environmental factors, and behavioral factors (Cliff, Okely, Morgan, Jones, \& Steele, 2009). Nonetheless, unhealthy dietary habits and inactive lifestyles seem to be the primary behaviors influencing energy imbalance which results in obesity (Goran \& Treuth, 2001). Hence, researchers have been investigating the relationship between levels of physical activity and adiposity in youth in order to gain a better understanding of the associations between these two variables. Must and Tybor (2005) reviewed 17 studies that examined the relationship between physical activity and sedentary behavior with obesity in youth and concluded that the available evidence showed protective effects of increased physical activity and decreased sedentary behavior against weight gain (Must \& Tabor, 2005). Likewise, Reichert, Menezes, Wells, Dumith, and Hallal (2009) published a systematic review of the literature pertaining to physical activity as a predictor of adolescent body fatness. The authors found that most of the 19 reviewed studies indicated protective effects of physical activity against adiposity, suggesting that PA engagement might have beneficial effects on weight status among youth (Reichert, Menezes, Wells, Dumith, \& Hallal, 2009). Although physical activity is not the only factor influencing adiposity in children and adolescents, the literature consistently indicates an inverse relationship between physical activity and body weight in youth (McMurray, Harrell, Creighton, Wang, \& Bangdiwala, 2008). These findings suggest that regular participation in physical activity might have beneficial effects on the prevention of overweight and obesity development among children and adolescents.

Mental health. Relationships between physical activity and psychological outcomes have been largely researched in adult populations but not as frequent in youth. Nevertheless, a small but growing number of studies that investigated the effects of physical activity on children and adolescents' mental health suggested positive results. The majority of this work has investigated the effects of physical activity on depression, anxiety, and self-esteem (Biddle \& Asare, 2011). Parfitt and Eston (2005) examined the relationships between children's physical activity and symptoms of depression and anxiety as well as 
indicators of self-esteem. Participants in the study were 70 children aged 10 to 11 years old and pedometers were used to measure their physical activity levels for seven days. Questionnaires were used to measure the psychological variables and the results confirmed the study's hypothesis that physical activity participation would be negatively correlated to anxiety and depression and positively correlated with self-esteem (Parfitt \& Easton, 2005). Although the study did not account for the intensity of physical activity, the results indicated that children who accumulated higher amounts of steps had significantly lower levels of depression and anxiety.

In a more recent and larger study, Goldfield at al. (2011), examined the relationship between physical activity and indicators of depression and anxiety in 1259 adolescents. Although the study used self-reported measures of physical activity amounts and intensity, the results indicated that moderate and vigorous physical activity was inversely correlated with symptoms of depression and anxiety in the overall sample. However, mild intensity physical activity was not correlated with the indicators of psychological health, whereas vigorous physical activity was correlated with reduced anxiety in females and with reduced depression in males. Hence, the authors suggested that vigorous physical activity may be more closely related to psychological wellbeing than the volume of physical activity and that gender may moderate the effects on PA on adolescents (Goldfield et al., 2011).

Ahn and Fedewa (2011) investigated the relationship between children's physical activity and mental health, through a comprehensive quantitative review of 73 studies that had searched for the effects of physical activity interventions on children and adolescents' mental health. The results showed that increased levels of physical activity had significant effects on children mental health. Specifically, increased levels of physical activity were associated with reduced depression, anxiety, and psychological disturbance in youth (Ahn \& Fedewa, 2011). Similarly, Biddle and Asare (2011) conducted a review of reviews with the purpose of synthesizing evidence of the relationship between physical activity participation and youth's mental health. The review focused on studies that indicated evidence of physical activity associations with depression, anxiety, self-esteem, and cognitive functioning. According to Biddle and Asare, the results showed that physical activity had the potential to produce positive 
psychological outcomes in youth. The authors suggested that evidence seems to be stronger for associations between physical activity and self-esteem and that children and adolescents who participate regularly in physical activity are more likely to be emotionally healthy and to have improved cognitive functioning (Biddle \& Asare, 2011). Also, the authors noted promising effects of physical activity on depression, but emphasized the fact that inconsistency in methodological approaches and lack of objective measures of physical activity indicate the need for further inquiries in the area of physical activity effects on youth mental health (Biddle \& Asare, 2011). Although further research on the association between physical activity and youth psychological wellbeing is needed (specially using objective measures of physical activity), the findings of the aforementioned studies' findings clearly indicate that regular participation in physical activity can positively influence youth's mental health.

Physical activity habit development. Another potential benefit of regular participation in physical activity during the early years of life is the possibility for this habit to be carried out through adulthood (Rowland, 2007). Researchers have been seeking to examine if physical activity behavior established during adolescence persists into adulthood. Some findings indicate low to moderate associations between physical activity during adolescence and adulthood (Hallal et al., 2006; Malina, 2001; Trudeau, Laurencelle, \& Shepard, 2004). However, Telama et al. (2005) tracked physical activity behavior of several age cohorts over an 18-years period and found that physical activity participation from ages 9 to 18 significantly predicted adult physical activity. Hallal et.al (2006) conducted a literature review to search for the short and long term health benefits of physical activity in children and adolescents and indicated that the reviewed studies demonstrated a consistent effect of adolescent physical activity on adult physical activity patterns (Hallal et al., 2006). In the same way, Kjønniksen, Torsheim, and Wold (2008) investigated the relationship between participation in specific types of physical activity during adolescence and leisure time physical activity in adulthood. The results showed a moderate correlation between adolescents' and adults' engagement in physical activity, suggesting that diverse physical activity opportunities in youth are more likely to produce active lifestyles in adulthood (Kjønniksen et al., 2008). 
From a related research perspective, Graham, Sirad, and Neumark-Sztainer (2011) conducted a longitudinal study to investigate if adolescents' attitudes towards physical activity would predict their participation in physical activity 5 and 10 years later. Participants were 1902 middle and high students who completed self-reported measures of physical activity as well as a physical activity attitudes' questionnaire at baseline and after 5 and 10 years. The statistical analysis indicated that adolescents who had more positive attitudes towards physical activity reported approximately $40 \%$ more levels of physical activity at the 5 and 10 years follow-up than the ones who had less positive attitudes towards physical activity. These results suggest that adolescents' attitudes towards physical activity can be an important factor influencing physical activity behavior tracking into adulthood (Graham, Sirad, \& NeumarkSztainer, 2011). Similarly, Cleland, Dwyer, and Venn (2012) inquired if specific types of childhood physical activity predicted adult participation in physical activity. The sample of this study were 2,879 individuals who completed self-reported measures of physical activity at ages 7-15 and then 20 years later. The results showed that different types of childhood physical activity were associated with physical activity in adulthood. However, it is interesting to note, that weekly physical education and weekly school sports predicted adult physical activity more frequently than other contexts of childhood physical activity such as leisure time physical activity and active transportation (Cleland, Dwyer, \& Venn, 2012). Although associations between physical activity participation in youth and physical activity habits during adulthood seems to be moderate, there is agreement in the literature that children and adolescents who are active are more likely to engage in active pursuits when they become adults (Trudeau et al., 2004). Although studies that had aimed at finding evidence of this relationship are limited due to the methodological constraints of longitudinal studies, it has been argued that physical activity habit formation during childhood and adolescence is possibly the strongest rationale for promoting healthy lifestyles among youth (Hallal et al., 2007; Rowland, 2007).

\section{Physical Activity Guidelines for Adolescents}

In 2008, The U.S. Department of Health and Human Services (USDHHS) released the first comprehensive set of physical activity guidelines for Americans. The 2008 Physical Activity Guidelines 
for Americans was designed as an attempt to provide policy makers and health professionals with information regarding the types and amounts of physical activity that can produce the most beneficial outcomes (U.S. Department of Health and Human Services [USDHHS], 2008). The document is based on an extensive review of the scientific evidence concerning the benefits of physical activity for health and wellbeing and includes specific physical activity guidelines for children and adolescents, adults, and specific groups of individuals such as pregnant women, adults with disabilities, older adults, and individuals with chronic medical conditions (USDHHS, 2008). The Guidelines recommends that children and adolescents aged 6-17 engage in "60 minutes or more of physical activity daily" (USDHHS, 2008, p.16). More specifically, it is recommended that children and adolescents spend most of these 60 minutes in moderate or vigorous aerobic physical activity and engage in vigorous intensity physical activity at least three days per week (USDHHS, 2008). Additionally, the Guidelines recommended that youth participate in developmentally appropriate muscular strengthening activities and bone strengthening activities in at least three days per week. The Guidelines also emphasize that children and adolescents should meet these guidelines through activities that are adequate for their age. Particularly, adolescents, who are able to engage in sustained periods of activity and organized games or sports, are encouraged to meet the guidelines through free play, lifetime activities, games, and/or structured exercise and sports programs (USDHHS, 2008).

\section{Status of Physical Activity Levels among Adolescents in the U.S.}

Despite the increasing efforts to promote healthy and physically active lifestyles among youth, evidence shows declining levels of physical activity in adolescents and low incidence of youth meeting the 2008 Physical Activity Guidelines for Americans (Centers for Disease Control and Prevention [CDC], 2012). A study examining the prevalence of adolescents aged 12-17 who met the 2008 physical activity Guidelines indicated that less than $20 \%$ of the surveyed adolescents reported meeting the guidelines for both aerobic and muscular strengthening activities (Song, Carroll, \& Fulton, 2013). Recent data from national surveys also indicate low percentages of adolescents being active for 60 minutes on seven days per week. Data from the 2010 National Youth Physical Activity and Nutrition Study (NYPANS) showed 
that in a national sample of 9,701 high school students only $15.3 \%$ of the students reported doing some type of aerobic physical activity on the seven days prior the survey (CDC, 2011a). Similar, the 2011 Youth Risk Behavior Surveillance System (YRBSS) revealed that only $28.7 \%$ of the surveyed students in grades $9^{\text {th }}$ to $12^{\text {th }}$ reported doing any type of moderate or vigorous physical activity for 60 minutes on the seven days before the survey (CDC, 2012). Additionally, only $49.5 \%$ of students reported being physically active for 60 minutes on at least five days per week. Overall, the 2011 YRBSS data show that the prevalence of regular physical activity was higher in $9^{\text {th }}$ grade $(52.9 \%)$ and $10^{\text {th }}$ grade $(51.8 \%)$ than in $11^{\text {th }}$ grade $(47.3 \%)$ and $12^{\text {th }}$ grade $(44.8 \%)$ which supports the findings from other studies that consistently indicated a decline in physical activity participation with age during adolescence (Biddle, Atkin, Cavil, \& Foster, 2011; CDC, 2012; Gordon-Larsen, Nelson, \& Popkin, 2004; Kjønniksen et al., 2008).

\section{Psychosocial and Environmental Influences of Physical Activity in Youth}

\section{Review of Physical Activity Correlates in Youth}

In order to understand why some children and adolescents are physically active and others are not, researchers have been seeking to discern the factors that influence youth physical activity behavior. Understanding the variables that influence children and adolescents to be active is considered to be a significant element for public health because this knowledge can better inform the design of interventions aimed at enhancing physical activity among youth (Salmon, 2010). A growing body of literature clearly indicates that youth physical activity is a complex behavior influenced by a combination of personal, social, and environmental factors (Bauman, Sallis, Dzewaltowiski, \& Owen, 2002; Biddle et al., 2011; Sallis, Prochaska, and Taylor, 2000). This understanding is a result of several cross-sectional studies which examined the correlations between physical activity levels in children and adolescents and different personal, social, and environmental variables.

Sallis, Prochaska, and Taylor (2000) published a comprehensive review of studies that examined the variables associated with children and adolescents PA behavior. One hundred and six studies of possible correlates of physical activity in youth were reviewed and the variables identified in those studies were classified into individual, social, and environmental categories. The most consistent findings across 
the reviewed studies were girls being less active than boys and negative associations between age and physical activity. Moreover, Sallis et al. (2000) indicated that nine variables were associated with children's and adolescents' physical activity in the reviewed studies: "perceived physical competence, intention, barriers, parent support, direct help from parents, support from significant others, program/facility access, opportunities to be active, and time outdoors" (p.969). Particular to adolescents' physical activity, achievement orientation, perceived competence, and intention to be active were the individual variables consistently associated with physical activity in the reviewed studies (Sallis et al., 2000). In the same way, social and environmental variables such as parental support, siblings' physical activity participation, and opportunities to be active were positively related with adolescents' levels of physical activity. These findings were relevant to raise awareness that youth physical activity is influenced by multiple factors and that interventions focused at promoting physical activity among this age group should address variables from multiple domains (individual, social, and environmental) in order to generate behavior change.

A few years later, Van der Horst, Paw, Twisk, and Mechelen (2007) conducted another review of the literature directed at extending the findings provided by Sallis et al. (2000) in regard to the correlates of youth physical activity. The purpose of this review was to present an update of the factors that had previously been correlated with children's and adolescents' physical activity and sedentary behavior. Fifty seven studies were examined and the results concerning physical activity showed that gender, perceived self-efficacy, and family support were variables consistently associated with physical activity levels in both children and adolescents. More specifically, the review indicated that factors correlated with adolescents' physical activity were "gender, self-efficacy, goal orientation/motivation, physical education/school sports participation, family influences, and friend support" (Van der Horst et al., 2007, p.1246). In a more recent study, Biddle et al. (2011) searched for the correlates of physical activity in youth and adolescents by conducting a systematic review of reviews of non-intervention research related to youth participation in physical activity. Nine reviews were selected for analysis and the correlates examined by them were also classified into several individual, social, and environmental categories. The 
nine reviews found consistent negative associations between physical activity and age as well as gender associations with physical activity (e.g., boys being more active than girls) (Biddle et al., 2011). In addition, Biddle et al. indicated that perceptions of self-competence seemed to be highly associated with physical activity engagement, especially among girls. Enjoyment, although thought to be logically associated with physical activity participation did not appear to be consistent related with physical activity behavior across the reviewed studies, while parents' support was shown to have a high relationship with youth physical activity behavior across all the reviews (Biddle et al., 2011). These results confirmed the concept that youth physical activity is a complex behavior influenced by a myriad of variables that must be considered for the design of initiatives focused on promoting active lifestyles among children and adolescents.

\section{Social Ecological Models of Health Behavior}

Ecological models of health behavior have been indicated as a contemporary approach in the health behavior promotion literature (Rimer \& Glanz, 2005). Rather than theories, ecological models are frameworks designed with the purpose of guiding health-behavior interventions and research (Sallis \& Owen, 2002). According to Sallis and Owen (2002) the term ecology refers to relationships between organisms and in regard to health behaviors, ecological approaches are used to explain how behaviors are determined by the interactions between individual factors and the social and physical environment (Sallis \& Owen, 2002). For this reason, ecological models acknowledge that health behaviors are influenced by different variables in multiple levels. McLeroy, Bibeau, Steckler, \& Glanz (1988) proposed that health behaviors are affected at the following levels: (a) intrapersonal, (b) interpersonal, (c) institutional, (d) community, and (e) policy. In each of these levels, health behaviors are influenced by different variables that have been indicated by research to be associated with specific behaviors (McLeroy et al., 1988). In addition, it has been argued that all these levels are interdependent and mutually influence one another (Spence \& Lee, 2003). The intrapersonal level includes individual attributes such as knowledge, skills, behavioral management skills, perceived self-efficacy, perceived barriers and benefits, outcomes expectation, motivation, and enjoyment. The interpersonal level includes the influence that relationships 
with friends, family members, coworkers, neighbors, and others play on health behaviors. The institutional level is related to the internal structures of particular institutions such as schools, work places, community centers, faith-based organizations, and others. The community level encompasses the relationships between institutions or organizations and the policy level refer to public policies that regulate health behaviors (McLeroy et al., 1988).

Ecological models of health behavior were conceptualized within the field of public health with the purpose of providing health professionals and researchers with a framework for the design and evaluation of health-related interventions (Sallis \& Owen, 2002). This approach claims that initiatives targeting more than one level of influence on a particular health behavior have greater potential to succeed (Rimer \& Glanz, 2005). In regard to physical activity promotion, ecological models have been recognized as a promising approach to address the multiple factors that have been associated with physical activity behavior. Since physical activity engagement is influenced by individual factors, social relationships, and environmental attributes, it has been argued that physical activity promotion initiatives should be based on ecological models of health behaviors and focus on more than one level of influence on physical activity (Zhang, Solmon, Gao, \& Kosma, 2013). Consequently, several conceptual models and frameworks for physical activity promotion based on ecological approaches have been developed and research over the past years.

\section{The Youth Physical Activity Promotion Model}

Welk (1999) developed the Youth Physical Activity Promotion (YPAP) model articulating correlates of physical activity from multiple theories into a conceptual framework to explain children and adolescents' participation in physical activity. Built upon the ecological perspective (Sallis \& Owen, 2002), the YPAP model acknowledges that assorted personal, social, and environmental factors influence children and adolescents' physical activity behavior. Welk summarized the correlates that other researchers have found to influence youth's physical activity behavior into a conceptual framework designed to facilitate physical activity promotion and research among this age group. The YPAP model 
(See Figure 1) classifies those correlates into enabling, predisposing, reinforcing, and personal demographics (Welk, 1999).

Enabling factors. Enabling factors involve variables that allow for children and adolescents to be active. According to the YPAP model (Welk, 1999), enabling factors involve both biological and environmental variables that potentially enable children and adolescents to be active.

Environmental variables. According to the YPAP model (Welk, 1999) the environmental variables that enable physical activity in youth are: access to programs, facilities, and equipment, weather conditions, safety, and the presence of sidewalks. These variables are called enabling factors by Welk (1999) because they are "necessary but not sufficient determinants of physical activity" (p.14). Particularly to children and adolescents, characteristics of the school, home and neighborhood environments have been associated with physical activity participation. Since children and adolescents spend a great proportion of their time in the school, the school physical environment and structure have a significant influence on the range of opportunities available for youth to be active (Langille \& Rodgers, 2010). Examples of how the school environment influence physical activity behavior are: (a) the physical environment (e.g., the presence of adequate sports facilities, large areas designed for recess and free play, and safe playgrounds), (b) the school structure (e.g., number of physical education class periods per week, duration of physical education classes, and duration of recess), and (c) school physical activity opportunities (e.g., physical activity before, during, and after school hours, physical activity opportunities during the weekend and summer vacation, intramurals and interscholastic sports). Several studies have been conducted in order to examine the extent to which school-related environmental factors affect youth physical activity. Sallis et al. (2001) studied the relationship between schools facilities, equipment, and supervision with students' levels of physical activity outside of physical education classes. The researchers assessed potential areas for physical activity in 24 schools and observed middle school students' levels of physical activity during unstructured play time. Results indicated that boys and girls were more active in schools identified as having higher environmental support (e.g., facilities, equipment, and supervision) (Sallis et al., 2001). Likewise, Haerens et al. (2009) examined the relationship between 
school environments' features and adolescents' physical activity and concluded that access to extracurricular physical activity opportunities in which supervision was provided contributed to adolescents' increased levels of physical activity (Haerens et al., 2009).

Similar to schools, home and neighborhood environments have also been indicated as an influence on youth physical activity behavior (Dunton, Kaplan, Wolch, Jarret, \& Reynolds, 2009). Researchers investigating the relationship between the physical environment characteristics and youth physical activity have suggested that the presence or absence of sidewalks, parks, walking and biking trails, and other public recreational facilities might enable or inhibit physical activity engagement (Davison \& Lawson, 2006). Furthermore, safe communities have also been appointed as an enabler for youth participation in physical activity (Carver, Timperio, Hesketh \& Crawford, 2009). Millstein et al. (2011) examined the characteristics of school, home and neighborhood environments in order to understand their contribution to children and adolescents' physical activity engagement. The authors concluded that access to physical activity equipment at home was the variable mostly correlated with youth physical activity (Millstein et al., 2011). Also, access to sports and physical activity equipment in schools was also correlated with adolescents' physical activity indicating that the availability of such equipment fostered physical activity engagement in the school setting (Millstein et al., 2011).

Davison and Lawson (2006) published a review of studies that examined the correlations between youth's physical activity and environmental factors. Specifically, the authors reviewed studies that investigated associations between youth's physical activity and community attributes pertaining to recreational, transport, and overall local infrastructure. Thirty-three studies were included in the review and the results showed that transport infrastructure such as the presence of sidewalks and lack of road hazards was consistently related to youth's levels of physical activity (Davison and Lawson, 2006). Also, the presence of parks and public recreational facilities in neighborhoods was related to children's physical activity engagement. Likewise, the availability of physical activity equipment at home and in the school setting were found to be related with higher levels of physical activity among youth (Davison and Lawson, 2006). Although there is growing evidence to suggest that the physical environment is 
associated with children's and adolescents' levels of physical activity, it is important to note that environmental variables are not considered to be determinants of physical activity in youth by the YPAP model (Welk, 1999); rather they are presented as variables that permit and facilitate children and adolescents to be active while other variables might be of greater influence on youth physical activity behavior (Erwin, Mays Woods, Woods, \& Castelli, 2007).

Biological variables. In the YPAP model biological variables refer to individual characteristics of children and adolescents' that have the potential to influence physical activity behavior because they facilitate a child or adolescent to be active (Welk, 1999). These variables comprise physical/motor skill development and levels of physical fitness. According to Welk (1999), youth who have developed a variety or motor skills and are physically fit are most likely to engage in physical activity. Hence, it seems logical to assume that motor skill development is associated with physical activity levels in youth since children and adolescents who have developed a wide range of motor skills are less limited in the variety of activities they can participate. Although several studies have been conducted in order to examine the associations between motor competency and children and adolescents levels of physical activity, only weak and moderate correlations have been found between these two variables (Raudsepp \& Päll, 2006; Reed, Metzker, \& Phillips, 2004; Wrotniak, Epstein, Dorn, Jones, \& Kondilis, 2006). One possible explanation for these moderate findings is the disassociation between the measurements of physical activity used in the studies and the types of activities that children and adolescents usually engage as a result of motor competency. In these studies, researchers have often used step-counts to measure physical activity and motor skill tests measures abilities such as throwing, catching or balancing. Reed, Metzker, \& Phillips (2004), investigated the association between levels of physical activity and motor skill performance in a sample of 217 middle school students. The amount of daily steps was used to measure physical activity levels while motor skill development was assessed thorough three different motor skill tests. The findings indicated significant but weak correlations between the skill tests' results and the amount of steps taken by the participants (Reed et al., 2004). Raudsepp and Päll (2006) studied the associations between motor skills development and engagement in physical activity after the school 
hours. Accelerometers and systematic observation of children were used to measure levels of physical activity and jumping and throwing tests were used to assess motor proficiency. According to the authors, the results showed that motor development was associated with outside of school physical activities considered to be skill-related (Raudsepp \& Päll, 2006). These findings support the hypothesis that the measures of physical activity and skill development in research looking for associations between these two variables might influence the results.

Similar to motor skill competency, Welk (1999) argued that health-related physical fitness components such as aerobic capacity, muscular strength, and body composition are related to levels of physical activity in youth (Hands, Larkin, Parker, Straker, \&Perry, 2009; Kristensen et al., 2010). Castelli and Valley (2007) examined the association between motor competency, physical fitness, and physical activity in a sample of 230 children enrolled in a summer physical activity program. The results indicated that both motor competency and physical fitness were predictors of physical activity in the sampled children, supporting the notion that these variables influence physical activity in youth through an enabling process (Castelli \& Valley, 2007). Likewise, Hands, Larkin, Parker, Straker, and Perry (2009) investigated the correlations between motor competence, physical fitness, and physical activity in a sample of 1585 adolescents. The results showed that physical fitness was correlated with motor competency and levels of physical activity were associated with aerobic capacity in both male and females (Hands et al., 2009). Similar findings were reported by Kristensen et al. (2010) who examined the relationship between physical activity and aerobic capacity in children and adolescents as part of the European youth heart study. Almost 2,000 youth participated in the study and the results indicated significant but moderate correlations between aerobic fitness and levels of physical activity (Kristensen et al., 2010).

Although enhancing levels of physical fitness and motor skill development can only be obtained through engagement in sports and physical activity, it has been argued that the acquisition of these physical attributes facilitate and foster children and adolescents to seek and engage in physical activity opportunities (Castelli \&Valley, 2007). Similar to the environmental variables, the biological variables 
included in the YPAP model indicate factors that enable but do not determine physical activity behavior in youth. Children's and adolescents perceptions of motor competency rather than their actual levels of skill proficiency might have a greater influence on their participation in physical activity (Welk, 1999).

Predisposing factors. Predisposing factors include variables that have been indicated to enhance the likelihood that a child or adolescent will regularly participate in physical activity (Welk, 1999). These variables also called psychological variables, are related to the value that children and adolescents attributes to physical activity as well as their perceptions of their competence to take part in a certain activity. According to Welk and Schaben (2004), predisposing factors are based on two constructs included in the social cognitive theory proposed by Albert Bandura (1986): efficacy expectation and outcome expectation. In the YPAP model, these constructs are summarized into two questions: (a) Am I able? and (b) Is it worth it? The first question addresses the individuals' perceptions of his or her capabilities to perform a physical activity-related task while the second question addresses the perceivedvalue and outcomes of engaging in physical activities (Welk \& Schaben, 2004). The YPAP model suggests that predisposing factors are: (a) Perceptions of competence, (b) enjoyment, (c) beliefs, and (d) attitudes (Welk, 1999). Predisposing factors of physical activity in youth have been widely researched and there is evidence in the literature shwoing that perceived self-competence as well as enjoyment and attitudes are positively related to youth physical activity (Craggs, Corder, van Sluijs, \& Griffin, 2011; Sallis et al., 2000; Welk \& Schaben, 2004). Furthermore, Welk and Schaben (2004) argue that predisposing factors directly influence physical activity behavior in youth because "they reflect the child's personal 'predisposition' or interest in being physically active” (p.66). The following sections will address the variables associated with the questions Am I able? and Is it worth it?

Am I able?. According to Welk and Schaben (2004), the question Am I able? refers to efficacy expectancy, which means the child or adolescent's perceptions of his or her level of motor competency. Children's and adolescents' perceptions of their competency to perform a sport or activity have been consistently related with levels of physical activity. Reviews of studies that examined the correlations between perceived motor competence, self-efficacy, or perceived athletic competence and youth physical 
activity have indicated that children and adolescents who have high perceptions of their motor abilities tend to pursue physical activity participation more than youth who have low perceptions of their motor abilities (Biddle et al., 2011; Sallis et al., 2000; Van der Horst et al., 2007). Also, it has been suggested that the relationship between perceived competence and physical activity are more consistent for adolescents that for children (Sallis et al., 2000) and for girls than for boys (Biddle, Whitehead, O’Donovan, \& Nevill, 2005).

Is it worth it?. In the YPAP model the question Is it worth it? refers to the expected outcomes of physical activity engagement, reflecting children's and adolescents' enjoyment, attitudes, and attraction to physical activity (Welk \& Schaben, 2004). Similar to perceived competence, the relationship between outcomes expectation have been largely researched. Enjoyment of physical activity have been found to be consistent associated with physical activity in several studies and it has been suggested that this association might be stronger among girls (Biddle et al., 2011). Welk and Schaben (2004) investigated the relationships between predisposing factors and levels of physical activity in children who had similar opportunities to participate in physical activity and found that perceived athletic competency and attractiveness to physical activity was associated with higher physical activity levels. In the same way, Spink et al., (2006) examined the correlates of physical activity in active adolescents and found that enjoyment, perceived health beliefs, and perceived competence were the variables most highly correlated to physical activity behavior, supporting the hypothesis that these constructs have the potential to prompt youth to engage in active lifestyles (Spink et al., 2006). In a more recent study, Lawman, Wilson, Van Horn, Resnicow, and Kitzman-Ulrich (2011) searched for correlations between predisposing factors and physical activity behavior in underserved adolescents. The results reported by the authors indicated that self-efficacy and motivation predicted physical activity in girls, but only motivation predicted boys' physical activity supporting previous findings that predisposing factors might be moderated by gender (Biddle et al., 2005). Although perceived competence and attraction to physical activity are distinct constructs, Welk (1999) placed them at the center of the YPAP model as predisposing factors of physical 
activity, inferring that these factors mutually influence physical activity and are also affected by personal demographics, enabling, and reinforcing factors.

Reinforcing factors. Reinforcing factors comprise variables that reinforce a child or adolescent's physical activity behavior. This dimension includes social relationships that have been appointed as influential on youth physical activity (Welk, 1999). Numerous studies have investigated the relationship between the influence of parents, siblings, peers, coaches, and physical education teachers on youth physical activity with parental being influence the most researched variable (Sallis et al., 2000). There is evidence showing that children and adolescents' physical activity behavior is highly influenced by their parents through different mechanisms: (a) modeling (e.g., parents being active), (b) support (e.g., parents registering and paying for physical activity programs, purchasing physical activity equipment and driving their children to practice), and (c) encouragement (parents' verbal persuasion, cheering, and attendance to games and practice sessions) (Biddle et al., 2011, Gustafson \& Rhodes, 2006). Gustafson and Rhodes (2006) reviewed 34 studies that had examined the parental correlates of physical activity in youth and concluded that parents' modeling and support for physical activity were the variables mostly associated with children's and adolescents physical activity engagement. Similar, Pugliese and Tinsley (2007) conducted a meta-analysis in order to review studies that had examined parental influences on youth physical activity. The findings indicated that the mechanisms by which parents influence youth's physical activity behavior varies according to age. For example, modeling was found to be correlated with children's physical activity but not with adolescents' physical activity, whereas encouragement was related to both children and adolescents' physical activity engagement (Pugliese \& Tinsley, 2007).

In the same way that parents can influence youth physical activity behavior through varied mechanisms, researchers have found that peer influence on children and adolescent physical activity can also occur though different avenues. Fitzgerald, Fitzgerald, \& Aherne (2012) conducted an extensive review of studies that had investigated the influences of peers on adolescents' physical activity and found evidence of associations between peers and youth physical activity through different processes such as peer acceptance, peer support, and established norms. According to Fitzgerald et al. (2012), "adolescents' 
positive relationships with their peers contribute significantly to physical activity participation” (p.954). Further, the authors indicated that peers can also negatively influence youth's physical activity though peer victimization in physical activity settings. Although fewer studies have investigated the influences of siblings on youth physical activity participation, there is some evidence in the literature that siblings might also influence children's and adolescents' physical activity habits through encouragement, modeling, and support (Hohepa, Scragg, Schofield, Kolt, \& Schaaf, 2007). Finally, the YPAP model also suggest positive experiences with coaches and teachers might reinforce youth physical activity engagement through modeling (e.g., being active, providing appropriate instruction) and encouragement (e.g., verbal persuasion) (Erpic, 2013; Welk, 2009). Parents, siblings, peers, and coaches or teachers represent the social influences on youth physical activity behavior and are referred as reinforcing factors of YPAP model because these are variables that support or boost youth participation in physical activity. Welk (1999) explains that reinforcing factors can influence physical activity behavior directly as when parents provide opportunities for their children to be active or indirectly as when children develop higher perceptions of self-competencies or become attracted to physical activity as result of these social interactions. In addition, it has been suggested that the social influences on youth physical activity behavior might be moderated by demographic factors such as age, gender, and socio-economic status (Biddle et al., 2011).

Personal demographics. According to Welk (1999), demographic factors were placed in the YPAP model because of their potential to affect how a specific individual respond to the other factors associated with physical activity included to the model (i.e., enabling, predisposing, and reinforcing factors). To date, the most studied demographic factor in relation to youth physical activity is gender and there is a consensus in the literature reporting that boys tend to be more active than girls (Belcher et al., 2010; Biddle et al., 2011; Hilland, Ridgers, Stratoon, \& Fairclough, 2011; Sallis et al., 2000). Moreover, Welk (1999) argued that gender has been found to influence the way that youth respond to enabling, predisposing, and reinforcing factors. For example, some studies have found that the relationship between enjoyment and physical activity was stronger for girls than for boys (Bidle et al., 2011), whereas 
other research has appointed that boys received more parental support than girls (Gustafson et al., 2006). Hilland, Ridgers, Stratoon and Fairclough (2011) explained that the discrepancy in levels of physical activity among male and female youth can be attributed to various factors such as differences in biological maturation, perceived self-competence, and opportunities to be active and family support.

Another commonly investigated personal demographic factor associated with physical activity is age. Numerous studies have searched trends in physical activity participation related to age and identified a decline in physical activity with age, specifically when children move into adolescence (Biddle et al., 2011, Kahn et al., 2008; Sallis, 2000; Sallis et al., 2000). Belcher et al. (2010) examined demographic associations with objective measures of physical activity in youth ages 6-19 and indicated that children ages 6-11 were active twice as much as the adolescents. According to the authors these findings were "consistent with the observation that the most dramatic age-related decline in physical activity may occur at the start of puberty" (Belcher et al., 2010, p.2218). Welk (1999) also claimed that age might influence youth responses to the enabling, predisposing, and reinforcing factors of physical activity. For example, studies have found that associations between perceived competence and physical activity were stronger in adolescents than in children (Sallis et al., 2000) while the relationship between parental support and physical activity seems to be stronger for children than for adolescents (Gustafson et al., 2006).

Ethnicity is another demographic factors included in the YPAP model that has also been shown to be related with physical activity levels in adolescents (Welk, 1999). Nevertheless, it appears that findings related to the association between ethnicity and physical activity in youth are not as consistent as between gender, age, and physical activity (Belcher et al., 2010). Sallis et al. (2000) found in the literature that non-Hispanic white adolescents were more active than the other ethnic groups. This finding was recently supported by the 2011 YRBSS data (CDC, 2012), which reported that the prevalence of adolescents being active 60 minutes on at least five days prior to the survey was higher among white students (52.7\%) than black (44.4\%) than Hispanic (45.4\%). On the other hand, Belcher et al. (2010) found lower levels of physical activity among white non-Hispanic youth than in other ethnic groups. In a recent study, Kaczynski, Stanis, Besenyi, and Child (2013) investigated the relationship between gender and ethnicity 
with levels of moderate to vigorous physical activity (MVPA) in youth. The study was conducted in several parks and MVPA was measured through a direct observation system. The results showed that white youth were the most active ethnic group, suggesting that white youth had greater access to these parks and that access might be influenced by ethnicity (Kaczynski, Stanis, Besenyi, \& Child, 2013).

The last personal demographic factor included in the YPAP model is socioeconomic status (Welk, 1999). It has been claimed that socioeconomic status might be associated with the amount of access that children and adolescents have to physical activity opportunities (Sallis, Zakarian, Hovel, \& Hofstetter, 1996). However, it appears that findings regarding this relationship are still inconsistent and questions about this association in youth physical activity remain (Ball, Cleland, Timperio, Salmon, \& Crwford, 2009; Sallis et al., 2000).

\section{Research Based on the Youth Physical Activity Promotion Model}

The YPAP model was designed to foster research and physical activity promotional efforts among children and adolescents. Consequently, since its conceptualization researchers have investigated its implications for physical activity promotion among youth. Crimi, Hensley, and Finn (2009) examined the relationship between selected psychosocial factors from the YPAP model and the physical activity behaviors of children and adolescents in a rural community environment. Participants were 90 girls and 77 boys, ranging from 9 to 18 years of age. Physical activity behavior was measured through selfreported questionnaires and the psychosocial correlates of physical activity were measured through the Children's Physical Activity Correlates (CPAC) questionnaire. Results indicated no significant difference in physical activity behavior between males and females whereas a significant decrease in physical activity with grade level was observed. Results suggested a moderate, yet meaningful relationship between the investigated psychosocial factors and the participants physical activity behavior. Moreover, findings reported by the authors supported the association of some of the YPAP model's predisposing factors (liking exercise, perceived competence) and reinforcing factors (parental support) with physical activity levels among the study participants (Crimi, Hensley, \& Finn, 2009). 
Rowe, Raedeke, Wiersma, and Mahar (2007) conducted a cross-sectional study to investigate the validity of the YPAP model using a sample of 296 middle school students. Specifically, the study examined the associations between predisposing factors included in the YPAP model (attractions to physical activity and perceived competence) with enabling (boy fatness) and reinforcing factors (parental and peer support). Physical activity was measured though both objective measures (daily step count) and a self-reported instrument (Leisure Time Exercise Questionnaire). The authors indicated that the YPAP model presented internal validity because of the significant associations found among its constructs (Rowe, Raedeke, Wiersma, \& Mahar. 2007). On the other hand, a study conducted by Erwin, Mays Woods, Woods, and Castelli (2007) to investigate the associations between physical activity levels, physical fitness, and motor competence with access to physical activity facilities found contradictory results regarding some of the variables present in the YPAP model. The authors concluded that access to physical activity, an enabling factor in the YPAP model, was not related to high amounts of physical activity. Additionally, physical activity was not found to be associated with gender, a personal demographic factor in the YPAP model (Erwin et al., 2007). This study has some limitations, being the most prominent the sample size. Only 47 adolescents participated in the study making it difficult to generalize the results obtained from the data. More recently, Hilland et al. (2011) investigated the correlations between adolescents’ physical activity and selected demographic, biological, and environmental factors included in the YPAP model. Participants were 299 middle school students and physical activity data were collected through both self-reported instruments and objective measurements. The results are in accordance with previous research findings (Sallis et al., 2000, Van der Horst et al., 2007) and indicated that gender, perceived competence, and expected outcomes of physical activity were most strongly associated with adolescents' physical activity behavior. The authors supported the employment of the YPAP model in physical activity-related interventions, especially in the context of school-based physical activity initiatives suggesting that physical activity programing in the school setting can play an important role in affecting the influencing factors of physical activity outlined in the model (Hilland et al., 2011). 


\section{Physical Activity in the School Setting}

\section{The Role of Schools in Promoting Physical Activity}

Schools have been acknowledged as an ideal setting for physical activity promotion and recently, have been urged to expand their efforts to increase physical activity opportunities for youth (Pate et al., 2006). Children and adolescents spend a great proportion of their time in the school and schools have existing facilities and equipment that can be used for the establishment of various physical activity programming (Ward, Sanders, \& Pate, 2007). Schools can also reach large populations of children and adolescents from various ethnic, cultural, and social-economic backgrounds (Naylor \& McKay, 2009). Furthermore, schools are a potential setting for the implementation of interventions based on ecological approaches that consider the intrapersonal, interpersonal, institutional, community, and policy levels of influence on physical activity behavior (Lohrman, 2010; Perry, Garside, Morones, \& Hayman., 2012).

As a result, several recommendations, guidelines, and position papers have been published in the past twenty years issuing the school setting the leadership role in youth physical activity promotion (Sallis et al., 2012). In 2006, the American Heart Association Council on Nutrition, Physical Activity and Metabolism published a scientific statement indicating that schools should increase their efforts in promoting physical activity among youth (Pate et al, 2006). The paper discussed findings from schoolbased intervention reviews and presented recommendations for schools to adopt policies and practices to increase physical activity opportunities for children and adolescents. According to the document "schools need to renew and expand their role in providing and promoting physical activity for our nation's young people" (Pate et al., 2006, p.121). In 2008, the National Association for Sports and Physical Education (NASPE) released a position statement calling all P-12 schools to implement a Comprehensive School Physical Activity Program (CSPAP) and expand the physical activity opportunities in the school setting in order to help children and adolescents meet the recommended 60 minutes of daily physical activity (National Association for Sports and Physical Education [NASPE], 2008). Similarly, the National Physical Activity Plan, released in 2010, included specific strategies for the education sector to foster physical activity promotion. Among these strategies is the establishment of comprehensive physical 
activity initiatives in the school setting founded on quality physical education programs (Pate, 2009). In 2011, the CDC released a comprehensive set of guidelines for schools to plan and implement initiatives aimed at improving dietary and physical activity habits of children and adolescents. The document was developed based on the scientific literature regarding best practices in the areas of nutrition and physical activity and, in accordance with the NASPE position statement on CSPAP (NASPE, 2008), recommended that schools adopt a comprehensive approach to physical activity programing and include various opportunities for youth to be active before, during, and after school day as well as opportunities for families, staff and community involvement (CDC, 2011b). The CSPAP position statement released by NASPE in 2008 was recently revised and published by the American Association for Health, Physical Education, Recreation, and Dance (AAHPERD) reinforcing the notion that schools play a key role in fostering active lifestyles among young people (American Association for Health, Physical Education, Recreation, and Dance [AAHPERD], 2013).

\section{Comprehensive School Physical Activity Programs}

The concept of comprehensive approaches to physical activity in the school setting is a result of several studies and recommendations published by various public, educational and health-related organizations indicating that schools are the optimal environment for physical activity promotion among youth (Kulinna, 2013). The main goal of CSPAP is to maximize the physical activity opportunities offered in the school setting for children and adolescents in order to help them meet the recommended 60 minutes of daily physical activity. According to AAHPERD (2013) Comprehensive School Physical Activity Programs are defined as:

a systematic approach by which schools use all opportunities for school-based physical activity to develop physically educated students who participate in the nationally recommended 60-plus minutes of physical activity each day and who develop the knowledge, skills and confidence to be physically active for a lifetime (AAHPERD, 2013, p.3).

Comprehensive school physical activity programs recognize that physical activity behavior is influenced by individual, social, and environmental factors and aim to address those influences trough 
multi-component approaches. The five components included in CSPAP are: (a) high-quality physical education, (b) physical activity during school, (c) physical activity before and after school, (c) staff involvement, and (d) family and community engagement (AAHPERD, 2013). These components represent the opportunities that different levels of influence on physical activity behavior can be addressed in the school setting as indicated by ecological approaches such as the Youth Physical Activity Promotion model (Welk, 1999). For example, enabling factors such as access to physical activity programs can be addressed through the establishment of before and after school physical activity clubs allowing for students access to assorted physical activity opportunities with minimal cost and no transportation issues (Beets, Beighle, Erwin, \& Huberty, 2009). Also, the school physical environment can be changed in order to facilitate physical activity engagement through the establishment of recess areas, safe playgrounds, and provision of sports and physical activity equipment (Sallis et al., 2001).

In the same manner, predisposing factors such as perceived competence and enjoyment can be approached through the enhancement of quality physical education programs in which students engage in meaningful and enjoyable activities and develop the motor skills and knowledge needed to participate in various sports and physical activities (Wallhead \& Buckworth, 2004). In regard to reinforcing factors, parents and siblings influence on physical activity can be addressed through the establishment of physical activity programs that are extended to family members such as family night activities, group fitness lessons, and health and wellness seminars (NASPE, 2008). Another reinforcing factor of youth physical activity that might be approached through CSPAP is the involvement of coaches and physical education teachers through the provision of continuous professional training as well as wellness opportunities for staff. The following sections will present a more detailed discussion of each the five components.

High-quality physical education. High-quality physical education is the foundation of CSPAP because it is in physical education that students receive movement-related instruction that results in the acquisition of the "knowledge, skills, and confidence" necessary to engage in various types of sports and physical activities (AHHPERD, 2013, p. 3). Physical education is an established element of the U.S. educational system and, as a curricular discipline it has the potential to reach more young people than any 
other type of structured physical activity program (Sallis et al., 2012). When the CSPAP position statement was first published in 2008, NASPE proposed that quality physical education programs include daily physical education, standards-based curriculum, student assessment, certified physical education teachers, class sizes equivalent to other disciplines, and appropriate equipment (NASPE, 2008). The recently reviewed CSPAP position statement emphasizes the relevance of physical education as the cornerstone of CSPAP and indicates that high-quality physical education programs should: (a) follow a curriculum based on state and/or national standards for physical education; (b) incorporate MVPA during at least 50 percent of the class period; (c) provide students with motor skills development; (d) adopt developmentally appropriate instructional practices; and (e) aim to meet the physical, cognitive, and social/emotional needs of the diverse population of students (AAHPERD, 2013). The main difference between the 2008 and the 2013 CSPAP position statements in regard to quality physical education is the emphasis on having students engaged in MVPA at least $50 \%$ of the class time. However, it is important to note that engagement in MVPA during PE classes should not happen at the expense of skill development because it is in physical education that students should receive instruction that will ultimately result in the development of motor capabilities (AAHPERD, 2013). Furthermore, there is agreement in the literature that quality physical education should offer students ample opportunities to learn through meaningful content and appropriate instruction (NASPE, 2008). Meaningful content refers to physical activities that are challenging and relevant for the students as they foster the development of motor, cognitive, and affective competencies associated with several types of physical activity (Pagnano, 2006). Appropriate instruction refers to practices that are designed to maximize students learning, independent of their abilities and background (Rink, 2003). Hence, quality physical education plays a critical role in school-based physical activity initiatives because of its instructional nature and ultimate goals of providing youth with the competences and dispositions needed for physically activity lifestyles. A more detailed discussion of the importance of physical education for CSPAP will be further presented in this literature review. 
Physical activity during school. Given the reduced time allocated to physical education in the overall school curriculum, it has been argued that schools should strive to provide other opportunities for youth to be active during the school day. These opportunities include, but are not limited to physical activity breaks during other subject matter classes, daily recess, and establishment of physical activity clubs or intramural sport competitions during recess (NASPE, 2008). However, the inclusion of physical activity opportunities during the day is not meant to replace physical education, rather to be an extension of quality physical education programs in which students have further opportunities to be active while in the school environment (AAHPERD, 2013). As a result of the growing advocacy for extended physical activity during the school day, researchers have been examining if these initiatives have an effect on children's physical activity. Several school-based interventions have placed their efforts in designing programs aimed at providing classroom teachers with instructional materials to implement short physical activity breaks during their lessons. Studies that investigated the effects of these types of programs on children's levels of physical activity have found positive results especially at the elementary school level (Bershwinger \& Brusseau, 2012; Kibbe et al, 2011). Similar, studies that investigated the effects of recess time on youth physical activity have provided some evidence that recess can favor increased levels of physical activity. A review of studies that examined school-based interventions directed at increasing or improving recess time was recently published by Ickes, Erwin, and Beighle (2013). The authors concluded that physical activity levels were enhanced across the majority of the studies and that strategies for physical activity promotion were quite varied among the interventions such as the redesign of playgrounds, provision of physical activity equipment and supervision (Ickes, Erwin, \& Beighle, 2013). The majority of studies that examined the effects of recess on physical activity were conducted at the elementary school level like the studies related to classroom physical activity breaks. This suggests that recess and classroom breaks initiatives might be more effective to promote physical activity among younger children.

A common approach to increasing physical activity opportunities during the school day at the middle and high school levels is the establishment of intramural sports competition. Intramural sports 
have been appointed as an alternative for youth sports in school which are focused on interscholastic competition and often limited to highly-skilled students (Kanters, Bocarro, Casper, \& Forrester, 2008). Although research on the effects of intramural sport competitions on youth physical activity is scarce, AAHPERD (2013) recommends that CSPAP adopt intramural sports programs as a means to promote physical activity during the school day, specifically, during lunch time. Moreover, it has been recommended that intramural team sports competitions are developed in alignment with the physical education objectives and content in order to foster greater participation (Hamilton \& Valerius, 2002). Another possible strategy to increase middle schools physical activity during the school day is the establishment of innovative physical activity clubs that meet during lunch time or recess and include alternative types of physical activity rather than team sports (e.g., walking, dance, martial arts, biking) since these types of activities might be suitable and attractive for students who are not interested or not skilled to join competitive team sports (Hamilton \& Valerius, 2002).

Physical activity before and after school. Physical activity opportunities offered in the school setting before and after the regular school hours have been indicated as a promising strategy to increase physical activity among children and adolescents. Before and after school physical activity opportunities include but are not limited to physical activity clubs, interscholastic sports, active transport programs, and youth sports programming (AHHPERD, 2013). According to the Afterschool Alliance (2009) it is estimated that over eight million K-12 children participate in afterschool programs in the U.S. and an additional 18 million would participate if these types of programs were offered in their schools (Afterschool Alliance, 2009). Before and after-school physical activity programs do not take away time from the school day and have been suggested to be a plausible solution for the reduction of time devoted to physical activity during the school day due to increased demands for academic achievement (Trost, Rosenkratnz, \& Dzewaltowski, 2008). However, studies examining the effects of before and after school programs on youth physical activity have not yet indicated evidence that these programs can improve physical activity levels on youth physical activity (Atkin, Gorely, Biddle, Cavill, \& Foster, 2011; Beets, Huberty, \& Beighle, 2012). Nevertheless, since research on before and after school physical activity 
programs is relatively new it has been reasoned that future studies are needed in order to investigate the effects of these initiatives on youth physical activity (Beets et al., 2012).

Staff involvement. The AAHPERD (2013) position statement on CSPAP proposes that staff should be involved in the school efforts to promote physical activity among students (AAHPERD, 2013). Specifically, AHHPERD recommends that CSPAP include opportunities for teachers and other school staff to be active in the school setting. The rationale behind this recommendation is that teachers and staff who participate in physical activity programming within the school grounds might act as role models for the students and engage in the process of delivering or supervising activities (NASPE, 2008). Since staff involvement in school-based physical activity initiatives is an emerging concept, few studies have examined the effect of this component of CSPAP on youth physical activity. Huberty, Beets, Beighle, and Mckenzie (2013) examined the influences of staff involvement in after school programs on children's physical activity participation. In this particular initiative staff was trained to deliver the after school program which consisted of academic and sports-related activities. The findings reported by the authors showed that certain staff behaviors such as encouragement positively influenced children's levels of MVPA, suggesting that involving school staff in physical activity opportunities might contribute to the effectiveness of school-based physical activity programming (Huberty, Beets, Beighle, \& Mckenzie, 2013).

Family and community involvement. The idea of engaging family and community members in school-based interventions is based on the extensive body of research indicating the influence of social relations on physical activity behavior (NASPE, 2008). Family involvement includes the establishment of opportunities for family members to participate in physical activity with students in the school setting, whereas community involvement refers to the establishment of partnerships with the community in order to increase physical activity opportunities for students in and outside of the school (AAHPERD, 2013). Although there is a consensus that school-based initiatives targeting family and community involvement is a promising approach to increasing physical activity among youth, it has been suggested that 
community and family engagement is the least commonly implemented and researched element of CSPAP (Cipriani, Richardson, \& Roberts, 2012).

\section{Review of School-based Physical Activity Interventions}

Since the concept of CSPAP program is a recent approach to increasing physical activity opportunities for youth in the school setting, research examining the effect of CSPAP with all its components on children's and adolescents' physical activity behavior is still in its early stages.

Nonetheless, several school-based initiatives have implemented one or more of the five components present in CSPAP as their strategy for changing youth physical activity habits. In fact, because schools have been identified as key setting for the promotion of physical activity among youth, the number of school-based physical activity interventions has grown significantly over the past 20 years (Trost \& Loprinzi, 2008). As a result, several studies have been conducted in order to examine the effectiveness of such programs and their findings provide valuable insights about the impact of school-based physical activity initiatives on youth physical activity behavior.

Early, in 2001 Ringuet and Trost published a review of studies that had examined school, home, and community physical activity interventions targeting children and adolescents. Ten studies were analyzed and the authors concluded that physical activity interventions directed at youth resulted in moderate increases in physical activity levels among children and adolescents. Ringuet and Trost also indicated that school-based interventions had significant greater effect sizes on youth physical activity behavior than home- and community-based initiatives, suggesting that interventions focusing on increasing the amount of physical activity in the school setting could possibly be more effective (Ringuet \& Trost, 2001). In 2004, Wallhead and Buckworth reviewed and summarized the findings of seven large-scale physical activity school-based interventions that had focused on the enhancement of physical education programs. According to the authors, the majority of the reviewed initiatives were effective in increasing the amount of physical activity during physical education classes, but not to enhance physical activity levels outside of the school setting (Wallhead \& Buckworth, 2004). Similar conclusions were reported by Trost and Loprinzi (2008) who reviewed physical activity interventions aimed at increasing 
physical activity among children and adolescents in schools, homes and health care settings with the purpose of bringing attention to what was viewed as promising strategies for promoting physical activity among youth. In regard to school-based interventions, the authors concluded that making changes in the physical education program can significantly increase the percentage of class time spent in MVPA (Trost \& Loprinzi, 2008). Among the recommendations for school-based physical activity initiatives presented by Trost and Loprinzi were: (a) establish professional development opportunities for physical education teachers, (b) expand the scope of activities offered during physical education classes, and (c) include behavioral skills such as self-monitoring and goal setting in the physical education program (Trost \& Loprinzi, 2008).

Van Sluijs, McMinn, and Griffin (2008) conducted a comprehensive review of physical activity interventions targeting children and adolescents in order to search for evidence related to the promotion of physical activity among youth. The authors reviewed 33 studies targeting children and 24 studies aimed at adolescents which were conducted at multiple settings. Specifically, 27 studies targeting children and 14 studies aimed at adolescents were conducted in the school environment. According to the authors, the reviewed school-based interventions were able to enhance the time students engaged in MVPA within the school hours. Furthermore, Van Sluijs et al. (2008) concluded that stronger evidence was found in the interventions that included a family or community-related component in its structure suggesting that ecological models might be a promising approach for interventions aiming at physical activity behavior change in schools.

In 2009 the Cochrane Collaboration published one of the most comprehensive review of studies that examined school-based interventions. In contrast to previous reviews, this paper only addressed physical activity initiatives carried-on in the school setting (Dobbins, De Corby, Robeson, Hussin, \& Tirilis, 2009). The authors examined 26 studies that evaluated the effects of school-based programs on children and adolescents' levels of physical activity. Similar to the previous reviews, the authors concluded that there is acceptable evidence that school-based physical activity interventions were effective in increasing levels of physical activity within the school hours but not during leisure time. In 
addition, findings from this review indicated that no evidence was found in regards to the effects of school-based interventions on physiological changes such as reduction of body fat, and improvements in blood pressure or blood lipids (Dobbins et al., 2009). Some of the recommendations for school-based physical activity programming addressed as a result of this review were: (a) focus on developing positive attitudes towards participation in physical activity, (b) encourage teachers and staff to act as role models by providing them with physical activity opportunities during the school day, and (c) involve parents and other family members in physical activity opportunities (Dobbins et al., 2009).

Kriemler et al. (2011) summarized four comprehensive literature reviews of school-based interventions aimed at increasing physical activity in youth conducted prior to 2007 . Their conclusions suggested that although an agreement had been established in regard to the effects of school-based initiatives on enhancements levels of physical activity during school hours, a lack of information about effective strategies used by these interventions remains (Kriemler et al., 2011). Kriemler et al. also included 20 other studies in their review which were conducted after 2007. Results of this additional review supported previous findings indicating that generally school-based physical activity interventions were effective to increase physical activity during school hours but increases in out-of school physical activity were not observed. Furthermore, similar to Van Sluijs et al., (2008) the authors suggested that interventions adopting a multicomponent approach that included a family or community element in its structure presented stronger results (Kriemler et al., 2011).

One of the most recent review examining interventions targeting youth physical activity in the school setting was published by Demetriou and Höner in 2012. One hundred and twenty nine studies were reviewed and the authors looked for effects of school-based initiatives on levels of physical activity, fitness outcomes, and psychological determinants of physical activity. The results indicated that the greatest impact of the reviewed studies was on physical activity levels, confirming previous findings. Positive effects were also observed in increased knowledge of health and physical activity as well as improved components of physical fitness (Demetriou \& Höner, 2012). Kulinna, Brusseau, Cothran, and Tudor-Locke (2012) examined the effects of four school-based interventions on elementary school 
students' physical activity levels. The uniqueness of this study is that it examined interventions that were designed from bottom-up, meaning that the school personnel and physical education teachers developed the initiatives and selected its elements. Each intervention was funded by a one-year grant and their components and strategies were chosen by each school based on the needs of the students, teachers, and the school. All four interventions addressed more than one level of influence on physical activity behavior. Among the components were: professional development, equipment purchase, recess structure, curriculum changes, schedule modifications, and collaboration with classroom teachers (Kulinna, Brusseau, Cothran, \& Tudor-Locke, 2012). Data were collected from 616 students enrolled in four different schools using pedometers. The results showed that three out of the four interventions produced an increase in daily school physical activity. The authors concluded that individually tailored interventions, designed by the school personnel and physical education teachers, addressing more than one level of behavior influence have the potential to foster increased physical activity levels in youth (Kulinna, et al., 2012).

The findings presented by these reviews show that schools are an optimal site for the implementation of physical activity interventions directed at promoting active lifestyles among children and adolescents. In addition, it appears that multicomponent initiatives which address more than one level of influence on physical activity behavior have greater chances to succeed given the complexity of the variables that account for youth physical activity participation. Nevertheless, it is important to highlight that most of the increases in youth physical activity achieved by the school-based interventions analyzed through the aforementioned reviews occurred in physical education (Kulinna, et al., 2012; Trost \& Loprinzi, 2008; Wallhead \& Buckworth, 2004). Hence, it can be inferred that physical education remains the primary setting for physical activity promotion among youth mainly because physical education is a curricular discipline, mandated in a majority of the states so therefore, has the potential to reach greater number of children and adolescents (Sallis et al., 2012). 


\section{Physical Education as the Foundation of School-Based Physical Activity Programming}

Multiple guidelines, recommendations, policies, and campaigns have been released during the last twenty years with the purpose of supporting school-based physical education as a critical component of physical activity promotion in the school setting (Sallis et al., 2012). Physical education plays a major role in creating active habits among children and adolescents and it has been designated as the cornerstone of CSPAP (AAHPERD, 2013). The main purpose of physical education is to provide children and adolescents with the knowledge, skills, dispositions, and confidence needed to engage in a variety of physical activities for a lifetime (AAHPERD, 2013). In other words, as a result of quality physical education programs individuals should have developed the necessary competencies to participate in physical activity and maintain an active lifestyle. According to the National Standards for Physical Education (NASPE, 2004), a physically educated individual: has motor competencies needed to participate in various activities; understands concepts and principles related to physical activity performance; engages frequently in physical activity; achieves adequate levels of physical fitness; participates in physical activity settings with respect, and values physical activity (NASPE, 2004). Since physical education is a curricular subject, mandated in more than $70 \%$ of the sates (NASPE \& American Heart Association [AHA], 2012), it has the potential to reach more children and adolescents than any other type of physical activity programming within our outside of the school setting (Sallis et al., 2012; Trost, 2004). Consequently, several school-based physical activity initiatives have focused specifically on enhancing the quality of physical education programs through professional training, curriculum development, inclusion of new activities in the program, equipment acquisition, and increased physical education allocated time.

To date, the most researched and disseminated school-based intervention focusing on the physical education program is Sport Play and Active Recreation for Kids (SPARK) (McKenzie, Sallis, \& Rosengard, 2009). SPARK was initiated in the late 80s through a large grant from the National Institutes of Health (NIH) awarded to researchers at San Diego University to plan, implement, and evaluate a physical education curriculum designed to increase levels of MVPA during physical education classes at the elementary school level. The curriculum was developed as a ready-to-use tool for physical education 
and classroom teachers and included several instructional units which focused on motor skills development and health-related physical fitness enhancement (McKenzie et al., 2009). In addition, SPARK provided teachers with professional training with the purpose of helping them to understand, value, and implement the curriculum. Initial research on the SPARK program was conducted through controlled trial studies and resulted in several publications reporting positive effects of SPARK on the amount of MVPA during physical education classes, enhanced motor skills and fitness, and academic performance (Dowda, Sallis, McKenzie, Rosengard, \& Kohl, 2005). Given the positive results presented by the research done on the SPARK curriculum, the program became available to physical educators in the U.S. through an educational company which began to commercialize the SPARK curriculum in 2002. The SPARK curriculum has been expanded to include pre-school and middle and high school levels but studies examining the effects of SPARK on these grade levels have yet to be conducted (McKenzie et al., 2009). The SPARK curriculum has made a significant contribution to the physical education field because it was the first physical education curriculum to be largely researched and disseminated in the country as an evidence-based practice. The positive effects of the SPARK curriculum on children's physical activity behavior support the idea that quality physical education is possibly the most reasonable avenue to increase levels of physical activity among youth during the school hours.

Similar to SPARK, another large intervention targeting physical education that has been widely disseminated is Middle School Physical Activity and Nutrition (M-SPAN) (McKenzie et al., 2004). The focus of M-SPAN was also to increase the quality of physical education programs but its main strategy was the establishment of professional development initiatives rather than the introduction of a new curriculum. The main goals of these professional development initiatives were to raise teachers' awareness of the need for increased MVPA during physical education classes and to provide teachers with resources to increase in class students' engagement in MVPA (McKenzie et al., 2004). The MSPAN program was implemented in 24 middle schools in California over a 2-year period and researchers conducted class observations in order to examine the intervention effectiveness on increasing the percentage of MVPA in physical education classes. Approximately 1,800 physical education lessons 
were observed through a systematic observation instrument (i.e., SOFIT) designed to measure students' activity levels during physical education. The results indicated that the M-SPAN intervention resulted in significant increases in the overall time students spent in MVPA with large effect sizes for boys and moderate effect sizes for girls (McKenzie et al., 2004). The M-SPAN study results implied that professional development is a relevant element for the enhancement of the quality of physical education programs because teachers are ultimately the changing agents in these types of interventions. According to McKenzie et al. (2004), it is important that teachers "buy into" the purpose, strategies, and concepts of a specific intervention before they actually implement it so they become fully engaged in the process.

Another widely disseminated school-based physical activity intervention that had a specific physical education component was the Child and Adolescent Trial for Cardiovascular Health (CATCH) (McKenzie et al., 2003). The physical education piece of CATCH consisted of the implementation of a physical education curriculum and professional development sessions for physical education and classroom teachers (McKenzie et al., 2003). The CATCH intervention was implemented in 96 elementary schools over a 3-year period with the intent of enhancing their physical education programs and increasing levels of MVPA during physical education. After baseline data collection, the schools were randomly assigned to either the intervention and control groups. The intervention schools received standardized intervention materials including a physical education curriculum, physical education equipment, and a series of professional training workshops. Similar to the M-SPAN study, in the CATCH study over 2,000 physical education lessons were systematically observed across the 96 schools and results indicate that intervention schools had greater increases in MVPA during physical education than the control schools (McKenzie et al., 1996; McKenzie et al., 2003).

The aforementioned interventions focused on enhancing the quality of physical education programs in order to provide students with higher amounts of MVPA during physical education classes. The common strategies used by SPARK, M-SPAN, and CATCH were the adoption or revision of physical education curriculums and the establishment of continuous professional development programs. These studies have been critical for the understanding of the effects of quality physical education 
programs on youths' achievement of the recommended 60 minutes of daily physical activity.

Nonetheless, questions related to the effects of these programs on students' attitudes towards physical education and physical activity as well as their engagement in sports and physical activity outside of the school environment remain (Wallhead \& Buckworth, 2004). Since the main goal of physical education is to prepare youth for a lifetime of physical activity engagement it is important that interventions focusing on enhancing the quality of physical education programs consider their impact on children's and adolescents' attitudes towards physical activity. According to Barney and Deutsch (2009), there is agreement in the literature suggesting that positive attitudes towards physical activity are associated with active lifestyles and that quality PE programs can foster or hinder the development of positive attitudes towards physical activity.

Although quality physical education is the core of CSPAP, the percentage of students who participate in physical education, particularly in the middle and high school levels have been decreasing over the past years due to low enrollment and reduced allocated time for physical education (NASPE \& AHA, 2012). Hence, it has been argued that initiatives aiming at improving the quality of physical education programs can no longer focus solely on increasing MVPA during PE classes (Wallhead \& Buckworth, 2004). Rather, efforts should be made towards designing physical education programs that are connected to the other components of CSPAP and aim to promote the development the competencies and dispositions necessary to engage in physical activity opportunities in and outside of the school setting.

Current status of school physical education in the U.S. According to NASPE (2008) middle and high school students should receive 225 minutes of physical education per week while elementary school students should receive a minimum of 150 minutes of physical education instruction each week. In 2012, NASPE and the American Heart Association [AHA] published a report providing an updated picture of physical education in the U.S. educational system titled The Shape of the Nation (NASPE \& AHA, 2012). According to the report, physical education is mandated in the majority of the states. At the elementary level, physical education is mandated in $84.3 \%$ of the states while in the middle and high 
school levels physical education is mandated in $80.4 \%$ and $86.3 \%$ of the sates respectively (NASPE \& AHA, 2012). However, the report indicates that most of the states do not establish requirements for the amount of physical education instruction and more than $50 \%$ of the states allow course substitutions, waivers, and exemptions from physical education (NASPE \& AHA, 2012). Unfortunately, time allocated for physical education has diminished in schools across the country over the past ten years due to the No Child Left Behind (NCLB) requirements for academic performance (Filburn \& Fletcher, 2008). Data from a study on the impact of the NCLB act showed that most districts that increased time in math and language arts reported significant cuts in allocated time from other subject matters including science, social studies, arts, music, and physical education (McMurrey, 2008). This is problematic because despite the increased advocacy and support for physical education as a public health contributor, time designated for physical education remains a constraint, particularly in the middle and high school setting.

Physical education in the middle school setting. There is consensus in the literature that physical activity levels in youth decline as age increases and that engagement in physical activity decreases as children transition from the elementary into the middle school level (Belcher et al., 2010; Wallhead \& Buckworth, 2004). Although several initiatives have been successful at increasing levels of physical activity among middle school students within the school setting (McKenzie et al., 2003; McKenzie et al., 2004; Jago et al., 2009) it has been argued that physical education programs at the middle school level are inadequate and have not been successful at meeting the physical, cognitive, and affective needs of youth who are transitioning from childhood into adolescence (McKenzie, 2001; Placek, 1992). One of the greatest challenges faced by physical education programs at the middle school level is to maintain students motivated and engaged and it has been suggested that traditional curriculum models might contribute to students' disengagement (Garn, Cothran, \& Jenkins, 2011). The most common approach to middle school physical education programming has been the multi-activity curriculum, in which students are usually presented with various team sports and are expected to successfully participate in full-sided games such as basketball, volleyball, soccer, flag football, among others (Ennis, 1999; Kirk, 2004). This approach has been indicated as problematic for several reasons (Garn et al., 2011). First, 
team sports units are often delivered in short periods of time and are oriented towards full-sided games. This type of structure allows limited time for skill development and understanding of game strategies, two important pre-requisites for successful participation in team sports (Mohr, Towsend, \& Pritchard, 2006). Middle school students' level of motor competency is often widely varied as a result of their previous physical activity experiences and developmental characteristics. Consequently, students who have higher levels of motor competency have more opportunities to participate in team sports and often dominate the games (Bernstein, Philips, \& Silverman, 2011). Participation in team sports without a considerable level of skill development is usually a frustrating experience that can negatively impact the individuals' perceptions of self-competence and activity enjoyment (Bernstein et al., 2011). Therefore, since these factors have been associated with youths' engagement in physical activity, physical education programs focused on team sports might prevent the development of positive attitudes towards physical activity, and can negatively influence the establishment of future physical activity habits (Bernstein et al., 2011; Mohr et al., 2006).

Another problem related to multi-activity physical education programs is the fact that team sports are not usually the type of physical activities that adults choose. Typically, adults engage in individual or dual physical activities for the purposes of leisure, health, and social interactions (Mohr et al., 2006). These activities, often called lifetime activities include but are not limited to cycling, swimming, golf, hiking, tennis, badminton, yoga, aerobics, jogging, kayaking, among several others (McCracken, 2001). Therefore, if middle school students are only exposed to team sports in physical education and do not have opportunities to acquire the abilities necessary to engage in other types of physical activities that can be carried out for a lifetime their possibilities for becoming active adults become limited (Rikard \& Woods, 1993).

Garn, Cothran, and Jenkins (2011) recently conducted a qualitative study to examine middle school students' interest in physical education in a program that followed a multi-activity curriculum. Eight students participated in the study and qualitative data were collected through interviews and field observations. The findings supported the aforementioned problems related to multi-activity curriculums. 
According to the authors the multi-activity curriculum negatively influenced the interest in physical education for students who were low-skilled or perceived themselves as low-skilled. Also, the students reported that minimum opportunities to participate and develop skills during physical education classes contributed to their lack of interest in physical education and in the activities presented in the curriculum (Garn et al., 2011). Although the data were collected from a small sample of students ( $n=8)$, field observations were conducted during 18 weeks and the study findings seems to be in accordance with the literature criticizing multi-activity approaches in physical education.

Barney and Deutsch (2009) found contradictory results when they examined the effects of a middle school physical education curriculum on students' attitudes related to PE. Participants were 227 students in grades sixth to eighth enrolled physical education in a Midwestern city. According to the authors, the investigated school was considered to have an excellent physical education program because of its low absence rates and its multi-activity format. Barney and Deutsch used the Physical Education Interest Questionnaire as well as interviews to collect data related to students' attitudes towards physical education. The authors concluded that students had a favorable attitude towards their physical education program and its multi-activity curriculum because the activities were considered fun and preferable over fitness-oriented tasks (Barney and Deutsch, 2009). However, the study presents a series of limitations. First, attendance and variety of activities is not a strong rationale to credit excellence to a physical education program. Other characteristics such as accountability, allocated time, quality of instruction, and available equipment and facilities are heavy indicators of physical education quality and were not discussed by Barney and Deutsch. Second, the authors did not indicate which percentage of the school population the 227 participants accounted for leaving room for questions related to the how well the sample represented the population under study. Third, data collected through the interviews were not fully discussed in the study and findings were mostly based on the survey results. Finally, the multiactivity model was compared with fitness-oriented tasks which have also been appointed as an inappropriate practice to foster positive attitudes towards physical activity among middle schools students (McKenzie, 2001). Although the findings of this study contradict the idea that multi-activity curriculums 
are not the ideal approach for physical education at the middle school level, there is a consensus in the literature arguing that multi-activity models are inadequate to prepare young adolescents to participate in physical activity for a lifetime and should be replaced by alternative curriculum models (Bulger \& Housner, 2009; Ennis, 1999; McCracker, 2001; Mohr et al., 2006)

The ultimate purpose of physical education is to enable individuals to become physically educated and gain the capabilities and dispositions needed to participate in various physical activities for a lifetime (NASPE, 2008). Hence, it has been argued that an important step for physical education to reach this mission at the middle and high school levels is a curriculum reform (Ennis, 1999; Rikard \& Woods, 1993). McKenzie (2001) discussed the importance of promoting physical activity within the middle school setting given the reported decline in physical activity levels among adolescents. McKenzie provided a series of recommendations for schools to increase physical activity among middle school students and in his words, "reaching this goal would require the implementation of curricular and instructional strategies that are substantially different from those provided in traditional fitness and sportoriented programs" (McKenzie, 2001, p. 331).

Over the past thirty years much had been discussed about what constitutes an adequate middle school physical education curriculum. The debate regarding what kind of physical education curriculum is the ideal model for middle school students revolves mainly around the different perspectives associated to the physical education objectives at the middle school level. As a result, different curriculum models and approaches have been designed, implemented, and evaluated based on the distinct objectives that have been attributed to middle school physical education. The M-SPAN and SPARK curriculums were designed as an attempt to meet the health-related objectives of physical education, particularly, the increase of MVPA during physical education class (McKenzie, 2009). The Sports Education model, proposed by Siedentop (2002) was designed to meet both psychomotor as well as cognitive objectives related to sports participation, such as skill development and literacy related to the full context of specific sports. Hellison and Walsh (2002) proposed the personal and social responsibility curricular model with the purpose of teaching life and behavioral skills through sports and physical activities. Each of these 
objectives is integrated into the NASPE standards for physical education, with the ultimate goal of preparing physically literate individuals (NASPE, 2004). Hence, the optimum curriculum at the middle school level is one that has the potential to favor the development of physically educated adolescents who have developed the competency and dispositions to seek and participate in a variety of physical activities for a lifetime. In other words, adequate physical education curriculums are based on the national and state standards for physical education and are designed to meet the specific needs of students who are at different physical, cognitive, social and emotional developmental levels as well as to include students who are culturally diverse and have different abilities and backgrounds (Lambert, 2000).

Alternative curriculum models for middle-school physical education. Given the problems associated with traditional approaches for middle school physical education, it has been suggested that physical education curriculums at the middle school level should include activities that are relevant and meaningful for a wide variety of students and not only for just a minority, usually the high-skilled and already active students (Ennis, 1999; McCraken, 2001; Pagnano, 2006). Because individuals who find meaning in physical activities are more likely to seek out active lifestyles, physical education curriculum should incorporate meaningful movement experiences in their structures as a means to promote students' engagement and consequently appreciation for physical activity (Kretchmar, 2000). Chen (1998) explained that meaning in physical education is defined by the students' perceptions of the content's purpose and relevance as well as their responses to it. Consequently, the degree to which students experience meaning in physical education often influences whether they choose to learn the content or simply avoid it (Chen, 1998). According to Kretchmar (2000), meaning in movement experiences happens as a result of the interaction between the individual and the cultural perspectives of physical activity. Thus, the inclusion of meaningful physical activities in the physical education curriculum involves an understanding of the students' individual experiences as well as the cultural significance of movement to specific communities. Furthermore, it is important to highlight that the ultimate purpose of developing innovative physical education curriculum models is to attract students into active lifestyles by 
fostering the discovery of personal and social meaning related to physical activity engagement (Kretchmar, 2000; McCaughtry; 2009).

McCaughtry (2009) criticized traditional approaches to physical education curriculum for not being centered on youth' needs and voices, but rather pathways for skill acquisition, health enhancement, obesity prevention, and other "top-down" objectives. The problem with such approaches is that physical education is often disconnected from students' culture and interests and have not been effective in captivating youth into active lifestyles (McCaughtry, 2009). Ennis (1999) proposed the adoption of a culturally-relevant approach to physical education that is "meaningful and nurturing" (p. 43) and aims to "enhance the engagement and satisfaction of students" (p.33), suggesting that alternative physical education curriculums would take into account the students backgrounds, values, and expectations. Likewise, McCaughtry (2009) suggested the concept of "cool" physical education to describe programs that are centered on students and incorporate meaningful physical activities. In his words, cool physical education happens when students "learn new things, in creative, problem-solving ways, while having fun and socializing with their peers, and while feeling safe physically and emotionally, as well as cared by the teacher" (McCaughtry, 2009, p. 191). This type of innovative approach to physical education, referred to as culturally-relevant by Ennis (1999) or "cool” by McCaughtry (2009) is rooted in the idea that meaningful movement experiences occur when the students' voices are heard and the cultural environment is considered. Therefore, developing student-centered physical education curriculum that include meaningful and relevant activities for children and adolescents requires researchers to gain a deeper understanding of their perspectives related to physical activity and physical education. Obtaining this understanding is particularly important at the middle school level given the decline in physical activity engagement observed when children transition from childhood into adolescence (Garn et al, 2011).

\section{Middle school students' perceptions and experiences related to physical education}

programs. A few studies have been conducted in order to understand middle school students' experiences, thoughts, and feelings related to physical activity and physical education programs. Cox, 
Smith, and Williams (2008) researched the relationship between middle school students' experiences in physical education and engagement in leisure-time physical activity. More specifically, the study was based on the self-determination theory and investigated how motivation-related variables in physical education explained leisure-time activities out of the school setting. The authors concluded that the quality of middle school students' experiences in physical education predicted physical activity engagement out of the school environment. Although limited information was provided about the type of physical education program that participants took part in, the authors indicated that students' enjoyment, perceived competence, and autonomy were found to mediate the relationship between motivation in physical education and physical activity outside of school (Cox, Smith, and Williams, 2008).

Subramaniam and Silverman (2007) conducted a study based on attitude theory to examine the attitudes of 995 middle school students towards their physical education program. According to the authors, the attitude theory proposes that attitude is a construct composed by both cognitive and affective elements. Therefore, the authors used an attitude survey composed of questions related to students' beliefs and feelings about physical education. The results suggested that the sampled students had positive but moderate attitudes about physical education (Subramaniam and Silverman, 2007). However, the authors did not provide any information about the type and quality of the physical education program delivered to the participants, leaving room for questions about what attributes of the programs caused participants to have positive attitudes. In the same way, Patterson and Collins (2012) examined middle school girls' attitudes towards their physical education programs. One hundred middle school girls completed a survey composed of Likert-type and open-ended questions about their attitude towards the physical education program. The results indicated that 92 percent of the students reported a positive attitude towards the program, but similar to Subramaniam and Silverman (2007), Patterson and Collins did not describe the physical education program in which these middle school girls participated.

From a different perspective, Bernstein, Phillips, and Silverman (2011) studied the attitudes and perceptions of middle school students about the inclusion of competitive activities in physical education with the purpose of gaining understanding of the students' feelings and experiences related to activities 
focused on competition. The study was conducted in six different schools that used the multi-activity approach aforementioned for their physical education curriculum. Qualitative data were collected through focus groups and field observations. The findings presented by the authors supported some of the criticism related to multi-activity approaches in physical education. Although the students mentioned enjoying competitive activities, many of them expressed the desire for more skill development opportunities. Also, the degree to which students reported enjoying competitive actives was associated with their experiences in those activities. Students who were successful and had more opportunities to participate reported higher degrees of enjoyment than the students who had less success and engagement opportunities (Bernstein et al, 2011). These findings suggest that competition in physical education might be a positive approach to physical education if associated with skill development opportunities and successful experiences. Similar, Garn et al., (2011) used a mixed methods approach to examine middle school students' interest in physical education. Participants were eight middle school students and data were collected through field observations and an interest survey. The observed physical education program followed a multi-activity curriculum model and findings indicated that participation opportunities and perceived competence were the factors mostly related to students' interest in physical education supporting Bernstein et al. (2011) conclusions. According to Garn et al. (2011), further studies should be carried to investigate how alternative physical education curriculums, designed to enhance the engagement and success of all students, influence middle school students interest, attitudes and perceptions of physical activity and physical education programs. 


\section{References}

Ahn, S., \& Fedewa, A. L. (2011). A meta-analysis of the relationship between children's physical activity and mental health. Journal of Pediatric Psychology, 36(4), 385-397. doi:10.1093/jpepsy/jsq107

Afterschool Alliance (2009). America after 3 pm: A household survey on after school in America. Retrieved from http://www.afterschoolalliance.org/documents/AA3PM_Key_Findings_2009.pdf

American Alliance for Health, Physical Education, Recreation and Dance. (2013). Comprehensive school physical activity programs: Helping students achieve 60 minutes of physical activity each day [Position statement]. Reston, VA: Author. Retrieved from http://www.aahperd.org/naspe/standards/upload/CSPAP-Final-7-22-13-2.pdf

Astrup, A., Hill, J. O., \& Rössner, S. (2004). The cause of obesity: Are we barking up the wrong tree? Obesity Reviews, 5(3) pp. 125-127. doi: 10.1111/j.1467-789X.2004.00143.x

Atkin, A., Gorely, T., Biddle, S., Cavill, N., \& Foster, C. (2011). Interventions to promote physical activity in young people conducted in the hours immediately after school: A systematic review. International Journal of Behavioral Medicine, 18(3), 176-187. doi:10.1007/s12529-010-9111-z

Baker, B. L., \& Davison, K. K. (2011). I know I can: A longitudinal examination of precursors and outcomes of perceived athletic competence among adolescent girls. Journal of Physical Activity \& Health, 8(2), 192-199.

Ball, K., Cleland, V. J., Timperio, A. F., Salmon, J., \& Crawford, D. A. (2009). Socioeconomic position and children's physical activity and sedentary behaviors: Longitudinal findings from the CLAN study. Journal of Physical Activity \& Health, 6(3), 289-298.

Bandura, A. (1986). The explanatory and predictive scope of self-efficacy theory. Journal of Social and Clinical Psychology, 4(3), 359-373. doi:10.1521/jscp.1986.4.3.359

Barney, D., \& Deutsch, J. (2009). The effect of middle school physical education curriculum on student attitudes. Asian Journal of Physical Education \& Recreation, 15(1), 12-20. 
Bauman, A. E., Sallis, J. F., Dzewaltowski, D. A., \& Owen, N. (2002). Toward a better understanding of the influences on physical activity: The role of determinants, correlates, causal variables, mediators, moderators, and confounders. American Journal of Preventive Medicine, 23(2 Suppl), 5-14.

Beets, M. W., Beighle, A., Erwin, H. E., \& Huberty, J. L. (2009). After-school program impact on physical activity and fitness: A meta-analysis. American Journal of Preventive Medicine, 36(6), 527-537. doi:10.1016/j.amepre.2009.01.033

Beets, M. W., Huberty, J., \& Beighle, A. (2012). Physical activity of children attending afterschool programs: Research- and practice-based implications. American Journal of Preventive Medicine, 42(2), 180-184. doi:10.1016/j.amepre.2011.10.007

Bélanger, M., Gray-Donald, K., O’Loughlin, J., Paradis, G., \& Hanley, J. (2009). When adolescents drop the ball: Sustainability of physical activity in youth. American Journal of Preventive Medicine, 37(1), 41-49. doi:10.1016/j.amepre.2009.04.002

Belcher, B., Berrigan, D., Dodd, K., Emken, B., Chih-Ping Chou, \& Spruijt-Metz, D. (2010). Physical activity in us youth: Effect of race/ethnicity, age, gender, and weight status. Medicine \& Science in Sports \& Exercise, 42(12), 2211-2221. doi:10.1249/MSS.0b013e3181e1fba9

Bernstein, E., Phillips, S. R., \& Silverman, S. (2011). Attitudes and perceptions of middle school students toward competitive activities in physical education. Journal of Teaching in Physical Education, $30(1), 69-83$.

Bershwinger, T., \& Brusseau, T. A. (2012). The impact of classroom activity breaks on the school-day physical activity of rural children. International Journal of Exercise Science, 5(4), 134-143.

Biddle, S. J. H., \& Asare, M. (2011). Physical activity and mental health in children and adolescents: A review of reviews. British Journal of Sports Medicine, 45(11), 886-895. doi:10.1136/bjsports-2011090185

Biddle, S. J. H., Atkin, A. J., Cavill, N., \& Foster, C. (2011). Correlates of physical activity in youth: A review of quantitative systematic reviews. International Review of Sport \& Exercise Psychology, $4(1), 25-49$. 
Biddle, S. J. H., Whitehead, S. H., O’Donovan, T. M., \& Nevill, M. E. (2005). Correlates of participation in physical activity for adolescent girls: A systematic review of recent literature. Journal of Physical Activity \& Health, 2(4), 423-436.

Brown, H., Hume, C., Pearson, N., \& Salmon, J. (2013). A systematic review of intervention effects on potential mediators of children's physical activity. BMC Public Health, 13(165), 1-10. doi:10.1186/1471-2458-13-165

Brustad, R. (1993). Who will go out and play? Parental and psychological influences on children's attraction to physical activity. Pediatric Exercise Science, 5(3), 210-223.

Brustad, R. J. (1996). Attraction to physical activity in urban schoolchildren: Parental socialization and gender influences. Research Quarterly for Exercise and Sport, 67(3), 316-323. doi:10.1080/02701367.1996.10607959

Buckley, C., \& Waring, M. (2009). The evolving nature of grounded theory: Experiential reflections on the potential of the method for analyzing children's attitudes towards physical activity. International Journal of Social Research Methodology: Theory \& Practice, 12(4), 317-334. doi:10.1080/13645570802221198

Bulger, S. M., \& Housner, L. D. (2009). Relocating from easy street: Strategies for moving physical education forward. Quest (00336297), 61(4), 442-469.

Carroll, B., \& Loumidis, J. (2001). Children's perceived competence and enjoyment in physical education and physical activity outside school. European Physical Education Review, 7(1), 24-43. doi:10.1177/1356336X010071005

Carver, A., Timperio, A., Hesketh, K., \& Crawford, D. (2010). Are safety-related features of the road environment associated with smaller declines in physical activity among youth? Journal of Urban Health: Bulletin of The New York Academy Of Medicine, 87(1), 29-43. doi:10.1007/s11524-009$9402-3$

Castelli, D. M., \& Valley, J. A. (2007). Chapter 3: The relationship of physical fitness and motor competence to physical activity. Journal of Teaching in Physical Education, 26(4), 358-374. 
Centers for Disease Control and Prevention. (2011). School Health Guidelines to Promote Healthy Eating and Physical Activity - United States 2010. MMWR 2011; 60 (5).

Centers for Disease Control and Prevention. (2012). Youth Risk Behavior Surveillance - United States, 2011. MMWR 2012; 61(4).

Chen, A. (1998). Meaningfulness in physical education: A description of high school students' conceptions. Journal of Teaching in Physical Education, 17(3), 285-306.

Cheung, P. Y. P., \& Chow, B. C. (2010). Parental mediatory role in children's physical activity participation. Health Education, 110(5), 351-366.

Chomitz, V. R., Aske, D. B., McDonald, J., Cabral, H., \& Hacker, K. A. (2011). The Role of Recreational Spaces in Meeting Physical Activity Recommendations Among Middle School Students. Journal of Physical Activity \& Health, 8, S8-S16.

Cipriani, K., Richardson, C., \& Roberts, G. (2012). Family and community involvement in the comprehensive school physical activity program. Journal of Physical Education, Recreation \& Dance, 83(7), 20-26. doi:10.1080/07303084.2012.10598807

Cleland, V., Dwyer, T., \& Venn, A. (2012). Which domains of childhood physical activity predict physical activity in adulthood? A 20-year prospective tracking study. British Journal of Sports Medicine, 46(8), 595-602.

Cliff, D. P., Okely, A. D., Morgan, P. J., Jones, R. A., \& Steele, J. R. (2010). The impact of child and adolescent obesity treatment interventions on physical activity: A systematic review. Obesity Reviews, 11(7), 516-530.

Cox, A., Smith, A., \& Williams, L. (2008). Change in physical education motivation and physical activity behavior during middle school. Journal of Adolescent Health, 43(5), 506-513.

Craggs, C., Corder, K., van Sluijs, E. M. F., \& Griffin, S. J. (2011). Determinants of change in physical activity in children and adolescents: A systematic review. American Journal of Preventive Medicine, 40(6), 645-658. doi:10.1016/j.amepre.2011.02.025 
Creswell, J. W. (2009). Research design: Qualitative, quantitative, and mixed methods approaches.

Thousand Oaks, CA: Sage Publications.

Crimi, K., Hensley, L. D., \& Finn, K. J. (2009). Psychosocial correlates of physical activity in children and adolescents in a rural community setting. International Journal of Exercise Science, 2(4), 230242.

Darbyshire, P., MacDougall, C., \& Schiller, W. (2005). Multiple methods in qualitative research with children: More insight or just more? Qualitative Research, 5(4), 417-436. doi:10.1177/1468794105056921

Davison, K. K. (2004). Activity-related support from parents, peers and siblings and adolescents' physical activity: Are there gender differences? Journal of Physical Activity \& Health, 1(4), 363.

Davison, Kirsten K., \& Lawson, C. T. (2006). Do attributes in the physical environment influence children's physical activity? A review of the literature. International Journal of Behavioral Nutrition and Physical Activity, 3(1), 19. doi:10.1186/1479-5868-3-19

Demetriou, Y., \& Höner, O. (2012). Physical activity interventions in the school setting: A systematic review. Psychology of Sport and Exercise, 13(2), 186-196. doi:10.1016/j.psychsport.2011.11.006

Dobbins, M., DeCorby, K., Robeson, P., Husson, H., \& Tirilis, D. (2009). School-based physical activity programs for promoting physical activity and fitness in children and adolescents aged 6-18. In Cochrane Database of Systematic Reviews. John Wiley \& Sons, Ltd. Retrieved from http://onlinelibrary.wiley.com/doi/10.1002/14651858.CD007651

Dowda, M., Sallis, J. F., McKenzie, T. L., Rosengard, P., \& Kohl, H. W. (2005). Evaluating the sustainability of SPARK physical education. Research Quarterly for Exercise and Sport, 76(1), 1119. doi:10.1080/02701367.2005.10599257

Dunton, G. F., Kaplan, J., Wolch, J., Jerrett, M., \& Reynolds, K. D. (2009). Physical environmental correlates of childhood obesity: A systematic review. Obesity Reviews, 10(4), 393-402. doi:10.1111/j.1467-789X.2009.00572.x 
Ennis, C. D. (1999). Creating a culturally relevant curriculum for disengaged girls. Sport, Education \& Society, 4(1), 31-48.

Erpic (Ljubljana Slovenia), S. C. (2013). The role of teachers in promoting students' motivation for physical education and physical activity: A review of the recent literature from a self-determination perspective. International Journal of Physical Education, 50(2), 2-12.

Erwin, H. E., Woods, A. M., Woods, M. K., \& Castelli, D. M. (2007). Chapter 6: Children’s environmental access in relation to motor competence, physical activity, and fitness. Journal of Teaching in Physical Education, 26(4), 404-415.

Filburn, A. D., \& Fletcher, J. S. (2008). NCLB: The next step in the diminishment of physical education and health. Illinois Journal for Health, Physical Education, Recreation \& Dance, 61, 58-60.

Fitzgerald, A., Fitzgerald, N., \& Aherne, C. (2012). Do peers matter? A review of peer and/or friends' influence on physical activity among american adolescents. Journal of Adolescence, 35(4), 941-958.

Gabel, C. P., Osborne, J., \& Burkett, B. (n.d.). The influence of "Slacklining" on quadriceps rehabilitation, activation and intensity. Journal of Science and Medicine in Sport. doi:10.1016/j.jsams.2013.11.007

Garn, A. C., Cothran, D. J., \& Jenkins, J. M. (2011). A qualitative analysis of individual interest in middle school physical education: Perspectives of early-adolescents. Physical Education \& Sport Pedagogy, 16(3), 223-236.

Gay, L. R., Mills, G. E., \& Airasian, P. (2009). Educational research: Competencies for analysis and applications. Upper Saddle River, NJ: Pearson Education.

Giles-Corti, B., \& Donovan, R. J. (2002). Socioeconomic status differences in recreational physical activity levels and real and perceived access to a supportive physical environment. Preventive Medicine, 35(6), 601-611. doi:10.1006/pmed.2002.1115

Glaser, B.G., \& Strauss, A.L. (1967). The Discovery of Grounded Theory: Strategies for Qualitative Research. New York: Aldine. 
Goldfield, G. S., Henderson, K., Buchholz, A., Obeid, N., Hien Nguyen, \& Flament, M. F. (2011). Physical activity and psychological adjustment in adolescents. Journal of Physical Activity \& Health, 8(2), 157-163.

Goran, M. I., \& Treuth, M. S. (2001). Energy expenditure, physical activity, and obesity in children. Pediatric Clinics of North America, 48(4), 931-953. doi:10.1016/S0031-3955(05)70349-7

Gordon-Larsen, P., Nelson, M. C., \& Popkin, B. M. (2004). Longitudinal physical activity and sedentary behavior trends: Adolescence to adulthood. American Journal of Preventive Medicine, 27(4), $277-$ 283. doi:10.1016/j.amepre.2004.07.006

Graham, D. J., Sirard, J. R., \& Neumark-Sztainer, D. (2011). Adolescents' attitudes toward sports, exercise, and fitness predict physical activity 5 and 10 years later. Preventive Medicine, 52(2), 130132.

Gustafson, S. L., \& Rhodes, R. E. (2006). Parental correlates of physical activity in children and early adolescents. Sports Medicine, 36(1), 79-97.

Haerens, L., Craeynest, M., Deforche, B., Maes, L., Cardon, G., \& De Bourdeaudhuij, I. (2009). The contribution of home, neighborhood and school environmental factors in explaining physical activity among adolescents. Journal of Environmental and Public Health, 2009. doi: $10.1155 / 2009 / 320372$

Hallal, P. C., Victora, C. G., Azevedo, M. R., \& Wells, J. C. K. (2006). Adolescent physical activity and health: A systematic review. Sports Medicine, 36(12), 1019-1030. doi:10.2165/00007256200636120-00003

Hamilton, M. L., \& Valerius, L. L. (2002). Increasing physical activity through intramural \& after school programs. TAHPERD Journal, 70(3), 10-12.

Hands, B., Larkin, D., Parker, H., Straker, L., \& Perry, M. (2009). The relationship among physical activity, motor competence and health-related fitness in 14-year-old adolescents. Scandinavian Journal of Medicine \& Science in Sports, 19(5), 655-663. 
Harter, S. (1982). The perceived competence scale for children. Child Development, 53(1), 87-97. doi:10.2307/1129640

Harter, S. (2012) Self-Perception Profile for Children: Manual and questionnaires (grades 3-8) [Revision of the Self- profile for Children, 1985]. University of Denver, Retrieved from http://portfolio.du.edu/SusanHarter/page/44210

Haywood, K., \& Lewis, C. (2006). Archery: Steps to success. Champaign, IL: Human Kinetics

Hellison, D., \& Walsh, D. (2002). Responsibility-based youth programs evaluation: Investigating the investigations. Quest (00336297), 54(4), 292-307.

Hilland, T. A., Ridgers, N. D., Stratton, G., \& Fairclough, S. J. (2011). Associations between selected demographic, biological, school environmental and physical education based correlates, and adolescent physical activity. Pediatric Exercise Science, 23(1), 61-71.

Hohepa, M., Scragg, R., Schofield, G., Kolt, G. S., \& Schaaf, D. (2007). Social support for youth physical activity: Importance of siblings, parents, friends and school support across a segmented school day. The International Journal of Behavioral Nutrition and Physical Activity, 4, 54-54.

Huberty, J. L., Beets, M. W., Beighle, A., \& Mckenzie, T. L. (2013). Association of staff behaviors and afterschool program features to physical activity: Findings from Movin' After School. Journal of Physical Activity \& Health, 10(3), 423-429.

Ickes, M. J., Erwin, H., \& Beighle, A. (2013). Systematic review of recess interventions to increase physical activity. Journal of Physical Activity \& Health, 10(6), 910-926.

Jago, R., McMurray, R. G., Bassin, S., Pyle, L., Bruecker, S., Jakicic, J. M., ... Volpe, S. L. (2009). Modifying middle school physical education: Piloting strategies to increase physical activity. Pediatric Exercise Science, 21(2), 171-185.

Janssen, I., \& LeBlanc, A. G. (2010). Systematic review of the health benefits of physical activity and fitness in school-aged children and youth. International Journal of Behavioral Nutrition \& Physical Activity, 7, 40-55. 
Kaczynski, A. T., Stanis, S. A. W., Besenyi, G. M., \& Child, S. (2013). Differences in youth and adult physical activity in park settings by sex and race/ethnicity. Preventing Chronic Disease, 10. doi:10.5888/pcd10.120276

Kahn, J., Huang, B., Gillman, M., Field, A., Austin, S., Colditz, G., \& Frazier, A. (2008). Patterns and determinants of physical activity in U.S. adolescents. Journal of Adolescent Health, 42(4), 369-377.

Kanters, M., Bocarro, J., Casper, J., \& Forrester, S. (2008). Determinants of sport participation in middle school children and the impact of intramural sports. Recreational Sports Journal, 32(2), 134-151.

Kibbe, D., Hackett, J., Hurley, M., McFarland, A., Schubert, K., Schultz, A., \& Harris, S. (2011). Ten years of TAKE 10! Integrating physical activity with academic concepts in elementary school classrooms. Preventive Medicine, 52, S43-50. doi:10.1016/j.ypmed.2011.01.025

Kirk, David. (2004). Framing quality physical education: The elite sport model or Sport Education? Physical Education \& Sport Pedagogy, 9(2), 185-195.

Kjønniksen, L., Torsheim, T., \& Wold, B. (2008). Tracking of leisure-time physical activity during adolescence and young adulthood: A 10-year longitudinal study. The International Journal of Behavioral Nutrition and Physical Activity, 5, 69-69. doi:10.1186/1479-5868-5-69.

Kretchmar, R. s. (2000). Movement subcultures: Sites for meaning. JOPERD: The Journal of Physical Education, Recreation \& Dance, 71(5), 19-25.

Kriemler, S., Meyer, U., Martin, E., van Sluijs, E., Andersen, L., \& Martin, B. (2011). Effect of schoolbased interventions on physical activity and fitness in children and adolescents: A review of reviews and systematic update. British Journal of Sports Medicine, 45(11), 923-930. doi:10.1136/bjsports2011-090186

Kristensen, P. L., Moeller, N. C., Korsholm, L., Kolle, E., Wedderkopp, N., Froberg, K., \& Andersen, L. B. (2010). The association between aerobic fitness and physical activity in children and adolescents: The European youth heart study. European Journal of Applied Physiology, 110(2), 267-275.

Krueger, R. A., \& Casey, A. M., (2009). Focus groups: A practical guide for applied research. Thousand Oaks, CA: Sage Publications. 
Kulinna, P. H. (2013). School-based physical activity and health behaviors among adolescents. Kinesiology Review, 2(1), 55-60.

Kulinna, P. H., Brusseau, T. A., Cothran, D., \& Tudor-Locke, C. (2012). Changing school physical activity: An examination of individual school designed programs. Journal of Teaching in Physical Education, 31(2), 113-130.

Ladson-Billings, G. (1994). The Dreamkeepers: Successful teachers of African American teachers. San Francisco, CA: Jossey-Bass.

Lambert, L. T. (2000). The new physical education. Educational Leadership, 57(6), 34.

Langille, J.-L. D., \& Rodgers, W. M. (2010). Exploring the influence of a social ecological model on school-based physical activity. Health Education \& Behavior, 37(6), 879-894. doi:10.1177/1090198110367877

Lawman, H. G., Wilson, D. K., Van Horn, M. L., Resnicow, K., \& Kitzman-Ulrich, H. (2011). The relationship between psychosocial correlates and physical activity in underserved adolescent boys and girls in the ACT trial. Journal of Physical Activity \& Health, 8(2), 253-261.

Lohrmann, D. (2010). A complementary ecological model of the coordinated school health program. Journal of School Health, 80(1), 1-9. doi:10.1111/j.1746-1561.2009.00460.x

MacPhail, A. (2011) Youth voices in physical education and sport: What are they telling us?. In Armour, K. (Ed.) Sport pedagogy: An introduction for teaching and coaching (pp.105-116). New York, NY: Routledge.

Malina, R. M. (2001). Tracking of physical activity across the lifespan. Washington, D.C: President's Council on Physical Fitness and Sports. Retrieved from http://purl.access.gpo.gov/GPO/LPS20625

Marshall, C., \& Rossman, G. B. (2006). Designing qualitative research. Thousand Oaks, CA: Sage Publications.

Maturo, C. C., \& Cunningham, S. A. (2013). Influence of friends on children's physical activity: a review. American Journal of Public Health, 103(7), e23-e38. 
McCaughtry, N. (2009). The child and the curriculum: Implications of Deweyan Philosophy in the pursuit of "cool” physical education for children. In L. Housner, M. Metzler, P. Schempp, \& T. Templin (Eds.), Historic traditions and future directions of research on teaching and teacher education. Morgantown, WV: Fitness Information Technology.

McCracken, B. (2001) It's not just gym anymore: Teaching secondary school students to be active for life. Champaign: IL: Human Kinetics.

McKenzie, T. L. (2001). Promoting physical activity in youth: Focus on middle school environments. Quest, 53(3), 326-334.

McKenzie, T., Li, D., Derby, C., Webber, L., Luepker, R., \& Cribb, P. (2003). Maintenance of effects of the CATCH physical education program: Results from the CATCH-ON study. Health Education \& Behavior, 30(4), 447-462.

McKenzie, T. L., Nader, P. R., Strikmiller, P. K., Yang, M., Stone, E. J., Perry, C. L., ... Kelder, S. H. (1996). School physical education: Effect of the child and adolescent trial for cardiovascular health. Preventive Medicine, 25(4), 423-431. doi:10.1006/pmed.1996.0074

McKenzie, T., Sallis, J., Prochaska, J., Conway, T., Marshall, S., \& Rosengard, P. (2004). Evaluation of a two-year middle-school physical education intervention: M-SPAN. Medicine \& Science in Sports \& Exercise, 36(8), 1382-1388.

McKenzie, T. L., Sallis, J. F., \& Rosengard, P. (2009). Beyond the stucco tower: Design, development, and dissemination of the SPARK physical education programs. Quest, 61(1), 114-127. doi:10.1080/00336297.2009.10483606

McLeroy, K., Bibeau, D., Steckler, A., \& Glanz, K. (1988). An ecological perspective on health promotion programs. Health Education Quarterly, 15(4), 351-377.

McMurray, R. G., Harrell, J. S., Creighton, D., Wang, Z., \& Bangdiwala, S. I. (2008). Influence of physical activity on change in weight status as children become adolescents. International Journal of Pediatric Obesity, 3(2), 69-77. doi:10.1080/17477160701789794 
Miles, M., B., \& Huberman, A., M. (1994). Qualitative data analysis. Thousand Oaks, CA: Sage Publications.

Millstein, R. A., Strobel, J., Kerr, J., Sallis, J. F., Norman, G. J., Durant, N., ... Saelens, B. E. (2011). Home, school, and neighborhood environment factors and youth physical activity. Pediatric Exercise Science, 23(4), 487-503.

Mohr, D. J., Townsend, J. S., \& Pritchard, T. (2006). Rethinking middle school physical education: Combining lifetime leisure activities and sport education to encourage physical activity. Physical Educator, 63(1), 18-29.

Muris, P., Meesters, C., \& Fijen, P. (2003). The Self-Perception Profile for Children: Further evidence for its factor structure, reliability, and validity. Personality and Individual Differences, 35(8), 17911802. doi:10.1016/S0191-8869(03)00004-7

Must, A., \& Tybor, D. J. (2005). Physical activity and sedentary behavior: A review of longitudinal studies of weight and adiposity in youth. International Journal of Obesity, 29(Suppl2), S84-S96. doi:10.1038/sj.ijo.0803064

National Association for Sport and Physical Education. (2004). Moving into the future: National standards for physical education. Reston, VA: National Association for Sport and Physical Education.

National Association for Sport and Physical Education. (2008). Comprehensive school physical activity programs [Position statement]. Reston, VA: National Association for Sport and Physical Education. Retrieved from http://www.aahperd.org/naspe/

National Association for Sport and Physical Education \& American Heart Association. (2012). 2012 Shape of the Nation Report: Status of Physical Education in the USA. Reston, VA: American Alliance for Health, Physical Education, Recreation and Dance. Retrieved from http://www.aahperd.org/naspe/publications/shapeofthenation.cfm 
Naylor, P. J., \& McKay, H. A. (2008). Prevention in the first place: Schools a setting for action on physical inactivity. British Journal of Sports Medicine, 43(1), 10-13. doi:10.1136/bjsm.2008.053447

Ogden, C., \& Carroll, M. (2010). Prevalence of obesity among children and adolescents: United States, trends 1963-1965 through 2007-2008. Atlanta: Centers for Disease Control and Prevention. National Center for Health Statistics, 201(0)

Ogden, C. L., Carroll, M. D., Curtin, L. R., Lamb, M. M., \& Flegal, K. M. (2010). Prevalence of high body mass index in US children and adolescents, 2007-2008. JAMA: The journal of the American Medical Association, 303(3), 242-249.

Pagnano, K. B. (2006). Finding meaning in middle school physical education. Teaching Elementary Physical Education, July 2006, 12-14.

Parfitt, G., \& Eston, R. G. (2005). The relationship between children's habitual activity level and psychological well-being. Acta Paediatrica, 94(12), 1791-1797. doi:10.1080/08035250500268266

Pate, R. R. (2009). A national physical activity plan for the United States. Journal of Physical Activity and Health, 6(Supplement 2), S157.

Patterson, D. L., \& Collins, J. (2012). Middle school girls' perceptions of their physical education classes and teachers. Medicina Sportiva, 16(1), 12-16.

Patton, M. (2002). Qualitative evaluation and research methods. Thousand Oaks, CA: Sage Publications.

Paxton, R. J., Estabrooks, P. A., \& Dzewaltowski, D. (2004). Attraction to physical activity mediates the relationship between perceived competence and physical activity in youth. Research Quarterly for Exercise and Sport, 75(1), 107-111. doi:10.1080/02701367.2004.10609139

Perry, C. K., Garside, H., Morones, S., \& Hayman, L. L. (2012). Physical activity interventions for adolescents: An ecological perspective. Journal of Primary Prevention, 33(2-3), 111-135.

Peterson-Sweeney, K. (2005). The use of focus groups in pediatric and adolescent research. Journal of Pediatric Health Care, 19(2), 104-110. doi:10.1016/j.pedhc.2004.08.006 
Placek, J. H. (1992). Rethinking middle school physical education curriculum: An integrated, thematic approach. Quest, 44(3), 330-341. doi:10.1080/00336297.1992.10484059

Prusak, K. A., Davis, T., Pennington, T. R., \& Wilkinson, C. (2014). Children's perceptions of a districtwide physical education program. Journal of Teaching in Physical Education, 33(1), 4-27. doi:10.1123/jtpe.2013-0004

Pugliese, J., \& Tinsley, B. (2007). Parental socialization of child and adolescent physical activity: A meta-analysis. Journal of Family Psychology, 21(3), 331-343. doi:10.1037/0893-3200.21.3.331

Raudsepp, L., \& Päll, P. (2006). The relationship between fundamental motor skills and outside-school physical activity of elementary school children. Pediatric Exercise Science, 18(4), 426-435.

Reed, J. A., Metzker, A., \& Phillips, D. A. (2004). Relationships between physical activity and motor skills in middle school children. Perceptual \& Motor Skills, 99(2), 483-494.

Reichert, D. F. F., Menezes, A. M. B., Wells, J. C. K., Dumith, S. C., \& Hallal, P. C. (2009). Physical activity as a predictor of adolescent body fatness. Sports Medicine, 39(4), 279-294. doi:10.2165/00007256-200939040-00002

Ridgers, N. D., Fazey, D. M. A., \& Fairclough, S. J. (2007). Perceptions of athletic competence and fear of negative evaluation during physical education. British Journal of Educational Psychology, 77(2), 339-349. doi:10.1348/0265006X28909

Rikard, G. L., \& Woods, A. M. (1993). Curriculum and pedagogy in middle school physical education. Middle School Journal, 24(4), 51-55.

Rimer, B. K., \& Glanz, K. (2005). Theory at a glance: A guide for health promotion practice. US National Institutes of Health, National Cancer Institute.

Ringuet, C. J., \& Trost, S. G. (2001). Effects of physical activity intervention in youth: a review. International SportMed Journal, 2(5), 1-10.

Rink, J.E. (2003). Effective instruction in physical education. In Silverman, S.J. \& Enis, C.D. (Eds.), Student learning in physical education: Applying research to enhance instruction. (pp.165-186). Champaingn, IL: Human Kinetics 
Rowe, D. A., Raedeke, T. D., Wiersma, L. D., \& Mahar, M. T. (2007). Investigating the Youth Physical Activity Promotion Model: Internal structure and external validity evidence for a potential measurement model. Pediatric Exercise Science, 19(4), 420-435.

Rowland, T. W. (2007). Promoting physical activity for children's health. Sports Medicine, 37(11), 929936.

Sallis, J. F. (2000). Age-related decline in physical activity: A synthesis of human and animal studies. Medicine \& Science in Sports \& Exercise, 32(9), 1598-1600.

Sallis, J. F., Conway, T. L., Prochaska, J. J., McKenzie, T. L., Marshall, S. J., \& Brown, M. (2001). The association of school environments with youth physical activity. American Journal of Public Health, 91(4), 618-620.

Sallis, J. F., McKenzie, T. L., Beets, M. W., Beighle, A., Erwin, H., \& Lee, S. (2012). Physical education's role in public health: Steps forward and backward over 20 years and HOPE for the future. Research Quarterly for Exercise and Sport, 83(2), 125-135.

Sallis, J. F., \& Owen, N. (2002). Ecological models of health behavior. In K. Glanz, B. K. Rimer, \& F.M. Lewis (Eds.), Health behavior and health education: Theory, research, and practice (pp. 462-484). San Francisco, CA: Jossey-Bass.

Sallis, J., Prochaska, J., \& Taylor, W. (2000). A review of correlates of physical activity of children and adolescents. Medicine \& Science in Sports \& Exercise, 32(5), 963-975.

Sallis, J. F., Zakarian, J. M., Hovell, M. F., \& Hofstetter, C. R. (1996). Ethnic, socioeconomic, and sex differences in physical activity among adolescents. Journal of Clinical Epidemiology, 49(2), 125134.

Salmon, J. (2010). Factors in youth physical activity participation: From psychological aspects to environmental correlates. Research in Sports Medicine, 18(1), 26-36.

Seabra, A. C., Maia, J., Seabra, A. F., Welk, G., Brustad, R., \& Fonseca, A. M. (2013). Evaluating the youth physical activity promotion model among Portuguese elementary schoolchildren. Journal of Physical Activity \& Health, 10(8), 1159-1165. 
Schneider, M., \& Cooper, D. M. (2011). Enjoyment of exercise moderates the impact of a school-based physical activity intervention. The International Journal of Behavioral Nutrition and Physical Activity, 8. doi:10.1186/1479-5868-8-64

Siedentop, D. (2002). Sport education: A retrospective. Journal of Teaching in Physical Education, 21(4), 409-418.

Slingerland, M., \& Borghouts, L. (2011). Direct and indirect influence of physical education-based interventions on physical activity: A review. Journal of Physical Activity \& Health, 8(6), 866-878.

Song, M., Carroll, D. D., \& Fulton, J. E. (2013). Meeting the 2008 physical activity guidelines for Americans among U.U. youth. American Journal of Preventive Medicine, 44(3), 216-222. doi:10.1016/j.amepre.2012.11.016

Spence, J. C., \& Lee, R. E. (2003). Toward a comprehensive model of physical activity. Psychology of Sport and Exercise, 4(1), 7-24. doi:10.1016/S1469-0292(02)00014-6

Spink, K. S., Shields, C. A., Chad, K., Odnokon, P., Muhajarine, N., \& Humbert, L. (2006). Correlates of structured and unstructured activity among sufficiently active youth and adolescents: A new approach to understanding physical activity. Pediatric Exercise Science, 18(2), 203-215.

Strong, W. B., Malina, R. M., Blimkie, C. J. R., Daniels, S. R., Dishman, R. K., Gutin, B., ... Trudeau, F. (2005). Evidence based physical activity for school-age youth. The Journal of Pediatrics, 146(6), 732-737. doi:10.1016/j.jpeds.2005.01.055

Subramaniam, P. R., \& Silverman, S. (2007). Middle school students' attitudes toward physical education. Teaching and Teacher Education, 23(5), 602-611. doi:10.1016/j.tate.2007.02.003

Teddlie, C., \& Tashakkori, A. (2009). Foundations of mixed methods research: Integrating quantitative and qualitative approaches in the social and behavioral sciences. Thousand Oaks, CA: Sage Publications.

Telama, R., Yang, X., Viikari, J., Välimäki, I., Wanne, O., \& Raitakari, O. (2005). Physical activity from childhood to adulthood: A 21-year tracking study. American Journal of Preventive Medicine, 28(3), 267-273. doi:10.1016/j.amepre.2004.12.003 
Tomik, R., \& Mynarski, W. (2009). School tourism and physical education in natural settings based on the principles and practices of outdoor education. Studies in Physical Culture \& Tourism, 16(4), 421-430.

Trombley, A. (2005). Serious mountain biking. Champaign, IL: Human Kinetics

Trost, S. G. (2004). School physical education in the post-report era: an analysis from public health. Journal of Teaching in Physical Education, 23(4), 318-337.

Trost, S. G., \& Loprinzi, P. D. (2008). Exercise: Promoting healthy lifestyles in children and adolescents. Journal of Clinical Lipidology, 2(3), 162-168. doi:10.1016/j.jacl.2008.03.001

Trost, S. G., Rosenkranz, R. R., \& Dzewaltowski, D. (2008). Physical activity levels among children attending after-school programs. Medicine \& Science in Sport \& Exercise, 40(4), 622-629. doi: 10.1249/MSS.0b013e318161eaa5

Trudeau, F., Laurencelle, L., \& Shephard, R. J. (2004). Tracking of physical activity from childhood to adulthood. Medicine \& Science in Sports \& Exercise, 36(11), 1937-1943. doi:10.1249/01.MSS.0000145525.29140.3B

Twisk, J. W. (2001). Physical activity guidelines for children and adolescents. Sports Medicine, 31(8), 617-627.

U.S. Department of Health and Human Services. (2008). 2008 Physical activity guidelines for Americans. Retrieved from http://www.health.gov/paguidelines/pdf/paguide.pdf

Van der Horst, K., Paw, M. J. C. A., Twisk, J. W. R., \& Van Mechelen, W. (2007). A brief review on correlates of physical activity and sedentariness in youth. Medicine \& Science in Sports \& Exercise, 39(8), 1241-1250. doi:10.1249/mss.0b013e318059bf35

Van Sluijs, E. M F, McMinn, A. M., \& Griffin, S. J. (2007). Effectiveness of interventions to promote physical activity in children and adolescents: Systematic review of controlled trials. $B M J$, 335(7622), 703-703. doi:10.1136/bmj.39320.843947.BE

Wallhead, T. 1., \& Buckworth, J. (2004). The role of physical education in the promotion of youth physical activity. Quest (00336297), 56(3), 285-301. 
Ward, D.S., Saunders, R.P., \& Pate, R.R. (2007). Physical activity interventions in children and adolescents. Champaing, IL: Human Kinetics.

Welk, G.J. (1999). The youth physical activity promotion model: A conceptual bridge between theory and practice. Quest, 51(1), 5-23.

Welk, G. J., \& Schaben, J. A. (2004). Psychosocial correlates of physical activity in children - a study of relationships when children have similar opportunities to be active. Measurement in Physical Education and Exercise Science, 8(2), 63-81.

Wrotniak, B. H., Epstein, L. H., Dorn, J. M., Jones, K. E., \& Kondilis, V. A. (2006). The Relationship between motor proficiency and physical activity in children. Pediatrics, 118(6), e1758-e1765. doi:10.1542/peds.2006-0742

Zhang, T., Solmon, M. A., Gao, Z., \& Kosma, M. (2012). Promoting school students' physical activity: A social ecological perspective. Journal of Applied Sport Psychology, 24(1), 92-105. 


\author{
Appendix B \\ Parental or Guardian Consent letter
}

Dear Parent/Guardian,

Greetings from the Greenbrier CHOICES Project Evaluation team at West Virginia University in the College of Physical Activity and Sport Sciences. Our Team is responsible for evaluating the effectiveness of the entire 3-year project that has been made possible by a Carol M. White PEP Grant from the US Department of Education.

In an attempt to help us "hear the voices of the students" regarding the new physical activity opportunities implemented in the school, we have selected some students to participate in small discussion groups. Discussion questions will center on the students' perceptions of and engagement in the new physical activities that have been part of their physical education classes. Your child,

, has been selected to participate in one group discussion that will be held

during school hours and will last for one class period. Each group will have approximately 6 participants, and there will be six (6) groups at Western Greenbrier Middle School. All student participants will receive a $\$ 10.00$ gift card.

Your child's participation in this study is voluntary and refusal to participate or withdraw will not affect his/her academic standing or his/her right to participate in the Greenbrier CHOICES Project activities. There are no known or expected risks to your child as a result of participating in this study.

All the information collected during the group discussion will be kept confidential. The group discussion will be audio recorded and the file will be deleted after the study is finished. If any publication results from this study neither your child's name nor any information from which your child might be identified will be published. West Virginia University's Institutional Review Board's acknowledgement of this project is on file.

If you have any questions about this evaluation, please contact Luciana Braga, at (304) 2930848 or lbraga@mix.wvu.edu. If you and your child agree to participate in this research study, please complete the form bellow and return it to the physical education teacher by (date).

Please indicate your approval/disapproval for your child to participate in this important study by completing the section below, and returning in to the physical education teacher by (date). A drawing for a \$50 Walmart Gift card will be conducted from all Parent Forms returned, regardless of approval, and the winner will be announced at the school. Failure to return the form by the date indicated will exclude your child from participating and receiving the $\$ 10.00$ gift card, and from parent entry into the $\$ 50$ gift card drawing.

Thank you in advance for your cooperation in allowing your child to be a part of this important evaluation component of the Greenbrier CHOICES Project. Without the students' voices, we cannot evaluate the effectiveness of the Project on the most important constituent - the children!

Sincerely,

Greenbrier CHOICES Evaluation Team 
I agree that my child may participate in a student discussion group about physical activity as part of the Greenbrier CHOICES Project Evaluation.

I do not agree to allow my child to participate in a student discussion group.

Printed Name of Parent/Guardian

Child's first name:

Child's last name:

Grade: Gender: Male Female

Parent/Guardian Signature:

Date:

Signature of Parent or Guardian 


\section{Appendix C}

Athletic Competence Subscale of the Self-Perception Profile for Children (SPPC)

\section{What I am Like}

Name

Age

Birthday

Boy Girl

$\begin{array}{cc}\text { Really } & \text { Sort of } \\ \text { true for } & \text { true for } \\ \text { me } & \text { me }\end{array}$

Sort of Really true for true for

me me

me

me

1. $-1 \quad \begin{aligned} & \text { Some kids do very well } \\ & \text { at all kinds of sports }\end{aligned}$

2.

$-\quad \begin{aligned} & \text { Some kids wish they } \\ & \text { could be a lot better at } \\ & \text { sports }\end{aligned}$

3.

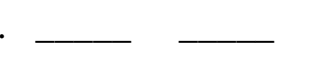

4.

5.

6.

Some kids think they could do well at just about any new sports activity they haven't tried before are better than others their age at sports

In games and sports some kids usually watch instead of play

Some kids don't enjoy new outdoor games
BUT Other kids feel they are good enough at sports

BUT Other kids are afraid they might not do well at sports they haven't ever tried

Other kids don't feel

they can play as well

BUT Other kids don't feel that they are very good when it comes to sports

BUT Other kids usually play instead of watch

BUT Other kids are good at new outdoor games 


\section{Appendix D}

Children's Attraction to Physical Activity Scale (CAPA)

\section{What I am like}

\begin{abstract}
Really Sort of
true for true for

me me
\end{abstract}

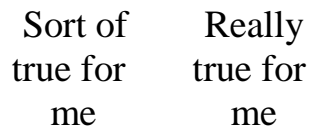

\section{EXAMPLE}

A.
A.

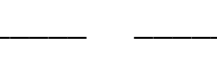
Some kids like to eat ice BUT cream more than anything else

1.

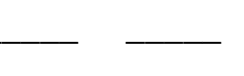

Some kids have more

sports than anything else

2.

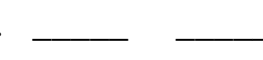

3.

4.

5.

6.

7.

8.
Some kids don't like to exercise very much

Some kids get told by other kids that they are not very good at games and sports

Some kids get teased by other kids when they play games and sports

Some kids think that the more exercise they get the better

Some kids don't enjoy exercise very much

Some kids don't like to run very much

Some kids don't like getting out of breath after they play hard
BUT Other kids like doing other things

BUT Other kids like to exercise a whole lot

BUT Other kids are told that they are good at games and sports

BUT Other kids don't get teased when they play games and sports

BUT Other kids think that it is not good to get a whole lot of exercise

BUT Other kids enjoy exercise a whole lot

BUT Other kids do like to run a whole lot

BUT Other kids don't mind getting out of breath after they play hard 
9.

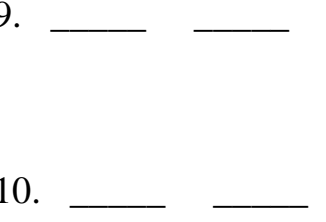

11.

12.

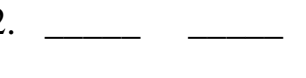

13.

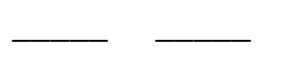

14.

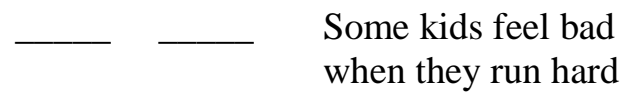

15.

Some kids try hard to stay in good shape be in good shape games and sports is their favorite thing like to exercise
BUT Other kids don't think it is so important to always be in good shape very important to always

For some kids, playing

BUT Other kids like other things more than games and sports

BUT Other kids are not very popular with other kids when they play games and sports

Some kids look forward BUT to playing games and sports

Some kids really don't

BUT

Other kids do like to exercise

BUT Other kids feel good when they run hard

BUT Other kids don't try hard to stay in good shape 


\author{
Appendix E \\ Combined Questionnaire \\ (Athletic Competence Subscale of the SPPC scale combined with the CAPA scale)
}

\title{
What I am like
}

Name:

Age:

Grade: $6^{\text {th }}$

$7^{\text {th }}-8^{\text {th }}$

Boy___ Girl__

\section{INSTRUCTIONS for completion:}

We are interested in understanding how middle school students feel about physical activity, games, and sports. This survey is designed to gather information about how you fell and what you are like. THERE IS NO RIGHT OR WRONG ANSWERS.

To complete the survey, read each pair of sentences bellow and choose the one that describes the kids that are MOST LIKE YOU. After deciding which kinds of kids are most like you, consider if that sentence is sort of true for you, or really true for you. If the sentence is only sort of true, then put an X on the line under Sort of True for me; if it is really true for you, then put an X on that line, under Really True for me.

\section{SAMPLE QUESTION}

\section{Really Sort of true for true for me me}

A.

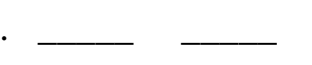

Some kids like to eat ice BUT cream more than anything else

$\begin{array}{cc}\begin{array}{c}\text { Sort of } \\ \text { true for } \\ \text { me }\end{array} & \begin{array}{c}\text { Really } \\ \text { true for }\end{array} \\ \text { me }\end{array}$

Other kids like other foods more than ice cream 


\section{Really Sort of true for true for \\ me me}

1.

2.

3.

4.

5.

6.

7.

8.

9.

10.

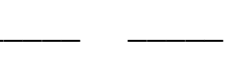

$+$

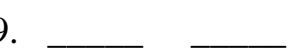

11.

Some kids have more

fun playing games and

sports than anything else

Some kids don't like to exercise very much

Some kids get told by other kids that they are not very good at games and sports

Some kids get teased by other kids when they play games and sports

Some kids think that the more exercise they get the better

\section{Sort of Really true for true for me me}

BUT Other kids don't feel that they are very good when it comes to sports

BUT Other kids feel they are good enough at sports

BUT Other kids are afraid they might not do well at sports they haven't ever tried

Other kids don't feel they can play as well

BUT Other kids usually play instead of watch

BUT Other kids are good at new outdoor games

BUT Other kids like doing other things

BUT Other kids like to exercise a whole lot

BUT Other kids are told that they are good at games and sports

BUT Other kids don't get teased when they play games and sports

BUT Other kids think that it is not good to get a whole lot of exercise 


\section{Really Sort of true for true for \\ me me}

12.

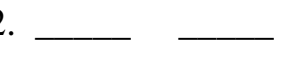

13.

14.

15.

16.

17.

18.

19.

20.

21.
Some kids don't enjoy exercise very much

Some kids don't like to run very much

Some kids don't like getting out of breath after they play hard

Some kids think it is very important to always be in good shape

For some kids, playing games and sports is their favorite thing

Some kids are popular with other kids when they play games and sports

Some kids look forward BUT to playing games and sports

Some kids really don't like to exercise

Some kids feel bad when they run hard

Some kids try hard to stay in good shape

\section{Sort of Really true for true for me me}

\section{BUT Other kids enjoy} exercise a whole lot

\section{BUT Other kids do like} to run a whole lot

BUT Other kids don't mind getting out of breath after they play hard

BUT Other kids don't think it is so important to always be in good shape

BUT Other kids like other things more than games and sports

BUT Other kids are not very popular with other kids when they play games and sports

Other kids don't look forward to playing games and sports

BUT Other kids do like to exercise
BUT Other kids feel good when they run hard

$\begin{array}{ll}\text { BUT } & \text { Other kids don't } \\ \text { try hard to stay } \\ \text { in good shape }\end{array}$




\author{
Appendix F \\ Script for Questionnaire (Phase One)
}

Good (morning/afternoon) my name is Luciana Braga and I am part of the CHOICES project evaluation team at West Virginia University in the College of Physical Activity and Sport Sciences. Today we would like for you to complete a short questionnaire to help us understanding how middle school students feel about physical activity, games, and sports, so we can better inform the development of school-based physical activity programs. Participating in this questionnaire is voluntary and there will be no academic consequences if you choose not to participate.

All students who complete the questionnaire will have their names put into a draw for a $\$ 50.00$ gift certificate. All information will be kept confidential and the West Virginia University's Institutional Review Board (IRB) has given us permission to conduct this project.

(Distribution of questionnaires and pencils)

As you receive your materials, please wait for directions to start filling it out. Does everybody have a questionnaire and a pencil? The first thing I would like you to do is to complete the headings. Write your name on the space provided and indicate your grade, your age and if you are a boy or a girl.

Ok, now let's look at the sample question. The sample questions says, "Some kids like to eat ice cream more than anything else but other kids like other foods more than ice cream." Raise your hand if you like to eat ice cream more than ANY OTHER food. Okay, if you raised your hand then circle the sentence on the left side. Now ask yourself, "Is this REALLY true for me or just SORT OF true for me that I like ice cream more than anything else?" Put your finger on the best answer for you. Place an "X" on the line according to how you feel.

Now, if you like other foods more than ice cream then you will circle the sentence on the right side. Now ask yourself, "Is it REALLY true that you like other foods more than ice cream or just SORT OF TRUE for you?" Place your finger on the line that has the best answer for you. Now place an "X" on that line. Does everyone have just one " $\mathrm{X}$ " for the sample question? Okay, good.

On each question, you are going to do the same thing and decide whether you are more like the kid on the left or the kid on the right and mark your answers. Remember to first CIRCLE the statement that best describes you, and then PLACE AN X if its' really true or sort of true for you. You should only have one circled answer and one $\mathrm{X}$ for each question. Are there any questions? When you have completed your survey, please turn your paper over and wait for it to be collected. You can begin answering the following questions now. 
Appendix G

Student Assent Letter

Dear Student,

You have been selected to participate in a group discussion about your physical education classes to help us better understand your perceptions of and engagement in the new physical activities that you are being offered, such as mountain biking, archery, and disc golf. This will help us to evaluate how students at your school feel about new physical activities that are a part of the Greenbrier CHOICES Project. Your parent/guardian has given permission for you to participate, but you are also required to sign this letter indicating that you are willing to be a part of the discussion group.

There will be a total of six discussion groups at your school, each made up of about 6 students. You will be asked to be a member of one discussion group. We will ask the group questions about physical activity and what you thing about different aspects of physical activity in which you participate. There are no right or wrong answers, and your responses will not be identified individually, and will be kept confidential. The discussion groups will take place during one class period during the school day. You will receive a $\$ 10.00$ gift card as a token of appreciation for your participation.

Your participation in this study is voluntary and refusal to participate or withdraw will not affect your academic standing or your right to participate in the CHOICES projects activities. The group discussion will be audio recorded and the file will be deleted after the study is finished. West Virginia University's Institutional Review Board has approved this study.

Please complete the information below indicating your willingness/unwillingness to participate, and sign your name.

We thank you in advance for helping us to better understand students' views of physical activity in the school setting.

Sincerely,

The Greenbrier CHOICES Evaluation Team

I am willing to participate in the Greenbrier CHOICES student discussion group about school physical activity.

I am NOT willing to participate in the Greenbrier CHOICES student discussion group.

Signature of participant

Grade

Printed Name

Date 


\section{Appendix H \\ Focus Group Interview Script}

Hello, my name is Luciana Braga, I am at West Virginia University and I am working with the Greenbrier CHOICES Project that has been going on in your school for the last two years.

Thank you for agreeing to be a part of this discussion group to talk about the new activity units that you have been offered as part of your physical education (PE) class through the CHOICES Project. The units include biking, archery, disc golf, and slack lining. The purpose of this discussion is for us to gain an understanding of your experiences in the new PE units.

During this group discussion, I will ask you questions related to the new activities and I hope that the questions will stimulate conversation within the group. There are no right or wrong answers to any of the questions. Everyone's opinion is welcome but you are not obligated to answer or talk if you so choose. Positive and negative comments are welcome and I encourage everyone to be honest about your thoughts.

This session will be recorded in order for me to capture all of your comments and opinions. However, the entire discussion will be kept confidential and your comments will not affect your grade in PE.

\section{During the discussion, please do not use names when talking to your peers so that comments cannot be identified. I will start recording our discussion now.}

Over the past few semesters some new activities were included in your physical education classes. We are talking specifically about biking, archery, disc golf, and slack lining. I have some cards with pictures of these activities. We call these "culturally relevant" activities because they are things you can do in the environment in which you live here in Greenbrier County - in your culture.

1. Take a look at the picture cards. Which activity would you like to discuss first?

OK, biking (or other activity). Lets' talk about (activity) first.

2. Let's talk specifically about (activity). Think back to when you first heard that you would learn (activity) in PE. What were your thoughts about it?

3. Now that you have gone through the (activity) lessons, what do you think about having the opportunity to participate in this activity as part of your PE class at school?

4. What do remember most about (activity)?

a. What did you like the most about this activity?

b. What did you like the least about it?

5. What do you think of doing this activity outside of school?

a. What would need to happen in order for you to participate in this activity outside of school?

6. Let's pick another activity now. Take a look at the cards again. What activity would you like to talk about?

7. OK, let's talk about (activity). Think back to when you first heard that you would learn (activity) in PE. What were your thoughts about it? 
8. Now that you have gone through the (activity) lessons, what do you think about having the opportunity to participate in (activity) as part of your PE class at school?

9. What do remember most about (activity)?

a. What did you like the most about this activity?

b. What did you like the least about it?

10. What do you think of doing this activity outside of school?

a. What would need to happen in order for you to participate in this activity outside of school?

11. Look at the cards again. Considering all the activities, what was the most memorable moment you had when you participated in them?

12. Which new skills did you learn while doing these new activities in PE class?

a. What helped you most in learning these new skills?

b. What do you think could be done differently in order to help you learn these new activities?

13. Did these new activities influence the way you think about PE classes? How?

a. Did these new activities change the way you participate in PE classes? How?

14. Did any of these units contribute to your general physical activity habits outside of school? How?

15. (If there is time) Would you like to talk about another activity? 